\title{
1 A phosphorylation of RIPK3 kinase initiates an intracellular apoptotic 2 pathway that promotes corpus luteum regression
}

4 Dianrong Li1 ${ }^{1,2}$, Jie Chen ${ }^{1,2}$, Jia Guo ${ }^{1,2}$, Lin $\mathrm{Li}^{1,2}$, Gaihong Cai ${ }^{1,2}$, She Chen ${ }^{1,2}$, Jia Huang ${ }^{3}$,

5 Hui Yang ${ }^{3}$, Yinhua Zhuang ${ }^{1,2}$, Fengchao Wang ${ }^{1,2}$, and Xiaodong Wang ${ }^{1,2,4, *}$

6

$7 \quad{ }^{1}$ National Institute of Biological Sciences, Beijing 102206, China

$8{ }^{2}$ Tsinghua Institute of Multidisciplinary Biomedical Research, Tsinghua University,

$9 \quad$ Beijing 100084, China

$10{ }^{3}$ Institute of Neuroscience, State Key Laboratory of Neuroscience, Key Laboratory of

11 Primate Neurobiology, CAS Center for Excellence in Brain Science and Intelligence

12 Technology, Shanghai Research Center for Brain Science and Brain-Inspired Intelligence,

13 Shanghai Institutes for Biological Sciences, Chinese Academy of Sciences, Shanghai

14 200031, China

$15{ }^{4}$ Lead Contact

$16 *$ *orrespondence: wangxiaodong@nibs.ac.cn 
26 Abstract

27 Receptor-interacting serine/threonine-protein kinase 3 (RIPK3) normally signals

28 to necroptosis by phosphorylating MLKL. We report here that when the cellular

29 RIPK3 chaperone Hsp90/CDC37 level is low, RIPK3 also signals to apoptosis. The

30 apoptotic function of RIPK3 requires phosphorylation of the serine 165/threonine

$31 \quad 166$ sites on its kinase activation loop, resulting in inactivation of RIPK3 kinase

32 activity while gaining the ability to recruit RIPK1, FADD, and caspase-8 to form a

33 cytosolic caspase-activating complex, thereby triggering apoptosis. We found that

34 PGF $_{2 \alpha}$ induces RIPK3 expression in luteal granulosa cells in the ovary to cause luteal

35 regression through this RIPK3-mediated apoptosis pathway. Mice carrying

36 homozygous phosphorylation-resistant RIPK3 S165A/T166A knockin mutations

37 failed to respond to $\mathrm{PGF}_{2 \alpha}$ but retained pro-necroptotic function, whereas mice with

38 phospho-mimicking S165D/T166E homozygous knockin mutation underwent

39 spontaneous apoptosis in multiple RIPK3-expressing tissues and died shortly after

40 birth. Thus, RIPK3 signals to either necroptosis or apoptosis depending on its serine

$41 \quad$ 165/threonine 166 phosphorylation status.

43 Introduction

44 Regulated cell death with distinctive associated morphological changes happens either

45 in the form of apoptosis or necrosis (Elmore, 2007; Fink and Cookson, 2005; Kroemer et

46 al., 2009; Wallach et al., 2016). Apoptosis is executed by intracellular caspases,

47 particularly caspase-3, whose cleavage of several intracellular substrates gives rise to

48 characteristic features of apoptotic cell death. Caspase-3 is activated by upstream

49 caspase- 8 or caspase-9, which are known to be activated respectively by being part of

50 plasma membrane-associated death-inducing signaling complexes induced by the TNF 
51 family of cytokines, or being part of the cytosolic apoptosome, which is formed as a result

52 of cytochrome c release from mitochondria (Elmore, 2007; Li et al., 1997; Wang et al.,

53 2008). Cells that die by apoptosis maintain their plasma membrane integrity and break

54 down into small vesicles phagocytosed by macrophages (Elmore, 2007; Kroemer et al.,

55 2009). Cells that die by regulated necrosis are executed by membrane-disrupting proteins

56 that, when activated, translocate from the cytosol to the plasma membrane and disperse

57 cellular contents into the cell surroundings. This process is often associated with

58 inflammatory response (Christofferson and Yuan, 2010; Vandenabeele et al., 2010;

59 Wallach et al., 2016).

60 One form of regulated necrosis, necroptosis, is executed by a pseudokinase namely

61 mixed lineage kinase-domain protein, MLKL (Sun et al., 2012). MLKL is a substrate of

62 receptor-interacting kinase RIPK3, which becomes activated either by: 1) the TNF family

63 of cytokines through a related kinase RIPK1 that interacts with RIPK3 through a RIP

64 homotypic interaction motif (RHIM) domain, or 2) by other RHIM domain-containing

65 proteins, such as TRIF or ZBP1/DAI, that relay necroptotic signals from Toll-like

66 receptors or intracellular Z-RNA, respectively (Cho et al., 2009; Degterev et al., 2008; He

67 et al., 2009; Sun et al., 2012; Upton et al., 2012; Zhang et al., 2009; Zhang et al., 2020).

68 Active RIPK3 phosphorylates MLKL at serine 357/threonine 358 (human origin) sites to

69 induce oligomerization and translocation from the cytosol to the plasma membrane and

70 cause loss of membrane integrity (Cai et al., 2014; Chen et al., 2014; Sun et al., 2012;

71 Wang et al., 2014).

72 Surprisingly, a kinase-dead mutant RIPK3, D161N, spontaneously causes host cells to

73 undergo apoptosis, resulting in embryonic lethality in mice bearing such homozygous

74 mutation (Newton et al., 2014). On the other hand, mice homozygous with another

75 kinase-dead mutant, K51A RIPK3, does not share this phenotype. However, cells that 
76 harbor this mutation are sensitive to apoptosis induction when treated with several

77 small-molecule RIPK3 inhibitors that bind to its ATP-binding pocket (Mandal et al.,

78 2014). Whether this apoptosis-inducing activity of RIPK3 is an anomaly of the mutant

79 protein, the small-molecule inhibitor bound form, or a true physiological function of

80 RIPK3 remains to be resolved.

81 Apoptosis and necroptosis play important physiological and pathological roles in

82 mammals (Christofferson and Yuan, 2010; Elmore, 2007; Vandenabeele et al., 2010;

83 Wallach et al., 2016). Apoptosis has essential functions during animal development and

84 maintaining cell homeostasis in adults (Elmore, 2007; Fink and Cookson, 2005).

85 Necroptosis functions include anti-viral infections, tissue damage response, and male

86 reproductive system aging (Cho et al., 2009; He and Wang, 2018; Li et al., 2017).

87 One of the important physiological functions of apoptosis in adult mammals is the

88 development and function of the ovary (Perez et al., 1997; Rimon-Dahari et al., 2016;

89 Rolaki et al., 2005; Tilly, 2001). From the neonatal stage to sex maturation, most eggs

90 within primordial follicles fail to develop and undergo a process called atresia - a process

91 driven by apoptosis of the egg and surrounding granulosa cells (Rimon-Dahari et al., 2016;

92 Tilly and Sinclair, 2013). After sex maturation, follicles develop from primordial to

93 primary and secondary follicles accompanied by the proliferation of surrounding granulosa

94 and theca cells (Rimon-Dahari et al., 2016; Sanchez and Smitz, 2012; Tilly and Sinclair,

95 2013). After egg release from the follicle during ovulation, the remaining granulosa and

96 theca cells become progesterone-producing sources, namely corpus luteum, which is easily

97 recognizable under a microscope (Rolaki et al., 2005). If the egg is unfertilized, the corpus

98 luteum dies through apoptosis and becomes corpus albicans, a scar tissue with a mixture of

99 cell debris, macrophages, type I collagen, and fibroblasts and is light in color compared to

100 the luteum. The process is also known as luteal involution or luteolysis (Rolaki et al., 2005; 
101 Stocco et al., 2007; Tilly, 2001). Such a process stops the production of progesterone and

102 triggers another cycle of ovulation. When mammals age, their follicles and corpora lutea

103 are gradually lost, and the ovary eventually becomes a corpus albicans-filled organ that

104 ceases to produce eggs and hormones (Perheentupa and Huhtaniemi, 2009; Tilly, 2001).

105 In the current study, we report that RIPK3 specifically induces apoptosis instead of

106 necroptosis in certain contexts and cell types. The apoptosis-inducing function of RIPK3

107 requires the auto-phosphorylation of the evolutionarily conserved serine 165/threonine 166

108 sites (mouse origin) on its kinase activation loop, resulting in the inactivation of its kinase

109 activity and acquiring the ability to recruit RIPK1-FADD-caspase-8, which leads to

110 activation of caspase-3 and apoptosis. The apoptosis vs necroptosis function of RIPK3

111 seemed to be determined by the cellular level of a RIPK3 chaperone Hsp90/CDC37. We

112 also found that the serine 165/threonine 166 phospho-RIPK3 signal specifically appeared

113 in corpora lutea/albicans when mice reached more than 4-month of age and $\mathrm{PGF}_{2 \alpha}$ can

114 specifically trigger this apoptotic pathway during the process of corpus luteum involution

115 in a mouse hyper-ovulation model.

\section{Results}

118 Ectopic expression of RIPK3 in cultured MCF7 or human granulosa lutein cells 119 activated apoptosis through the RIPK1-FADD-Caspase-8 pathway

120 We engineered three Dox-inducible RIPK3 expressing cell lines: HeLa/TO-RIPK3, 121 MCF7/TO-RIPK3, and KGN/TO-RIPK3, all of which do not express endogenous RIPK3.

$122 \mathrm{KGN}$ is a human granulosa tumor cell line (Nishi et al., 2001). Surprisingly we found that 123 simple expression of RIPK3 in MCF7 or KGN cells caused cell death (Figure 1A and 124 Figure 1-figure supplement 1), whereas the ectopic expression of RIPK3 in HeLa cells did 125 not affect cell viability, similar to previous studies (Sun et al., 2012). Moreover, these 
126 RIPK3-expressing MCF7 and KGN cells did not undergo necroptosis when we treated the

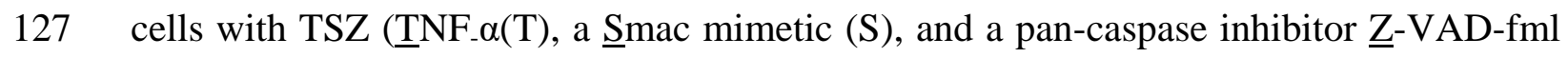

$128(\mathrm{Z})$ ), whereas such treatment caused robust necroptosis in RIPK3-expressing HeLa cells

129 (Figure 1B).

130 To determine what kind of cell death was triggered by RIPK3 in MCF7 and KGN 131 cells, we used caspase inhibitor z-VAD-fmk, RIPK1 inhibitor RIPA-56 (Li et al., 2017), 132 and MLKL inhibitor NSA (Sun et al., 2012) to co-treat these cells with Dox. Cell death

133 induced by Dox could be blocked by caspase inhibitor z-VAD-fmk (Figure 1C and Figure

134 1-figure supplement 1) but not by MLKL inhibitor NSA, nor RIPK1 kinase inhibitor

135 RIPA-56 (Figure 1C and Figure 1-figure supplement 1), indicating that the observed

136 RIPK3-mediated cell death was apoptotic. However, this form of apoptosis did not signal

137 through the classic intrinsic mitochondrial pathway, as the loss of cell viability through this

138 pathway could not be blocked by caspase inhibitors, nor was the apoptosis triggered by the

139 TNF receptor family, which would be RIPK1 kinase-dependent.

140 To further explore the molecular mechanism of this apoptosis pathway, we expressed a 141 previously reported kinase-dead mutant (K50A) of RIPK3 in MCF7 cells and found that 142 this kinase-dead mutant RIPK3(K50A) did not cause cell death (Figure 1D). Interestingly, 143 the expression of this kinase-dead mutant RIPK3(K50A) plus RIPK3 kinase inhibitor 144 GSK'872 resulted in robust apoptosis, similar to what was described by Mandal et al 145 (Figure 1D; Mandal et al., 2014). Moreover, the mutations at the RHIM domain of RIPK3 146 known to disrupt RHIM-RHIM interaction also caused complete loss of cell death 147 induction, indicating that RHIM domain interaction, possibly with another RHIM 148 domain-containing protein, is required for apoptotic induction by RIPK3 (Figure 1D).

149 RIPK3's dependence on the RHIM domain but not its kinase activity suggested that 150 the observed apoptosis might be through the RIPK1-FADD-caspase-8 pathway, as was 
151 seen in apoptosis induced by the D161N mutant RIPK3, a kinase-dead mutant of RIPK3

152 that causes spontaneous apoptosis and prenatal lethality in mice carrying this knock-in

153 mutation (Newton et al., 2014). We therefore immunoprecipitated the Flag-tagged RIPK3

154 and probed the immune-precipitate with antibodies against RIPK1, caspase-8, and FADD.

155 Indeed, all three proteins were co-immunoprecipitated with RIPK3. The amount of RIPK1

156 and caspase-8 associated with RIPK3 increased when a caspase inhibitor was present,

157 indicating the complex had increased stability when caspase- 8 activity was blocked,

158 presumably by preventing caspase-8-mediated cleavage of RIPK1, which serves as an

159 adaptor protein between RIPK3 (through the RHIM domain) and FADD (through the

160 DEAD domain) (Figure 2A; Mandal et al., 2014; Newton et al., 2014; Sun et al., 1999).

161 When we used the CRISPR/Cas9 to knock out either RIPK1, caspase-8, or FADD gene in

162 MCF7/TO-RIPK3 cells, we found that cell death upon addition of Dox was blocked

163 entirely (Figure 2B-2D). Interestingly, different from the previous report (Mandal et al.,

164 2014), knocking out the $c F L I P$ gene did not block RIPK3 induced apoptosis in MCF7 cells

165 but rather enhanced it (Figure 2E).

\section{RIPK3 auto-phosphorylates serine164/threonine 165 in apoptotic cells}

168 The differential apoptotic response of HeLa cells and MCF7/KGN cells to RIPK3 169 expression prompted us to search for the differences in RIPK3 protein in these cells. To

170 this end, we immunoprecipitated Flag-RIPK3 from HeLa cells and MCF-7 cells and

171 performed a detailed mass spectrometry analysis. We found two amino acid residues at the

172 activation loop of the RIPK3 kinase domain, serine 164 and threonine 165, that were

173 specifically phosphorylated in MCF7 cells but not in HeLa cells (Figure 3A). To validate

174 this phosphorylation event, we generated a monoclonal antibody against the

175 phopho-S164/T165 peptide. This phospho-specific antibody only recognized RIPK3 
176 protein expressed in KGN or MCF7 cells but not in HeLa cells (Figure 3B). We further

177 validated our monoclonal antibody's specificity by expressing a RIPK3 protein bearing

178 phosphorylation-resistant mutations S164A/T165A in MCF and KGN cells. The expressed

179 S164A/T165A RIPK3 was then analyzed by western blotting with antibodies against

180 RIPK3 or phospho-S164/T165 RIPK3. As shown in Figure 3-figure supplement 1A and

181 1B, Dox-induced wild-type RIPK3 was recognized by anti-RIPK3 and

182 anti-phospho-S164/T165 RIPK3 antibodies in both MCF7/TO-RIPK3 and

183 KGN/TO-RIPK3 cells. The phosphorylation-resistant S164A/T165A mutant protein could

184 only be recognized by the anti-RIPK3 antibody but not the anti-phospho-S614/T165

185 antibody. Notably, this anti-phospho-S164/T165 antibody did not recognize any

186 non-specific protein band across the entire set of protein size markers (15-250 kDa), nor in

187 cells without Dox addition to their media. Additionally, the expression of two kinase-dead

188 mutants RIPK3 D160N and RIPK3 K50A (equivalent of mouse D161N and K51A,

189 respectively) failed to generate the phospho-S164/T165 signal (Figure 3C and Figure

190 3-figure supplement 1C). Therefore, the RIPK3 induced apoptosis in KGN and MCF7 cells

191 is dependent on the serine 164/threonine 165 auto-phosphorylation of RIPK3 carried out by

192 its own kinase activity.

194 Phosphorylation of serine164 inactivates the kinase activity of RIPK3 and activates

\section{5 apoptosis}

196 To explore the functional significance of this phosphorylation event, we made 197 phospho-mimic point mutations in these two sites and assayed the kinase activity of mutant

198 RIPK3 by probing the serine 227 phosphorylation, which is known to be carried out by

199 RIPK3 kinase activity and is critical for recruiting its necroptosis executing substrate 200 MLKL (Li et al., 2015; Sun et al., 2012). After transiently transfecting the cDNA of mutant 
201 RIPK3 in human embryonic kidney 293T cells, we observed that RIPK3 bearing

202 phospho-mimic S164D/T165E mutations failed to auto-phosphorylate the serine 227 site,

203 similar to the kinase-dead mutant D160N, whereas wild type RIPK3 readily

204 phosphorylated serine 227 (Figure 3D).

205 We subsequently measured cell death after introducing these phospho-mimic or

206 phosphorylation-resistant mutations in MCF7 and KGN cells. As shown in Figure 3E and

207 3F, introducing phospho-mimic mutations S164D/T165E increased apoptosis in MCF7

208 and KGN cells compared to wild-type RIPK3, whereas the phosphorylation-resistant

209 mutant S164A/T165A lost the ability to induce apoptosis, similar to the RHIM domain

210 mutant. Remarkably, in HeLa cells, the phospho-mimic mutant S164D/T165E gained the

211 ability to induce apoptosis similar to the kinase-dead mutant D160N (Figure 3G),

212 indicating that phospho-mimic mutations activated RIPK3's apoptosis-inducing function

213 that is normally silenced in HeLa cells. Since the phospho-mimic mutations inactivate

214 RIPK3 kinase activity, this S164D/T165E mutant was no longer able to induce necroptosis

215 in HeLa cells when treated with necroptosis stimuli TSZ (Figure 3-figure supplement 1D).

216 The phosphorylation resistant mutant S164A/T165A still allowed HeLa cells to respond to

217 necroptosis induction, though the apoptosis-inducing function was lost in KGN and MCF7

218 cells (Figure 3-figure supplement 1D). Thus, the differential responses of RIPK3 in HeLa

219 cells compared to KGN and MGF7 cells are due to its inability to carry out

220 auto-phosphorylation at the serine 164/theorine165 sites.

221 We further narrowed down the effect of serine 164 and threonine 165 phosphorylation

222 by generating individual phospho-mimic or phosphorylation-resistant mutants at serine

223 S164 or threonine 165 sites and measured their kinase activity and apoptosis-inducing

224 ability. The phospho-mimic S164E, but not T165E, mutant lost necroptosis responsiveness

225 and gained the ability to induce apoptosis in HeLa cells, while phosphorylation resistant 
226 S164A, but not T165A, lost its apoptosis-inducing activity in KGN and MCF7 cells

227 (Figure 3-figure supplement 1D-1G). Together, these results indicated that RIPK3

228 auto-phosphorylation on the serine S164 site is a critical event that inactivates RIPK3

229 kinase activity while gaining apoptosis-inducing activity in KGN and MCF7 cells.

\section{Serine 164 phosphorylation allows RIPK3 binding to RIPK1-FADD-Caspase-8}

232 To study the mechanism by which phopho-S164/T165 RIPK3 activates the 233 RIPK1/FADD/caspase-8 pathway, we ectopically expressed Flag-RIPK3 (wild type), 234 phopho-mimic RIPK3 (S164D/T165E), and RIPK3 (D160N) kinase-dead mutants, as well 235 as RIPK3(AAAA) RHIM domain mutants in HeLa cells and performed 236 immunoprecipitation with an anti-Flag antibody. The immune-complexes were probed

237 with antibodies against RIPK1, FADD, and caspase-8. As shown in Figure 3H, very little 238 RIPK1, FADD, or caspase-8 were co-precipitated with wild type or RHIM mutant RIPK3, 239 consistent with its inability to induce apoptosis (Figure 3H, lanes 1 and 2). In contrast, two 240 kinase-dead mutants, either the artificial D160N or phospho-mimic S164D/T165E, 241 showed robust binding with RIPK1, FADD, and caspase-8 (Figure 3H, lanes 3 and 4).

242 Consistent with the cell death result, the phosphorylation-resistant mutant S164A/T165A

243 lost the ability to bind with RIPK1, FADD, and caspase-8 (Figure 3I).

244 Consistent with the finding that the serine 164 phosphorylation is most critical for 245 RIPK3 apoptosis-inducing activity, the phospho-mimic S164E mutant expressed in HeLa 246 cells was found to associate with RIPK1, FADD, and caspase-8, as did the S164D/T165E

247 double mutation (Figure 3-figure supplement 1H, lane 4), whereas T165E alone could not

248 bind to these proteins (Figure 3-figure supplement 1H, lane 2). Collectively, these findings 249 indicate that RIPK3 auto-phosphorylation on serine S164 allows RIPK3 to recruit RIPK1 
250 to form the RIPK3/RIPK1/FADD/Caspase-8 complex, in which caspase- 8 is activated to

251 drive apoptosis.

252

253 Hsp90/CDC37 chaperone determines the necroptotic or apoptotic function of RIPK3

254 kinase

255 We have previously observed that in order for RIPK3 to signal to necroptosis, the 256 protein needs to be correctly folded with the aid of a molecular chaperone consisting of

257 Hsp90 and CDC37 (Li et al., 2015). In HT29 and HeLa cells in which RIPK3 signals 258 primarily to necroptosis, we observed that the level of Hsp90/CDC37 was higher compared 259 to MCF7 and KGN cells, where RIPK3 predominantly causes apoptosis (Figure 4A). 260 Indeed, a human Hsp90 inhibitor 17AAG potently blocked necroptosis induced by TSZ in 261 HeLa-RIPK3 cells, whereas 17AAG did not block RIPK3 induced apoptosis in 262 MCF7/TO-RIPK3 or KGN/TO-RIPK3 cells (Figure 4B and 4C). When we knocked down 263 Hsp90 using shRNA or inhibits Hsp90 using 17AAG, after Dox induce RIPK3 expression, 264 we saw the switch of the cellular necroptosis response to apoptosis (Figure 4D and Figure 265 4-figure supplement 1A). Consistently, the serine 164/threonine 165 phosphorylation of 266 RIPK3 also occurred after the inhibition of Hsp90 (Figure 4E). Reciprocally, when Hsp90 267 and CDC37 were ectopically expressed in MCF7/TO-RIPK3 cells to a level matched or 268 exceeding that in HeLa cells, the serine 164/threonine 165 phosphorylation of RIPK3 no 269 longer occurred, and RIPK3-mediated apoptosis induction mostly ceased (Figure 4F and 270 4G). Consistent with the cell death result, when the inhibitor of Hsp90 17AAG was present 271 during RIPK3 induction in HeLa/TO-RIPK3 cells, the RIPK3 formed a complex with 272 RIPK1, FADD, and caspase-8 (Figure 4H).

273 Since serine 164/threonine 165 appeared to be at a critical regulatory region in RIPK3 274 on which phosphorylation switches its function from necroptosis to apoptosis, we checked 
275 this region among different mammalian species. As shown in Figure 3-figure supplement

$2762 \mathrm{~A}$, this region is conserved with no changes from amino acid residues 160-174 among

277 RIPK3s from human, chimpanzee, rat, mouse, and bovine origin (Xie et al., 2013). The

278 corresponding phospho-mimic mutations of mouse RIPK3(S165D/T166E), like

279 RIPK3(D161N) kinase-dead mutants (Newton et al., 2014), failed to auto-phosphorylate

280 the serine 232 site, the equivalent of the human serine 227 site (Figure 3-figure supplement

281 2B). Furthermore, these mutant RIPK3 proteins induced apoptosis in mouse L929

$282\left(\right.$ Ripk $\left.^{-/}\right)$cells after ectopic expression but not necroptosis when treated with the

283 necroptosis stimulus TSZ (Figure 3-figure supplement 2C). Previously, we noticed that

284 when we used a clinical relevant dose of 17AAG (200 nM) to treat mouse cells, the

285 necroptosis was augmented instead of inhibited like in human or rat cells (Li et al., 2015).

286 We therefore suggested that the Hsp90/CDC37 chaperone might not work in mouse cells.

287 Given the importance of this chaperone system in determining the apoptotic or necroptotic

288 fate and the conservation of the apoptosis-causing phosphorylation site in mice, we

289 explored the possibility that the previously tested concentration of human Hsp90 inhibitors

290 was simply not enough to inhibit the mouse Hsp90. Indeed, when the higher dose of

291 17AAG was used, the compound dose-dependently blocked TSZ-induced necroptosis in

292 L929 cells (Figure 4-figure supplement 1B). Moreover, when we knocked down Hsp90

293 using shRNA or inhibits Hsp90 using higher concentrations of 17AAG in L929

$294\left(\right.$ Ripk $\left.^{-/}\right) /$TO-RIPK3 cells, we saw the switch of the cellular necroptosis response to

295 apoptosis after Dox induced RIPK3 expression (Figure 4-figure supplement 1C and 1D).

296 The serine 165/threonine 166 phosphorylation of RIPK3 also occurred after the inhibition

297 of Hsp90 (Figure 4-figure supplement 1E). These results indicated that the observed

298 Hsp90/CDC37-determined, RIPK3 serine 164/threonine 165 phosphorylation-driven

299 apoptosis is conserved between human and mouse cells. 


\section{RIPK3 forms a unique structure in MCF7 and KGN cells}

302 RIPK3 is known to form diffused puncta within the cytosol (He et al., 2009). Indeed,

303 when the HeLa/TO-RIPK3 cells were treated with Dox plus TSZ, we observed expressed

304 RIPK3 in diffused puncta in the cytosol (Figure 4-figure supplement 2A). Interestingly,

305 when we performed a similar analysis of RIPK3 distribution in MCF7/TO-RIPK3 and

306 KGN/TO-RIPK3 cells, the RIPK3 formed a high order of structures distinct from the

307 diffused punctae in HeLa or HT29 cells (Figure 4-figure supplement 2A and 2B).

308 Furthermore, the phospho-S164/T165-RIPK3 signal appeared co-localized with RIPK3 in

309 MCF7 cells but no such signal was seen in HeLa cells (Figure 4-figure supplement 2C).

310 The formation of these high order structures and the appearance of the

311 phospho-S164/T165-RIPK3 signal was not affected when RIPK1, caspase-8, or FADD

312 genes were knocked out (Figure 4-figure supplement 2D and 2E).

313 To test whether this high order structure of RIPK3 is associated with its ability to

314 induce apoptosis, we treated the HeLa/TO-RIPK3 cells with Dox plus the Hsp90 inhibitor

315 17AAG and found that the diffused punctae of RIPK3 were now switched to the high order

316 structure (Figure 4I). Reciprocally, when Hsp90 and CDC37 were ectopically

317 overexpressed in MCF7/TO-RIPK3 cells, the high order structure of RIPK3 became

318 diffused punctae throughout the cytosol of the cells (Figure 4J). These findings collectively

319 indicated that RIPK3 forms distinctive cellular structures when signaling to apoptosis or

320 necroptosis, depending on the chaperone Hsp90/CDC37.

322 Ripk3 $3^{\text {S165D-T166E/S165D-T166E }}$ mice die within a month after birth due to spontaneous

\section{3 apoptosis in multiple tissues}


324 We subsequently sought genetic proof that the phosphorylation of RIPK3 at its serine 325 165/threonine 166 sites (equivalent to human serine164/threonine165 sites) drives 326 apoptosis in vivo. To this end, we generated Ripk3 knock-in mice with Ser ${ }^{165} \mathrm{Thr}^{166}$ mutated

327 to Ala-Ala or Asp-Glu (Figure 5-figure supplement 1A, 1B, and 1E) to either block or

328 mimic the phosphorylation on these sites (Figure 5-figure supplement 1A, 1B, and 1F).

329 Interestingly, the Ripk $3^{\text {S165A-T166A/S165A-T166A }}$ homozygous mice were viable and appeared

330 normal (Figure 5-figure supplement 1C, 1D, and 1F). Ripk3 ${ }^{\text {S165D-T166E/S165D-T166E }}$

331 homozygous mice, on the other hand, are smaller in size and all died within one month

332 after birth (Figure 5A-5C). Anatomical analysis of these Ripk3 $3^{\text {S165D-T166E/S165D-T166E }}$ mice

333 showed abnormal large intestine, small intestine, lung, spleen, and kidney, while other

334 major organs, including brain, cerebellum, heart, and liver, appeared normal (Figure 5D

335 and Figure 5-figure supplement 1G). Staining for cleaved caspase-3 revealed significantly

336 increased apoptosis in the large intestine, small intestine, lung, and spleen (Figure 5E and

337 5F). The Ripk3 $3^{\text {S165D-T166E/+ }}$ heterozygous mice, which were expected to make half the

338 amount of RIPK3 S165D/T166E protein, are viable, indicating that there must be a

339 threshold above which the RIPK3 S165D/T166E protein becomes lethal.

340 Consistent with what was seen in HeLa cells, in which the phospho-mimic mutations

$341 \mathrm{~S} 164 \mathrm{D} / \mathrm{T} 165 \mathrm{E}$ of RIPK3 were unable to signal necroptosis, the bone marrow-derived

342 macrophages (BMDM) from Ripk3 $3^{\text {S165D-T166E/S165D-T166E }}$ mice were resistant to necroptosis

343 induction by TSZ (Figure 5G). Conversely, the BMDM from Ripk3 $3^{\text {S165A-T166A/S165A-T166A }}$

344 mice readily underwent necroptosis when treated with TSZ, as did the BMDM from wild

345 type mice (Figure 5-figure supplement $1 \mathrm{H}$ ).

347 PGF $_{2 \alpha}$ elevates the expression of RIPK3 in luteal granulosa cells to promote luteum 348 regression 
Among all RIPK3 expressing tissues, RIPK3 expression levels in the ovary were the most notable, following a reversed bell curve pattern through the lifetime of the mice

351 (Figure 6A). In early life and young adulthood, RIPK3 expression was restricted to the 352 follicle granular cells around the egg (Figure 6B). In later life, RIPK3 protein starts to 353 appear in the corpus luteum and albican (Figure 6B). The second wave of expression 354 coincides with the elevation of prostaglandin $\mathrm{F} 2 \mathrm{alph}\left(\mathrm{PGF}_{2 \alpha}\right)$, which has been reported to 355 have a role in apoptosis induction during luteal involution (Parkening et al., 1985). Indeed, 356 when we measured the $\mathrm{PGF}_{2 \alpha}$ levels in the mouse ovary, we saw a significant 357 age-dependent increase as mice aged from 4 months to 10 and 16 months, coinciding with 358 the age-dependent elevation of RIPK3 (Figure 6C). Moreover, when we co-stained 359 12-month-old RIPK3-Flag knock-in ovaries with anti-Flag and prostaglandin F receptor 360 (PTGFR), we noticed that the PTGFR signal was primarily located in corpus lutea and 361 corpus albicans but not in the follicles and co-localized with that of RIPK3 (Figure 6D and 362 Figure 6-figure supplement 1).

363 We thus used the same anti-phospho-S164/T165 antibody to probe ovary extracts from 364 mice of different ages by western blotting. We found no phosphorylation signal in young 365 (2-month old) ovaries, despite the RIPK3 protein band being readily detectable (Figure 366 6E). The signal began to appear at 4 months and gradually increased when mice advanced 367 in age (Figure 6E). To locate this phosphorylation signal in aged ovaries, we used this 368 antibody for immunohistochemical analysis on 4, 8, and 12-month-old ovaries. Consistent 369 with the western blotting, there was minimal signal in the young (4-month old) ovary. 370 There were patches of signal in 8-month-old corpus luteum and albican, and the signal 371 became prominent and clustered in the corpus albicans in 12-month-old ovary (Figure 6F, 372 middle panels). In contrast, no such phospho-RIPK3 signal was seen in 12-month-old 373 ovaries of RIPK3 knockout mice, further confirming the specificity of this monoclonal 374 antibody (Figure 6F).

375 RIPK3 induce apoptosis or necroptosis depending on the chaperone Hsp90/CDC37 376 level in vitro. To measure the level of Hsp90/CDC37 in granulosa cells of follicles and 377 corpus lutea/albicans, we did immunofluorescence staining of 8-month old mouse ovaries 
378 using antibodies against these two proteins. Both antibodies stained follicle granulosa

379 much more strongly than corpus lutea and albicans, whereas RIPK3 staining signal was at a

380 similar level in both, indicating that the relative level of Hsp90/CDC37 vs RIPK3 is higher

381 in follicles than corpus lutea and albicans (Figure 4-figure supplement 3). Collectively,

382 these results suggested that RIPK3-induced apoptosis in aged corpus lutea and albicans

383 was due to lower levels of Hsp90/CDC37 chaperone in these regions of the ovary.

$384 \mathrm{PGF}_{2 \alpha}$ is known to stimulate the Raf/MEK1/Mitogen-activated protein kinase

385 signaling pathway to induce luteal regression (Chen et al., 1998; Rolaki et al., 2005; Wang

386 et al., 2003; Yadav et al., 2002). In mice, knockout caspase-3 blocks PGF $_{2 \alpha}$-induced

387 regression of the corpus luteum (Carambula et al., 2002; Carambula et al., 2003). Those

388 observations suggested that $\mathrm{PGF}_{2 \alpha}$ might induce RIPK3 expression by stimulating the

389 Raf/MEK1/Mitogen-activated protein kinase signaling pathway, thus causes

390 RIPK3-mediated apoptosis. To test if $\mathrm{PGF}_{2 \alpha}$ could directly induce RIPK3 expression, we

391 isolated primary granulosa lutein cells from young (3 months old) mouse ovaries and

392 treated them with a synthetic $\mathrm{PGF}_{2 \alpha}$ analog dinoprost tromethamine (DT) (Chebel et al.,

393 2007). We then observed the time and dose-dependent induction of RIPK3 protein, a

394 pattern that overlapped with the appearance of phospho-ERK/MEK signal, an indication of

395 PGF2 receptor activation (Figure 7A and 7B). The addition of two MEK kinase inhibitors

396 PD-98059 or U0126 blocked RIPK3 induction, confirming that the RIPK3 induction by

$397 \mathrm{PGF}_{2 \alpha}$ was indeed through the MEK pathway (Figure 7-figure supplement 1A).

398 Importantly, the DT-induced RIPK3 was phosphorylated at its serine 165/threonine166

399 sites, and the treated cells were undergoing apoptosis, as indicated by the presence of

400 active caspase-3 (Figure 7C and Figure 7-figure supplement 1B). Consistent with the

401 notion that apoptosis induced by $\mathrm{PGF}_{2 \alpha}$ is RIPK3 dependent, the primary granulosa lutein

402 cells isolated from the RIPK3 knockout mice failed to respond to PGF2 $\alpha$ activate 403 caspase-3 (Figure 7C). 
404 The ability of primary granulosa lutein cells from young animals to undergo 405 RIPK3-mediated apoptosis in response to $\mathrm{PGF}_{2 \alpha}$ allowed us to genetically verify the role of 406 the RIPK3-RIPK1-FADD-Caspase-8 pathway in luteum regression. To this end, we first 407 induced hyper-ovulation in young female mice 4 weeks of age with gonadotropins and then 408 treated them with DT as previously described (Carambula et al., 2002; Carambula et al., 409 2003; Figure 7-figure supplement 1C). The hyper-ovulation induced by gonadotropins 410 generated multiple corpus lutea in the ovaries of these young mice (Figure 7D). The 411 subsequent DT treatment induced the elevation of RIPK3 protein in their corpus lutea, and 412 the induced RIPK3 was phosphorylated at the serine 164/threonine165 sites (Figure 7D 413 and 7E). Moreover, the treatment of DT caused active caspase-3 signal to appear in the 414 corpus lutea of wild-type ovaries (Figure 7F and 7G). Mice with their PTGFR gene 415 knocked out failed to elevate the RIPK3 level in response to $\mathrm{PGF}_{2 \alpha}$ (Figure $7 \mathrm{E}$ and Figure 416 6-figure supplement 1). Although DT treatment induced the elevation of phosphorylation 417 resistant RIPK3(S165A/T166A) protein in the ovaries of Ripk3 $3^{\text {S165A-T166A/S165A-T166A }}$ 418 knockin mice to the same level as wild type RIPK3 protein (Figure 7-figure supplement 419 1D), significantly less active caspase-3 signal was observed in these ovaries, similar to the 420 ovaries of Ripk3 $^{-/}, \mathrm{Fadd}^{-/} / \mathrm{Mlkl}^{-/}$, or Ptgfr ${ }^{-/}$mice, confirming that the observed

421 DT-induced apoptosis in luteal cells was through the RIPK3/FADD-mediated apoptosis 422 pathway triggered by the phosphorylation of serine 165/threonine 166 sites (Figure 7F and 423 7G). We further co-stained the ovaries with antibodies against active caspase-3 and 424 phopho-S165/T166 RIPK3 and found that most of the positive signals were overlapping 425 (Figure 7H), indicating that serine165/threonine166 phosphorylated RIPK3 activates 426 apoptosis in corpus luteum, triggered by $\mathrm{PGF}_{2 \alpha}$. Interestingly, although significantly lower 427 overall, there was more active caspase-3 in Ripk $3^{-/}$and Ripk3 $3^{\text {S165A-T166A/S165A-T166A }}$ ovaries 428 than in $\mathrm{Fadd}^{-/} / \mathrm{Mlkl}^{-/}$ovaries, suggesting that there might be a redundant 
429 RIPK3-independent but FADD-dependent apoptosis pathway that also functions in

430 resolving the corpus luteum in this model. This residue cell death could be through the

431 classic extrinsic apoptosis pathway described previously (Carambula et al., 2003; Hu et al.,

432 2001). Collectively, these results demonstrated that most of the corpus luteum involution

433 induced by $\mathrm{PGF}_{2 \alpha}$ is indeed through the RIPK3-RIPK1/FADD/Caspase-8 pathway

434 triggered by RIPK3 induction and phosphorylation at serine 165/threonine 166.

\section{Discussion}

437 The function of RIPK3 in apoptosis and necroptosis is controlled by 438 auto-phosphorylation of the amino acid residue serine 164

439 The apoptotic role of RIPK3 has been observed ever since RIPK3 was first identified

440 (Sun et al., 1999). The initial characterization of RIPK3, mainly by ectopic overexpression,

441 indicated that it functioned in apoptosis (Sun et al., 1999). Later, however, RIPK3 was

442 identified as a key signaling molecule for necroptosis due to its ability to specifically

443 phosphorylate MLKL, the executioner of this form of cell death (Cho et al., 2009; He et al.,

444 2009; Zhang et al., 2009; Sun et al., 2012). The debate of the apoptotic or necroptotic role

445 of RIPK3 was further brought to the front by the observation that the D161N mutation of

446 RIPK3 (D160N of human origin), a mutation that takes out the key DFG motif of the

447 kinase active site and renders RIPK3 kinase-inactive, caused spontaneous apoptosis by

448 activating caspase-8 through RIPK1 and FADD (Newton et al., 2014). Yet surprisingly,

449 another kinase-dead mutant of RIPK3, the K51A mutant, does not induce apoptosis like

$450 \mathrm{D} 161 \mathrm{~N}$, but instead only starts to signal to apoptosis in the presence of small-molecule

451 RIPK3 kinase inhibitors that occupy the ATP-binding site of the kinase domain (Mandal et

452 al., 2014). These observations suggest that it is not the inactivation of kinase activity per se

453 that switches RIPK3 function from necroptosis to apoptosis. It is more likely the 
454 conformational change that happens due to particular mutations or kinase inhibitor binding

455 that triggered such a change. We now understand that this change of RIPK3 function from

456 pro-necroptotic to apoptotic most likely mimicked the specific phosphorylation at the

457 serine 164 (mouse 165) site, carried out by RIPK3 kinase itself. The serine 164 amide

458 nitrogen forms a conserved H-bond with the carbonyl oxygen of phenylalanine 160 (part of

459 the DFG motif of kinase), a feature important to maintain the RIPK3 active configuration

460 (Xie et al., 2013). Introducing a phosphate group at this site conceivably disrupts this

461 critical interaction, resulting in loss-of-function of the RIPK3 kinase and a conformational

462 change that allows the RHIM domain to be available for RHIM-RHIM interaction between

463 RIPK3 and RIPK1. Since it is the amide, not the side chain of serine 164 that participates in

464 maintaining the active configuration of RIPK3, it is not surprising that the

465 phosphorylation-resistant mutant S164A/T165A retains the kinase activity and is still able

466 to signal to necroptosis, although such a mutation loses its apoptosis-inducing activity.

467 Interestingly, RIPK1 kinase functions here purely as an adaptor for the recruitment of

468 FADD and caspase-8, and its kinase activity is not required for this apoptosis function.

469 Therefore, unlike the apoptosis and necroptosis-inducing functions of RIPK1 when it

470 responds to the TNF receptor family of proteins, the apoptosis-inducing activity of RIPK1

471 that is initiated by RIPK3 phosphorylation is not sensitive to RIPK1 kinase inhibitors.

472 Although we cannot completely rule out the possibility of another yet to be identified

473 kinase(s) that carries out the phosphorylation of serine 164/threonine 165 of RIPK3, our

474 current data favor the idea that the phosphorylation is catalyzed by RIPK3 itself. Both

475 D160N and K50A kinase dead mutant RIPK3 failed to generate the

476 phospho-Serine164/Threonine 165 signal (Figure 3C and Figure 3-figure supplement 3C).

477 Especially, the K50 site is not in the proximity of the S164/T165 phosphorylation sites,

478 thus, the loss of phosphorylation is unlikely due to interference with substrate recognition 
479 that might have occurred with the D160N mutant, if the phosphorylation is carried out by

480 another kinase.

482 The level of RIPK3 chaperone Hsp90/CDC37 determines the cellular necroptotic or 483 apoptotic function of RIPK3

484 Our investigation has now clearly shown that RIPK3 naturally has dual roles in both 485 necroptosis and apoptosis. In cells in which the RIPK3 kinase predominantly signals to 486 necroptosis, like in human colon cancer HT29 cells, the RIPK3 chaperone Hsp90/CDC37 487 level is relatively high, which allows RIPK3 to fold into a configuration that can only be 488 activated by upstream signaling molecules, be that either RIPK1 in response to TNF 489 receptor family members, or TRIF and ZBP1/DAI in response to toll-like receptors or 490 Z-RNA, respectively. In this case, RIPK3 kinase activity is silent, and no 491 auto-phosphorylation signal or downstream substrate MLKL phosphorylation occurs 492 before upstream activation signals arrive.

493 However, in cells in which Hsp90/CDC37 chaperone level is relatively low or 494 artificially inhibited by Hsp90 inhibitors, the newly generated RIPK3, either by artificial 495 induction (through transient transfection or Dox-induced expression) or by physiological 496 signals like $\mathrm{PGF}_{2 \alpha}$, can auto-phosphorylate its serine 164/threonine 165 sites of its 497 conserved kinase activation loop, triggering apoptosis by forming the

498 RIPK3-RIPK1-FADD-Caspase-8 complex, leading to caspase-8 activation. Indeed, mice 499 bearing the phospho-mimic mutations of these sites (S165D/T166E) showed spontaneous 500 activation of apoptosis in all RIPK3-expressing tissues, including lung, intestines, and 501 spleen, and these mice die within a month after birth.

502 We noticed previously that Hsp90 inhibitors developed against human Hsp90 did not 503 block necroptosis in mouse bone marrow-derived macrophages but was efficacious in 
504 BMDM from rat (Li et al., 2015). We now know that such a difference is mainly due to

505 species specificity of these Hsp90 inhibitors. Using higher concentrations of human Hsp90

506 inhibitor 17AAG or knockdown Hsp90 protein in mouse cells, we recapitulated the similar

507 necroptosis to apoptosis switch as in human cells (Figure 4-figure supplement 4B-4E). We

508 thus realized that the previous conclusion that Hsp90/CDC37 chaperone system is not

509 working in mouse cells is wrongly drawn due to lower efficacy of the Hsp90 inhibitors

510 tested, which was developed to inhibit human Hsp90 (Li et al., 2015). The chaperone level

511 of Hsp90/CDC37 is important to dictate the necroptotic or apoptotic function of mouse

512 RIPK3 as well. Consistently, the levels of Hsp90 and CDC37 in the mouse luteum

513 granulosa is much lower than that in the follicle granulosa (Figure 4-figure supplement 3).

514 Serine 164/threonine 165 phosphorylation of RIPK3 seems to be a unique biomarker

515 for this RIPK3-mediated apoptosis pathway. Our development of a monoclonal antibody

516 that specifically recognizes this phosphorylation event should be useful to identify tissues

517 and cells in which this pathway is activated.

519 PGF $_{2 \alpha}$ induces RIPK3-mediated apoptosis in luteal granulosa cells for luteum 520 regression

521 One of the tissues in which this specific anti-phospho-S164/T165 monoclonal

522 antibody picked up a signal was in luteal granulosa cells of aged mouse ovary. The

523 appearance of this phopho-RIPK3 signal in the ovary coincident with the elevation of

$524 \mathrm{PGF}_{2 \alpha}$ level and indeed, an analog of $\mathrm{PGF}_{2 \alpha}$ was able to induce the expression of

525 S165/T166 phosphorylated RIPK3 in the primary granulosa cells from ovaries of young

526 mice (Figure 7). The phenomenon of $\mathrm{PGF}_{2 \alpha}$-induced RIPK3-expression in the mouse

527 ovary granulosa cells allowed us to genetically validate this intracellular apoptotic

528 pathway. In a hyper-ovulation model in which many egg follicles from young mice were 
529 induced to mature simultaneously, the accumulated granulosa cells in the ovary of wild

530 type mice can be triggered into resolution by an agonist (DT) of $\mathrm{PGF}_{2 \alpha}$ through

531 RIPK3-mediated apoptosis. However, DT could not induce apoptosis and luteum

532 resolution in the ovary of PGF receptor knockout, RIPK3 knockout, FADD/MLKL double

533 knockout, and Ripk3 $3^{\text {S165A-T166A/S165A-T166A }}$ knockin mice, confirming this intracellular

534 pathway of apoptosis in vivo.

535 Although the RIPK3-mediated apoptosis can be recapitulated in this hyper-ovulation

536 model using young mice, the serine 165/threonine 166 phospho-RIPK3 signal only

537 naturally appears in luteal granulosa cells when mice reach a certain age. The RIPK3

538 knockout and Ripk3 $3^{\text {S165A-T166A/S165A-T166A }}$ knockin mice do not show any fertility defect in

539 their normal reproductive age, indicating that the RIPK3-mediated apoptotic pathway does

540 not have a critical role in luteum resolution when the mice are young. It is thus interesting

541 to speculate that such a pathway may have a specific role during mouse ovary aging when

542 all corpora lutea eventually become albicans.

\section{References}

546 Cai, Z., Jitkaew, S., Zhao, J., Chiang, H.C., Choksi, S., Liu, J., Ward, Y., Wu, L.G., and

547 Liu, Z.G. (2014). Plasma membrane translocation of trimerized MLKL protein is required

548 for TNF-induced necroptosis. Nat Cell Biol 16, 55-65.

549 Carambula, S.F., Matikainen, T., Lynch, M.P., Flavell, R.A., Goncalves, P.B., Tilly, J.L.,

550 and Rueda, B.R. (2002). Caspase-3 is a pivotal mediator of apoptosis during regression of

551 the ovarian corpus luteum. Endocrinology 143, 1495-1501.

552 Carambula, S.F., Pru, J.K., Lynch, M.P., Matikainen, T., Goncalves, P.B., Flavell, R.A.,

553 Tilly, J.L., and Rueda, B.R. (2003). Prostaglandin F2alpha- and FAS-activating 
554 antibody-induced regression of the corpus luteum involves caspase- 8 and is defective in

555 caspase-3 deficient mice. Reprod Biol Endocrinol 1, 15.

556 Chebel, R.C., Santos, J.E., Rutigliano, H.M., and Cerri, R.L. (2007). Efficacy of an

557 injection of dinoprost tromethamine when given subcutaneously on luteal regression in

558 lactating Holstein cows. Theriogenology 67, 590-597.

559 Chen, D.B., Westfall, S.D., Fong, H.W., Roberson, M.S., and Davis, J.S. (1998).

560 Prostaglandin F2alpha stimulates the Raf/MEK1/mitogen-activated protein kinase

561 signaling cascade in bovine luteal cells. Endocrinology 139, 3876-3885.

562 Chen, X., Li, W., Ren, J., Huang, D., He, W.T., Song, Y., Yang, C., Li, W., Zheng, X.,

563 Chen, P., et al. (2014). Translocation of mixed lineage kinase domain-like protein to

564 plasma membrane leads to necrotic cell death. Cell Res 24, 105-121.

565 Cho, Y.S., Challa, S., Moquin, D., Genga, R., Ray, T.D., Guildford, M., and Chan, F.K.

566 (2009). Phosphorylation-driven assembly of the RIP1-RIP3 complex regulates

567 programmed necrosis and virus-induced inflammation. Cell 137, 1112-1123.

568 Christofferson, D.E., and Yuan, J. (2010). Necroptosis as an alternative form of

569 programmed cell death. Curr Opin Cell Biol 22, 263-268.

570 Degterev, A., Hitomi, J., Germscheid, M., , I.L., Korkina, O., Teng, X., Abbott, D., Cuny,

571 G.D., Yuan, C., Wagner, G., et al. (2008). Identification of RIP1 kinase as a specific

572 cellular target of necrostatins. Nat Chem Biol 4, 313-321.

573 Elmore, S. (2007). Apoptosis: a review of programmed cell death. Toxicol Pathol 35,

574 495-516.

575 Fink, S.L., and Cookson, B.T. (2005). Apoptosis, pyroptosis, and necrosis: mechanistic

576 description of dead and dying eukaryotic cells. Infect Immun 73, 1907-1916. 
577 He, S., Wang, L., Miao, L., Wang, T., Du, F., Zhao, L., and Wang, X. (2009). Receptor

578 interacting protein kinase-3 determines cellular necrotic response to TNF-alpha. Cell 137,

$579 \quad 1100-1111$.

580 He, S., and Wang, X. (2018). RIP kinases as modulators of inflammation and immunity.

581 Nat Immunol 19, 912-922.

582 Hu, C.L., Cowan, R.G., Harman, R.M., Porter, D.A., and Quirk, S.M. (2001). Apoptosis of

583 bovine granulosa cells after serum withdrawal is mediated by Fas antigen (CD95) and Fas

584 ligand. Biol Reprod 64, 518-526.

585 Kroemer, G., Galluzzi, L., Vandenabeele, P., Abrams, J., Alnemri, E.S., Baehrecke, E.H.,

586 Blagosklonny, M.V., El-Deiry, W.S., Golstein, P., Green, D.R., et al. (2009).

587 Classification of cell death: recommendations of the Nomenclature Committee on Cell

588 Death 2009. Cell Death Differ 16, 3-11.

589 Li, D., Meng, L., Xu, T., Su, Y., Liu, X., Zhang, Z., and Wang, X. (2017).

590 RIPK1-RIPK3-MLKL-dependent necrosis promotes the aging of mouse male reproductive 591 system. Elife 6.

592 Li, D., Xu, T., Cao, Y., Wang, H., Li, L., Chen, S., Wang, X., and Shen, Z. (2015). A

593 cytosolic heat shock protein 90 and cochaperone CDC37 complex is required for RIP3

594 activation during necroptosis. Proc Natl Acad Sci U S A 112, 5017-5022.

595 Li, P., Nijhawan, D., Budihardjo, I., Srinivasula, S.M., Ahmad, M., Alnemri, E.S., and

596 Wang, X. (1997). Cytochrome c and dATP-dependent formation of Apaf-1/caspase-9

597 complex initiates an apoptotic protease cascade. Cell 91, 479-489.

598 Mandal, P., Berger, S.B., Pillay, S., Moriwaki, K., Huang, C., Guo, H., Lich, J.D., Finger,

599 J., Kasparcova, V., Votta, B., et al. (2014). RIP3 induces apoptosis independent of

600 pronecrotic kinase activity. Mol Cell 56, 481-495. 
601 Newton, H., Picton, H., and Gosden, R.G. (1999). In vitro growth of oocyte-granulosa cell

602 complexes isolated from cryopreserved ovine tissue. J Reprod Fertil 115, 141-150.

603 Newton, K., Dugger, D.L., Wickliffe, K.E., Kapoor, N., de Almagro, M.C., Vucic, D.,

604 Komuves, L., Ferrando, R.E., French, D.M., Webster, J., et al. (2014). Activity of protein

605 kinase RIPK3 determines whether cells die by necroptosis or apoptosis. Science 343,

$606 \quad 1357-1360$.

607 Nishi, Y., Yanase, T., Mu, Y., Oba, K., Ichino, I., Saito, M., Nomura, M., Mukasa, C.,

608 Okabe, T., Goto, K., et al. (2001). Establishment and characterization of a steroidogenic

609 human granulosa-like tumor cell line, $\mathrm{KGN}$, that expresses functional follicle-stimulating

610 hormone receptor. Endocrinology 142, 437-445.

611 Parkening, T.A., LaGrone, L.F., and Brouhard, B.H. (1985). Concentrations of

612 prostaglandins in plasma, seminal vesicles, and ovaries of aging C57BL/6NNia mice. Exp

613 Gerontol 20, 291-294.

614 Perez, G.I., Knudson, C.M., Leykin, L., Korsmeyer, S.J., and Tilly, J.L. (1997).

615 Apoptosis-associated signaling pathways are required for chemotherapy-mediated female

616 germ cell destruction. Nat Med 3, 1228-1232.

617 Perheentupa, A., and Huhtaniemi, I. (2009). Aging of the human ovary and testis. Mol Cell

618 Endocrinol 299, 2-13.

619 Rimon-Dahari, N., Yerushalmi-Heinemann, L., Alyagor, L., and Dekel, N. (2016).

620 Ovarian Folliculogenesis. Results Probl Cell Differ 58, 167-190.

621 Rolaki, A., Drakakis, P., Millingos, S., Loutradis, D., and Makrigiannakis, A. (2005).

622 Novel trends in follicular development, atresia and corpus luteum regression: a role for

623 apoptosis. Reprod Biomed Online 11, 93-103.

624 Sanchez, F., and Smitz, J. (2012). Molecular control of oogenesis. Biochim Biophys Acta

$6251822,1896-1912$. 
626 Stocco, C., Telleria, C., and Gibori, G. (2007). The molecular control of corpus luteum

627 formation, function, and regression. Endocr Rev 28, 117-149.

628 Sun, L., Wang, H., Wang, Z., He, S., Chen, S., Liao, D., Wang, L., Yan, J., Liu, W., Lei, X.,

629 et al. (2012). Mixed lineage kinase domain-like protein mediates necrosis signaling

630 downstream of RIP3 kinase. Cell 148, 213-227.

631 Sun, X., Lee, J., Navas, T., Baldwin, D.T., Stewart, T.A., and Dixit, V.M. (1999). RIP3, a

632 novel apoptosis-inducing kinase. J Biol Chem 274, 16871-16875.

633 Tian, Y., Shen, W., Lai, Z., Shi, L., Yang, S., Ding, T., Wang, S., and Luo, A. (2015).

634 Isolation and identification of ovarian theca-interstitial cells and granulose cells of

635 immature female mice. Cell Biol Int 39, 584-590.

636 Tilly, J.L. (2001). Commuting the death sentence: how oocytes strive to survive. Nat Rev

637 Mol Cell Biol 2, 838-848.

638 Tilly, J.L., and Sinclair, D.A. (2013). Germline energetics, aging, and female infertility.

639 Cell Metab 17, 838-850.

640 Upton, J.W., Kaiser, W.J., and Mocarski, E.S. (2012). DAI/ZBP1/DLM-1 complexes with

641 RIP3 to mediate virus-induced programmed necrosis that is targeted by murine

642 cytomegalovirus vIRA. Cell Host Microbe 11, 290-297.

643 Vandenabeele, P., Galluzzi, L., Vanden Berghe, T., and Kroemer, G. (2010). Molecular

644 mechanisms of necroptosis: an ordered cellular explosion. Nat Rev Mol Cell Biol 11,

$645700-714$.

646 Wallach, D., Kang, T.B., Dillon, C.P., and Green, D.R. (2016). Programmed necrosis in

647 inflammation: Toward identification of the effector molecules. Science 352, aaf2154.

648 Wang, H., Sun, L., Su, L., Rizo, J., Liu, L., Wang, L.F., Wang, F.S., and Wang, X. (2014).

649 Mixed lineage kinase domain-like protein MLKL causes necrotic membrane disruption

650 upon phosphorylation by RIP3. Mol Cell 54, 133-146. 
651 Wang, L., Du, F., and Wang, X. (2008). TNF-alpha induces two distinct caspase-8

652 activation pathways. Cell 133, 693-703.

653 Wang, Z., Tamura, K., Yoshie, M., Tamura, H., Imakawa, K., and Kogo, H. (2003).

654 Prostaglandin F2alpha-induced functional regression of the corpus luteum and apoptosis in 655 rodents. J Pharmacol Sci 92, 19-27.

656 Xie, T., Peng, W., Yan, C., Wu, J., Gong, X., and Shi, Y. (2013). Structural insights into

657 RIP3-mediated necroptotic signaling. Cell Rep 5, 70-78.

658 Yadav, V.K., Sudhagar, R.R., and Medhamurthy, R. (2002). Apoptosis during spontaneous

659 and prostaglandin $\mathrm{F}$ (2alpha)-induced luteal regression in the buffalo cow (Bubalus

660 bubalis): involvement of mitogen-activated protein kinases. Biol Reprod 67, 752-759.

661 Ying, Z., Pan, C., Shao, T., Liu, L., Li, L., Guo, D., Zhang, S., Yuan, T., Cao, R., Jiang, Z.,

662 et al. (2018). Mixed Lineage Kinase Domain-like Protein MLKL Breaks Down Myelin

663 following Nerve Injury. Mol Cell 72, 457-468 e455.

664 Zhang, D.W., Shao, J., Lin, J., Zhang, N., Lu, B.J., Lin, S.C., Dong, M.Q., and Han, J.

665 (2009). RIP3, an energy metabolism regulator that switches TNF-induced cell death from

666 apoptosis to necrosis. Science 325, 332-336.

667 Zhang, T., Yin, C., Boyd, D.F., Quarato, G., Ingram, J.P., Shubina, M., Ragan, K.B.,

668 Ishizuka, T., Crawford, J.C., Tummers, B., et al. (2020). Influenza Virus Z-RNAs Induce

669 ZBP1-Mediated Necroptosis. Cell 180, 1115-1129 e1113.

670 Zhang, X., Fan, C., Zhang, H., Zhao, Q., Liu, Y., Xu, C., Xie, Q., Wu, X., Yu, X., Zhang,

671 J., et al. (2016). MLKL and FADD Are Critical for Suppressing Progressive

672 Lymphoproliferative Disease and Activating the NLRP3 Inflammasome. Cell Rep 16,

$673 \quad 3247-3259$.

674

675 


\section{Figure legend}

681 Figure 1. RIPK3-induced apoptosis in MCF7 and KGN cells.

682 (A) Cultured MCF7/TO-RIPK3 and HeLa/TO-RIPK3 cells were treated with DMSO or $683 \operatorname{Dox}(1 \mu \mathrm{g} / \mathrm{ml})$ induction for 36 hours. Cell viability was determined by measuring cellular 684 ATP levels (upper panel). The data are represented as the mean \pm SD of triplicate wells. 685 The cell lysates were analyzed by western blotting using antibodies against RIPK3 or $686 \beta$-actin (lower panel).

687 (B) Cultured MCF7/TO-RIPK3, KGN/TO-RIPK3, and HeLa/TO-RIPK3 cells were 688 treated with DMSO, Dox, or Dox plus TSZ for 36 hours. Cell viability was determined by 689 measuring cellular ATP levels. The data are represented as the mean \pm SD of triplicate 690 wells.

691 (C) Cultured MCF7/TO-RIPK3 cells were treated with DMSO or Dox, plus the indicated 692 agents for 36 hours. Cell viability was determined by measuring cellular ATP levels (upper 693 panel). The data are represented as the mean \pm SD of triplicate wells. The cell lysates were 694 analyzed by western blotting using antibodies against RIPK3 or $\beta$-actin (lower panel). 20 $695 \mu \mathrm{M} Z$, pan-caspase inhibitor z-VAD; $2 \mu \mathrm{M}$ RIPA-56, RIPK1 inhibitor; $2 \mu \mathrm{M}$ NSA, MLKL 696 inhibitor.

697 (D) Cultured MCF7 cells were infected with lentiviruses encoding RIPK3(WT), 698 RIPK3(AAAA), RIPK3(K50A), and RIPK3(K50A)+GSK'872 plus Z for 36 hours. Cell

699 viability was determined by measuring cellular ATP levels (upper panel). The data are 
700 represented as the mean $\pm \mathrm{SD}$ of triplicate wells. $* * * P<0.001$. The lysates were measured

701 by western blotting using antibodies against RIPK3 or $\beta$-actin as indicated (lower panel).

702 GSK'872, RIPK3 inhibitor.

703 The online version of this article includes the following figure supplement(s) for figure 1:

704 Figure supplement 1. RIPK3-induced apoptosis in human granulosa lutein cells (KGN).

705

706 Figure 2. RIPK3-induced apoptosis was dependent on RIPK1, FADD and caspase-8.

707 (A) Cultured MCF7/TO-RIPK3 cells were treated with DMSO or Dox plus the indicated

708 agent for 24 hours. The cells were then harvested, and RIPK3 was immunoprecipitated

709 from the cell lysates using anti-Flag resin. The cell lysates and immunocomplexes were

710 analyzed by western blotting using antibodies as indicated.

711 (B-E) Cultured MCF7/TO-RIPK3(wild type (WT), RIPK1 ${ }^{-/}$, Caspase $^{-/-}$, FADD ${ }^{-/}$, and

$712 c F L I F^{--}$) cells were treated with DMSO or Dox induction for 36 hours. Cell viability was

713 determined by measuring cellular ATP levels (upper panel). The data are represented as the

714 mean \pm SD of triplicate wells. The cell lysates were analyzed by western blotting using

715 antibodies against RIPK1, Caspase8, FADD, cFLIP or $\beta$-actin (lower panel).

717 Figure 3. RIPK3-mediated apoptosis is dependent on the auto-phosphorylation of the

718 S164/T165 sites.

719 (A) Cultured MCF7/TO-RIPK3 and HeLa/TO-RIPK3 cells were treated with Dox plus

720 z-VAD for 24 hours. RIPK3 was immunoprecipitated from the cell lysates using anti-Flag

721 resin. The RIPK3 bands were excised and subjected to mass spectrometry analysis. RIPK3

722 specific phosphorylation site in MCF7/TO-RIPK3 cells is highlighted in red.

723 (B) Cultured KGN/TO-RIPK3, MCF7/TO-RIPK3, and HeLa/TO-RIPK3 cells were

724 treated with Dox plus z-VAD for 24 hours. The lysates were analyzed by western blotting 
725 using antibodies against the phopho-Serine164/theronine165 of RIPK3, Flag (RIPK3), and

$726 \beta$-actin as indicated.

727 (C) Cultured MCF7 stably transfected with either wild type RIPK3 (WT) or kinase-dead

728 mutant (D160N) cells under the control of Dox-inducible promoter were treated with

729 DMSO(-) or Dox plus z-VAD for 24 hours. The lysates were analyzed by western blotting

730 using antibodies against the phopho-Serine164/theronine165 RIPK3, Flag (RIPK3), and

$731 \beta$-actin as indicated.

732 (D) Cultured $293 \mathrm{~T}$ cells were transfected with Vector (Vec), RIPK3(WT), 733 RIPK3(D160N), RIPK3(AAAA) (RIPK3-AAAA, residues 459-462 mutated to AAAA)

734 and RIPK3(S164D/T165E) for 24 hours. The level of phospho-S227-RIPK3 and RIPK3

735 were measured by western blotting.

736 (E and F) Cultured MCF7 (E) and KGN (F) cells were infected with lentiviruses encoding

737 RIPK3(WT), RIPK3(S164D/T165E), RIPK3(S164A/T165A) and RIPK3(AAAA) plus

738 z-VAD for 36 hours. Cell viability was determined by measuring cellular ATP levels

739 (upper panel). The data are represented as the mean \pm SD of triplicate wells. $* * * P<0.001$.

740 The lysates were measured by western blotting using antibodies against RIPK 3 or $\beta$-actin 741 as indicated (lower panel).

742 (G) Cultured HeLa cells were infected with lentiviruses encoding RIPK3(WT),

743 RIPK3(D160N), RIPK3(AAAA), and RIPK3(S164D/T165E) plus z-VAD for 36 hours.

744 Cell viability was determined by measuring cellular ATP levels (upper panel). The data are

745 represented as the mean \pm SD of triplicate wells. $* * P<0.01, * * * P<0.001$. The expressed

746 RIPK3 in the cell lysates were measured by western blotting using antibodies against

747 RIPK3 or $\beta$-actin as indicated (lower panel). Vector (Vec, control viruses)

748 (H) Cultured HeLa cells were transfected with Flag-tagged RIPK3(WT), RIPK3(D160N),

749 and RIPK3(S164D/T165E) for 24 hours. RIPK3 was immunoprecipitated using anti-Flag 
750 resin. The lysates and immunocomplexes were analyzed by western blotting using

751 antibodies against RIPK1, Caspase-8, FADD, and RIPK3 as indicated.

752 (I) Cultured MCF7/TO-RIPK3 and MCF7/TO-RIPK3(S164A/T165A) cells were treated

753 with Dox plus $\mathrm{Z}$ for 24 hours. The cells were then harvested, and RIPK3 was

754 immunoprecipitated from the cell lysates using anti-Flag resin. The cell lysates and

755 immunocomplexes were analyzed by western blotting using antibodies as indicated.

756 The online version of this article includes the following figure supplement(s) for figure 3:

757 Figure supplement 1. Characterization of RIPK3 auto-phosphorylation sites.

758 Figure supplement 2. The phosphorylation site of RIPK3 is conserved among different

759 mammalian species.

761 Figure 4. Hsp90/CDC37 chaperone determined the apoptotic and necroptotic function of 762 RIPK3 kinase.

763 (A) The cell lysates from cultured HT29, HeLa, MCF7, and KGN cells were analyzed by 764 western blotting using antibodies as indicated.

765 (B and C) Cultured HeLa-RIPK3, MCF7/TO-RIPK3, and KGN/TO-RIPK3 cells were 766 treated with the indicated stimuli for 36 hours. Cell viability was determined by measuring 767 cellular ATP levels. The data represented as the mean \pm SD of triplicate wells. 17AAG, 768 Hsp90 inhibitor.

769 (D and E) HeLa/TO-RIPK3 cells were treated with the indicated stimuli for 36 hours. Cell

770 viability was determined by measuring cellular ATP levels in (D). The data represented as

771 the mean \pm SD of triplicate wells. $* * * P<0.001 .24$ hours after treatment, the cell lysates

772 were analyzed by western blotting using antibodies against

773 phopho-Serine164/Theronine165 of RIPK3, RIPK3, and $\beta$-actin as indicated in (E). 
774 (F and G) Cultured MCF7/TO-RIPK3 cells co-transfected with HSP90 and CDC37 as

775 indicated were treated with DMSO or Dox for 36 hours. Cell viability was determined by

776 measuring cellular ATP levels in $(\mathrm{F})$. The data are represented as the mean \pm SD of

777 triplicate wells. $* * * P<0.001 .24$ hours after treatment, the cell lysates were analyzed by

778 western blotting using antibodies against phopho-Serine164/Theronine165 of RIPK3,

779 RIPK3, Hsp90, CDC37, and $\beta$-actin as indicated in (G).

780 (H) Cultured HeLa/TO-RIPK3 cells were treated with Dox or Dox plus 17AAG for 24

781 hours. The cells were then harvested, and RIPK3 was immunoprecipitated from the cell

782 lysates using anti-Flag resin. The cell lysates and immunocomplexes were analyzed by

783 western blotting using antibodies as indicated.

784 (I) Cultured HeLa/TO-RIPK3 cells were treated with Dox or Dox plus 17AAG for 24

785 hours. Immunofluorescence of the cells with Flag-RIPK3 (red) antibody. Counterstaining

786 with DAPI (blue). Scale bar, $10 \mu \mathrm{m}$. Higher-power views (right panels) were acquired from

787 the selected boxed areas from the left panel.

788 (J) Cultured MCF7/TO-RIPK3 cells co-transfected with HSP90 and CDC37 as indicated

789 were treated with Dox for 24 hours. Immunofluorescence of the cells with Flag-RIPK3

790 (red) antibody. Counterstaining with DAPI (blue). Scale bar, $10 \mu \mathrm{m}$. Higher-power views

791 (right panels) were acquired from the selected boxed areas from the left panel.

792 The online version of this article includes the following figure supplement(s) for figure 4:

793 Figure supplement 1. Hsp90/CDC37 chaperone determines the necroptotic or apoptotic

794 function of RIPK3 kinase.

795 Figure supplement 2. RIPK3 form amyloid-like structure in MCF7 and KGN cells.

796 Figure supplement 3. Hsp90/CDC37 chaperone protein levels was low in corpus luteum

797 and corpus albicans. 
799 Figure 5. Ripk3 $3^{S 165 D-T 166 D / S 165 D-T 166 D}\left(\operatorname{Ripk}^{S T-D E / S T-D E}\right)$ mice die within one month after

800 birth.

801 (A and B) Macroscopic features (A) and body weights (B) of Ripk $3^{+/+}$and Ripk3 $3^{S T-D E / S T-D E}$

802 littermate mice at 14 days of age $(n \geq 9)$. The result from each individual animal is presented

803 as an indicated dot. $* * * P<0.001$.

804 (C) Kaplan-Meier plot of survival of Ripk $^{+/+}$and Ripk3 $3^{S T-D E / S T-D E}$ littermate mice (n=10

805 for each genotype) after birth within two months. $* * * P<0.001$.

806 (D) Histological analysis of large intestine, small intestine, lung, and spleen of Ripk $3^{+/+}$

807 and Ripk3 $3^{S T-D E / S T-D E}$ littermate mice $(\mathrm{n}=5)$ at 14 days of age. Scale bar, $20 \mu \mathrm{m}$.

808 (E and F) Representative immunohistochemistry (IHC) images of the large intestine, small

809 intestine, lung, and spleen of Ripk ${ }^{+/+}$and Ripk $3^{S T-D E / S T-D E}$ littermate mice (n=5, 14 days)

810 stained with a Cleaved-Caspase3 (C-C3) antibody in (E). C-C3 positive cells were counted

811 in two fields per organ and quantified in (F). Scale bar, $10 \mu \mathrm{m}$. Data represent the mean \pm

812 s.e.m. $* * P<0.01, * * * P<0.001$.

813 (G) Cell viability measurement of bone marrow-derived macrophages from the Ripk $3^{+/+}$

814 and Ripk3 $3^{S T-D E / S T-D E}$ littermate mice (n=3, 14 days) after treatment with the indicated

815 Z-VAD or necroptosis stimuli for 24 hours. Cell viability was determined by measuring

816 cellular ATP levels. The data are represented as the mean \pm SD of triplicate wells.

817 The online version of this article includes the following figure supplement(s) for figure 5:

818 Figure supplement 1. Generation of Ripk $3^{S T-D E / S T-D E}$ and Ripk $3^{S T-A A / S T-A A}$ mice.

820 Figure 6. Phospho-serine164/threonine165-RIPK3 signals were present in aged ovary 821 corpus albican.

822 (A) Western blot analysis of RIPK1, RIPK3, and MLKL levels in perfused mouse ovary 823 extracts of different ages. Each group is representative of at least 3 mice. 
824 (B) H\&E and immunofluorescence (IF) imaging of an 8-month-old ovary. Two adjacent

825 sections were analyzed. One section was stained with H\&E, and the other was IF stained

826 with a RIPK3 antibody (red) and DAPI (blue). Scale bar, $500 \mu \mathrm{m}$. Higher-power views of

827 selected areas were acquired in a (primordia follicle), b (secondary follicle), c (corpus

828 luteum), and $\mathbf{d}$ (corpus albicans) as indicated. PF, primary follicle; CL, corpus luteum; CA,

829 corpus albicans.

830 (C) Ovarian $\mathrm{PGF}_{2 \alpha}$ levels of wild-type mice $(\mathrm{n}=8)$ at the indicated age assayed by ELISA.

831 Data represent the mean \pm s.e.m. $* * P<0.01, * * * P<0.001$.

832 (D) Immunofluorescence images of a RIPK3 C-terminus HA-3×Flag knock-in mouse

833 ovary ( $\mathrm{n}=5 ; 12$ months) stained with antibodies against prostaglandin $\mathrm{F}$ receptor (PTGFR,

834 green) and Flag (red). Counterstaining with DAPI (blue). Scale bar, $500 \mu \mathrm{m}$. Higher-power

835 views (right panels) were acquired from the indicated boxed area in the second lower left

836 panel. CL, corpus luteum. CA, corpus albicans. Scale bar, $100 \mu \mathrm{m}$.

837 (E) Western blot analysis of p-S164/T165-RIPK3 and RIPK3 levels in extracts from

838 perfused ovaries prepared from mice at the indicated age. Each group is representative of at 839 least 3 mice.

840 (F) Immunofluorescence images of ovaries from Ripk $3^{+/+}$and Ripk $3^{-/-}$mice (4 Month, 8

841 Month and 12 Month; n=3) at the indicated ages stained with the p-S164/T165-RIPK3

842 antibody (red). Counterstaining with DAPI (blue). Scale bar, $200 \mu \mathrm{m}$. Higher-power views

843 (lower two panels) were acquired from the selected boxed areas from the upper panel.

844 (CL), b (CL), c (CL, CA) and d (CL). F, follicle; CL, corpus luteum; CA, corpus albicans.

845 Scale bar, $100 \mu \mathrm{m}$.

846 The online version of this article includes the following figure supplement(s) for figure 6:

847 Figure supplement 1. Generation of RIPK3 C-terminus HA-3×Flag knock-in and Ptgfr ${ }^{-/}$

848 mice. 
850 Figure 7. Prostaglandin F2alpha $\left(\mathrm{PGF}_{2 \alpha}\right)$ induces ovarian RIPK3 expression for corpus

851 luteum involution.

852 (A to C) Primary granulosal lutein cells (WT, Ripk3 $3^{-/}$) were isolated from 3-month-old

853 mice ovaries. The cells were treated with Dinoprost Tromethamine (DT) at the indicated

854 concentration for 36 hours in (A); with $1.5 \mu \mathrm{M}$ DT at the indicated time in (B); or with 1.5

$855 \mu \mathrm{M}$ DT for 36 hours in (C). The cell lysates from the DT-treated cells were analyzed by

856 western blotting using antibodies as indicated.

857 (D and E) Ptgfr ${ }^{+/+}$and Ptgfr ${ }^{-/-}$littermate female mice (n=16; 25-26 days) were given 7.5

858 IU pregnant mare serum gonadotropin (PMSG) intraperitoneally(IP) followed by 7.5 IU

859 serum gonadotropin and chorionic gonadotropin (SCG) 46 hours later to synchronize

860 ovulation. The animals were then injected with Dinoprost Tromethamine (DT) (10

861 micrograms, i.p.) or saline 24 hours post-ovulation. Ovaries were then collected 12 hours

862 later and stained with anti-RIPK3 antibody (red) in (D). The ovary lysates were analyzed

863 by western blotting using antibodies as indicated in (E). (*) indicates Corpus luteum.

864 Counterstaining with DAPI (blue). Scale bar, $500 \mu \mathrm{m}$.

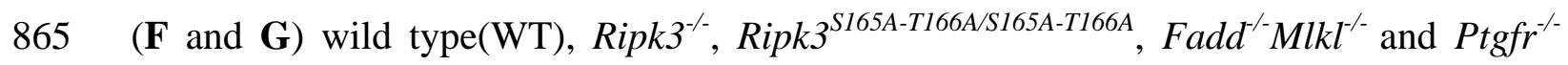

866 female mice (each group, $n=16 ; 25-26$ days) were treated as in ( $D$ and $F$ ). Ovaries from

867 each group were then collected 24 hours after injecting with DT and stained with

868 anti-cleaved-caspase 3 antibody in (F). The Cleaved-Caspase $3^{+}$cells were counted in five

869 fields per ovary Corpus luteum(CL) and quantified in (G). Scale bar, $20 \mu \mathrm{m}$. Data represent

870 the mean \pm s.e.m. $* * P<0.01, * * * P<0.001$.

871 (H) wild type female mice ( $\mathrm{n}=3 ; 25-26$ days) were treated as in (D and F). Ovaries were

872 then collected 12 hours after injecting with DT and stained with anti-cleaved-caspase3(red) 
873 and p-S164/T165-RIPK3(green) antibody. Counterstaining with DAPI (blue). Scale bar,

$874100 \mu \mathrm{m}$.

875 The online version of this article includes the following figure supplement(s) for figure 7 :

876 Figure supplement 1. Prostaglandin F2alpha $\left(\mathrm{PGF}_{2 \alpha}\right)$ stimulates RIPK3 expression

877 through the MAPK pathway.

\section{$880 \quad$ Figure supplement legend}

881 Figure 1-figure supplement 1. RIPK3-induced apoptosis in human granulosa lutein cells $882(\mathrm{KGN})$.

883 Cultured KGN/TO-RIPK3 cells were treated with DMSO or Dox $(1 \mu \mathrm{g} / \mathrm{ml})$ induction for 36

884 hours. Cell viability was determined by measuring cellular ATP levels (upper panel). The

885 data are represented as the mean \pm SD of triplicate wells. The cell lysates were analyzed by

886 western blotting using antibodies against RIPK3 or $\beta$-actin (lower panel).

888 Figure 3-figure supplement 1. Characterization of RIPK3 auto-phosphorylation sites.

889 (A) Cultured MCF7/TO-RIPK3 and MCF7/TO-RIPK3(S164A/T165A) cells were treated 890 with DMSO (-) or Dox plus z-VAD for 24 hours. The lysates were analyzed by western

891 blotting using antibodies against the phopho-Serine164/theronine165 of RIPK3, Flag 892 (RIPK3), and $\beta$-actin as indicated.

893 (B) Cultured KGN7/TO-RIPK3 and KGN/TO-RIPK3(S164A/T165A) cells were treated

894 with DMSO or Dox plus z-VAD for 24 hours. The lysates were analyzed by western

895 blotting using antibodies against the phopho-Serine164/theronine165 of RIPK3, Flag 896 (RIPK3), and $\beta$-actin as indicated. 
897 (C) Cultured MCF7/TO-RIPK3 and MCF7/TO-RIPK3(K50A) cells were treated with

898 DMSO (-) or Dox plus z-VAD for 24 hours. The lysates were analyzed by western blotting

899 using antibodies against the phopho-Serine164/theronine165 of RIPK3, Flag (RIPK3), and

$900 \quad \beta$-actin as indicated.

901 (D) Cultured HeLa cells were infected with lentiviruses encoding wild type RIPK3(WT),

902 and mutant RIPK3 including RIPK3(D160N), RIPK3(S164D/T165E), RIPK3(S164E),

903 RIPK3(T165E), RIPK3(S164A/T165A), RIPK3(S164A), RIPK3(T165A) and

904 RIPK3(AAAA) and treated with TSZ for 36 hours. Cell viability was determined by

905 measuring cellular ATP levels (upper panel). The data represented as the mean \pm SD of

906 triplicate wells. $* * P<0.01$. The levels of expressed RIPK3 in the cell lysates were

907 measured by western blotting (lower panel).

908 (E) RIPK3 single site (S164E) mutation blocks auto-phosphorylation. 293T cells were

909 transfected with Flag-tagged RIPK3(WT), RIPK3(D160N), RIPK3(S164D/T165E),

910 RIPK3(S164E), RIPK3(T165E), RIPK3(S164A/T165A), RIPK3(S164A), RIPK3(T165A)

911 and RIPK3(AAAA) for 24 hours. The level of p-S227-RIPK3 and RIPK3 were measured

912 by western blotting.

913 (F and G) Cultured MCF7 (E) and KGN (F) cells were infected with lentiviruses encoding

914 wild type RIPK3(WT), and mutant forms of RIPK3(S164A/T165A), RIPK3(S164A) and

915 RIPK3(T165A) and treated with z-VAD as indicated for 36 hours. Cell viability was

916 determined by measuring cellular ATP levels (upper panel). The data are represented as the

917 mean \pm SD of triplicate wells. $* * * P<0.001$. The levels of RIPK3 in the cell lysates were

918 measured by western blotting (lower panel).

919 (H) Cultured HeLa cells were transfected with Flag-tagged wild type RIPK3(WT), and

920 mutant forms of RIPK3(T165E), RIPK3(S164D/T165E), and RIPK3(S164E) for 24

921 hours. RIPK3 was immunoprecipitated from the cell lysates using anti-Flag resin. The 
922 lysates and immunocomplexes were analyzed by western blotting using antibodies against

923 RIPK1, caspase-8, RIPK3, and $\beta$-actin as indicated.

924

925 Figure 3-figure supplement 2. The phosphorylation site of RIPK3 is conserved among

926 different mammalian species.

927 (A) Alignment of amino acid sequences of RIPK3 orthologs in five mammalian species.

928 Amino acid residues conserved in $80 \%$ or more of the sequences are shaded in black. The

929 putative phosphorylation residues are denoted by asterisks (*).

930 (B) Cultured $293 \mathrm{~T}$ cells were transfected with Vector (Vec), mouse RIPK3(WT),

931 RIPK3(S165D/T166E), and RIPK3(S165A/T165A) for 24 hours. The level of

932 phospho-S232-RIPK3 and RIPK3 were measured by western blotting.

933 (C) Cultured mouse sarcoma cells L929(Ripk3 $\left.{ }^{-/}\right)$were transfected with Vector, wild type

934 mouse RIPK3, and mutant forms of mRIPK3(D161N), and mRIPK3(S165D/T166E) and

935 treated with z-VAD or TSZ as indicated for 36 hours. Cell viability was determined by

936 measuring cellular ATP levels (upper panel). The data represented as the mean \pm SD of

937 triplicate wells. The lysates were analyzed by western blotting using antibodies as

938 indicated (lower panel).

940 Figure 4-figure supplement 1. Hsp90/CDC37 chaperone determines the necroptotic or 941 apoptotic function of RIPK3 kinase.

942 (A) HeLa/TO-RIPK3 and HeLa/TO-RIPK3-shRNA-HSP90 cells were treated with the

943 indicated stimuli for 36 hours. Cell viability was determined by measuring cellular ATP

944 levels. The data represented as the mean \pm SD of triplicate wells. $* * * P<0.001$. The cell

945 lysates were analyzed by western blotting using antibodies as indicated (right panel). 
946 (B) L929 cells were treated with the indicated stimuli for 5 hours. Cell viability was

947 determined by measuring cellular ATP levels. The data represented as the mean \pm SD of

948 triplicate wells.

949 (C) L929(Ripk3 $\left.{ }^{--}\right) /$TO-RIPK3 and L929(Ripk3 $\left.{ }^{-/}\right) /$TO-RIPK3-shRNA-HSP90 cells were

950 treated with the indicated stimuli for 36 hours. Cell viability was determined by measuring

951 cellular ATP levels. The data represented as the mean \pm SD of triplicate wells. ***P<

9520.001 . The cell lysates were analyzed by western blotting using antibodies as indicated

953 (right panel).

954 (D and E) L929(Ripk3 ${ }^{-/}$)/TO-RIPK3 cells were treated with the indicated stimuli for 36

955 hours. Cell viability was determined by measuring cellular ATP levels in (D). The data

956 represented as the mean \pm SD of triplicate wells. $* * P<0.01$, $* * * P<0.001 .24$ hours after

957 treatment, the cell lysates were analyzed by western blotting using antibodies against

958 phopho-Serine165/Theronine166 of RIPK3, RIPK3, and $\beta$-actin as indicated in (E).

960 Figure 4-figure supplement 2. RIPK3 form amyloid-like structure in MCF7 and KGN 961 cells.

962 (A) Cultured HeLa/TO-RIPK3 and MCF7/TO-RIPK3 cells were treated with DMSO or

963 Dox plus TSZ for 24 hours. Immunofluorescence of the cells with Flag-RIPK3 (green)

964 antibody. Counterstaining with DAPI (blue). Scale bar, $10 \mu \mathrm{m}$. Higher-power views (right

965 panels) were acquired from the selected boxed areas from the left panel.

966 (B) Cultured HT29 and KGN/TO-RIPK3 cells were treated with DMSO, TSZ, or Dox for

96724 hours. Immunofluorescence of the cells with Flag-RIPK3 (green) antibody.

968 Counterstaining with DAPI (blue). Scale bar, $10 \mu \mathrm{m}$. Higher-power views (right panels)

969 were acquired from the selected boxed areas from the left panel. 
970 (C) Cultured HeLa/TO-RIPK3 and MCF7/TO-RIPK3 cells were treated with Dox plus Z

971 for 24 hours. Immunofluorescence of the cells with Flag-RIPK3 (red) and

972 p-S164/T165-RIPK3(green) antibody. Counterstaining with DAPI (blue). Scale bar, $10 \mu \mathrm{m}$.

973 Higher-power views (right panels) were acquired from the selected boxed areas from the

974 left panel.

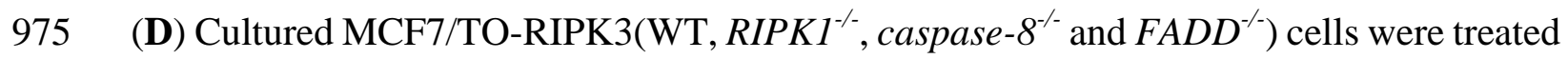

976 with Dox plus Z for 24 hours. Immunofluorescence of the cells with Flag-RIPK3 (red) and

977 p-S164/T165-RIPK3(green) antibody. Counterstaining with DAPI (blue). Scale bar, $10 \mu \mathrm{m}$.

978 Higher-power views (right panels) were acquired from the selected boxed areas from the

979 left panel.

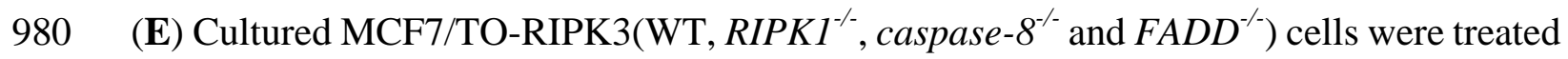

981 with DMSO or Dox plus Z for 24 hours. The lysates were analyzed by western blotting

982 using antibodies as indicated.

983

984 Figure 4-figure supplement 3. Hsp90/CDC37 chaperone protein levels was low in corpus

985 luteum and corpus albicans.

986 (A and B) Immunofluorescence of ovary from wild type mice (8 Month; n=3) with RIPK3

987 (red) and HSP90 (green) antibody in (A). Higher-power views of selected areas were

988 acquired in right panel. The HSP90/RIPK3 levels were quantified in (B). F, follicle. CA,

989 corpus albicans. Scale bar, 100/200 $\mu \mathrm{m}$.

990 (C and D) Immunofluorescence of ovary from wild type mice (8 Month; $n=3$ ) with RIPK3

991 (red) and CDC37 (green) antibody in (C). Higher-power views of selected areas were

992 acquired in right panel. The CDC37/RIPK3 levels were quantified in (D). F, follicle. CA,

993 corpus albicans. Scale bar, $200 \mu \mathrm{m}$.

994 
995 Figure 5-figure supplement 1. Generation of Ripk3 $3^{S T-D E / S T-D E}$ and Ripk3 $3^{S T-A A / S T-A A}$ mice.

996 (A) Two guide RNA and donate oligo sequences of Ripk3(S165D/T166E) and

997 Ripk3(S165A/T166A) knock-in mice.

998 (B) Schematic of CRISPER-Cas9 strategy for the generation for Ripk3(S165D/T166E) and

999 Ripk3(S165A/T166A) knock-in mice. The gene structure of RIPK3 and two guide RNA

1000 sequences targeting the exon 4 of RIPK3 were shown with the PAM sequences highlighted

1001 in red and blue.

1002 (C and D) Macroscopic features (C) and body weights (D) of Ripk $3^{+/+}$and Ripk3 $3^{S T-A A / S T-A A}$

1003 littermate mice at 14 days of age $(n=10)$. The result from each individual animal was

1004 presented as an indicated dot. NS, not significant.

1005 (E and F) Immunoblot of RIPK3 from lung extracts of 14 days old Ripk $3^{+/+}$,

1006 Ripk $3^{S T-D E / S T-D E}$, and Ripk $3^{S T-A A / S T-A A}$ littermates using antibodies against RIPK3 and

1007 GAPDH as indicated $(\mathrm{n}=3)$.

1008 (G) Histological analysis of brain, cerebellum, heart, kidney, and liver of Ripk $3^{+/+}$and

1009 Ripk3 $3^{S T-D E / S T-D E}$ littermate mice $(\mathrm{n}=5)$ at 14 days of age. Scale bar, $20 \mu \mathrm{m}$. PTC, Proximal

1010 tubular cell.

1011 (H) Cell viability measurement of bone marrow-derived macrophages from the Ripk $3^{+/+}$

1012 and Ripk3 $3^{S T-A A / S T-A A}$ littermate mice (n=3, 14 days) after treatment with the indicated

1013 necroptosis stimuli for 24 hours. Cell viability was determined by measuring cellular ATP

1014 levels. The data represented as the mean \pm SD of triplicate wells.

1015

1016 Figure 6-figure supplement 1. Generation of RIPK3 C-terminus HA-3×Flag knock-in

1017 and Ptgfr $^{-/}$mice. 
1018 (A) Schematic of CRISPER-Cas9 strategy for RIPK3 C-terminus HA-3×Flag knock-in

1019 mice. The gene structure of RIPK3 and guide RNA sequences targeting the Ripk3 were

1020 shown with the PAM sequences highlighted in red.

1021 (B) Western blotting analysis using protein extracts from the ovary of wild type,

1022 heterozygous knock-in, and homozygous knock-in mice generated as illustrated in (A).

1023 (C) Schematic of CRISPER-Cas9 strategy for the generation for Ptgfr ${ }^{-/}$mice. The gene

1024 structure of PTGFR and two guide RNA sequences targeting the Ptgfr were shown with the

1025 PAM sequences highlighted in red.

1026 (D) Immunoblot of PTGFR from ovary extracts of 2-month old Ptgfr ${ }^{+/+}$and Ptgfr ${ }^{-/}$

1027 littermates using antibodies against PTGFR and GAPDH as indicated $(n=3)$.

1028

1029 Figure 7-figure supplement 1. Prostaglandin F2alpha $\left(\mathrm{PGF}_{2 \alpha}\right)$ stimulates RIPK3

1030 expression through the MAPK pathway.

1031 (A) Primary granulosal lutein cells were isolated from the 3-month-old mice ovary. The

1032 cells were then treated with $1 \mu \mathrm{M}$ DT or plus MAPK inhibitors PD-98059 (5 $\mu \mathrm{M})$ and

$1033 \mathrm{U} 0126(5 \mu \mathrm{M})$ as indicated for 36 hours. The lysates were analyzed by western blotting

1034 using antibodies as indicated.

1035 (B) Primary granulosal lutein cells were isolated from 3-month-old mice ovaries. The cells

1036 were treated with $1 \mu \mathrm{M}$ DT at the indicated time. The cell lysates from the DT-treated cells

1037 were analyzed by western blotting using antibodies as indicated.

1038 (C) Diagram of induction of corpus luteum regression in vivo.

1039 (D) Ripk $^{+/+}$and Ripk3 $3^{\text {S165A-T166A/S165A-T166A }}$ and littermate female mice (n=3; 25-26 days)

1040 were given 7.5 IU pregnant mare serum gonadotropin (PMSG) intraperitoneally(IP)

1041 followed by $7.5 \mathrm{IU}$ serum gonadotropin and chorionic gonadotropin (SCG) 46 hours later

1042 to synchronize ovulation. The animals were then injected with Dinoprost Tromethamine 
1043 (DT) (10 micrograms, i.p.) or saline 24 hours post-ovulation. The ovary lysates were

1044 analyzed by western blotting using antibodies as indicated.

1045

1046 Materials and methods

1047 Animals

1048 The Ripk $^{-/-}$and $M l k l^{-/}$mice (C57BL/6J strain) have been described previously (He et al., 1049 2009; Ying et al., 2018). Fadd $^{+/} \mathrm{Mlkl}^{-/}$mice were provided by Dr. Haibing Zhang 1050 (Institute for Nutritional Sciences, Shanghai, China) (Zhang et al., 2016). C57BL/6J wild 1051 type (WT) mice were obtained from Vital River Laboratory Co. WT, Ripk3 ${ }^{-/}, M_{k l} l^{-/}$and $1052 \mathrm{Fadd}^{-/} \mathrm{Mlkl}^{-/}$mice were produced and maintained at the SPF animal facility of the 1053 National Institute of Biological Sciences, Beijing. Animals for the aging study were 1054 produced by mating wild type males with wild type females purchased from Vital River 1055 Laboratory Co; Ripk $3^{-/}$mice were produced by mating Ripk $^{-/-}$males with Ripk $^{-/-}$ 1056 females. Fadd Mlkl $^{-/}$mice were produced by mating Fadd $^{+/}$Mlkl $^{-/}$males with $1057 \mathrm{Fadd}^{+/-} \mathrm{Mlkl}^{-/-}$females. Ripk3 ${ }^{\text {S165D-T166E/S165D-T166E }}$ and Ripk3 ${ }^{\text {S165A-T166A/ S165A-T166A }}$ knock-in 1058 mice were generated using the CRISPR-Cas9 system (Figure 5-figure supplement 1). The 1059 Ripk3 C terminus HA-3xFlag knock-in and Ptgfr knockout mice were generated using the 1060 CRISPR-Cas9 system (Figure 6-figure supplement 1).

1061 The primers used for genotyping are listed below:

1062 Ripk3-(WT)-F: 5'-GCTAGCAGATTTTGGCCTGTCCACG-3';

1063 Ripk3-(S165D/T166E)-F: 5'-GCTAGCAGATTTTGGCCTGGACGAA-3';

1064 Ripk3-(S165A/T166A)-F: 5'-GCTAGCAGATTTTGGCCTGGCAGCA-3';

1065 Ripk3-R: 5'-GGCCTCTGGCGAGACTTCTTTCCTG-3';

1066 Ptgfr-WT-F: 5'-GCTGTGTTAGCCCATTGAGTCAGGTAGA-3';

1067 Ptgfr-KO-F: 5'-TGATGGTGTCAGTTTGGGCGGTAT-3'; 
Ptgfr-KO-R: 5'-GCTTTACTTCTGCTACTGAATTCCCTTGG-3';

1069

1070 Mouse husbandry

1071 Mice were group-housed in a 12 hours light/dark (light between 08:00 and 20:00) in a

1072 temperature-controlled room $\left(21.1 \pm 1^{\circ} \mathrm{C}\right)$ at the National Institute of Biological Sciences

1073 with free access to water. The ages of mice are indicated in the figure, figure legends, or

1074 methods. All animal experiments were conducted following the Ministry of Health

1075 national guidelines for the housing and care of laboratory animals and were performed in

1076 accordance with institutional regulations after review and approval by the Institutional

1077 Animal Care and Use Committee at the National Institute of Biological Sciences, Beijing.

1078

1079 Antibodies and reagents

1080 Antibodies for mouse RIPK3 (\#2283; WB, 1:1000; IHC, 1:100) were obtained from

1081 ProSci. There other antibodies used in this study were anti-RIPK3(LS-C336804, LSBio;

1082 WB, 1:1000; IHC 1:100), anti-GAPDH-HRP (M171-1, MBL; WB, 1:5000),

1083 anti- $\beta$-Actin-HRP (PM053-7, MBL; WB, 1:5000), anti-Tubulin-HRP (PM054-7, MBL;

1084 WB, 1:5000), anti-RIPK1 (\#3493S, Cell Signaling; WB, 1:2000), anti-Human-MLKL

1085 (ab184718, abcam; WB, 1:2000), anti-Mouse-MLKL (AO14272B, ABGENT; WB,

1086 1:2000), anti-Caspase8 (\#9746, Cell Signaling; WB, 1:1000), anti-FADD (\#2782, Cell

1087 Signaling; WB, 1:1000), anti-cFLIP (ab6144, Abcam; WB,

1088 1:1000), anti-Cleaved-Caspase3 (\#9661, Cell Signaling; WB, 1:1000; IHC, 1:100),

1089 anti-Cleaved-Caspase3 (STJ97448, St John's Laboratory; IHC, 1:100),

1090 anti-Cleaved-Caspase3 (ab2302, abcam; 1:1000),

1091 anti-Human-p-S227-RIPK3(ab209384, abcam; WB, 1:1000), anti-Flag-HRP (A8592,

1092 Sigma-Aldrich; WB, 1:5000), anti-Prostaglandin F2 alpha(PTGFR) (ab203342, abcam; 
1093 IHC, 1:100), anti-HSP90 (13171-1-AP, proteintech; WB, 1:1000; IHC, 1:100),

1094 anti-CDC37 (B109419, abcam; WB, 1:1000; IHC, 1:100), anti-FLAG ${ }^{\circledR}$ M2 (F1840,

1095 Sigma-Aldrich; IHC, 1:100), anti-Phospho-p44/42 MAPK (4370S, Cell Signaling; WB,

1096 1:1000), anti-p44/42 MAPK (4965S, Cell Signaling; WB, 1:1000),

1097 anti-Phospho-MEK1/2 (9154S, Cell Signaling; WB, 1:1000), anti-MEK1/2 (ab178876,

1098 abcam; WB, 1:1000). Donkey anti-Mouse, Alexa Fluor 488 (Thermo Fisher, A-21202),

1099 Donkey anti-Mouse, Alexa Fluor 555 (Thermo Fisher, A-31570), Donkey anti-Rabbit,

1100 Alexa Fluor 488 (Thermo Fisher, A-21206), Donkey anti-Rabbit, Alexa Fluor 555

1101 (Thermo Fisher, A-31572). Dinoprost Tromethamine(S5056), PD-98059(S1177) and

1102 U0126(S1102) were purchased from Selleck. pyridine-3-sulfonyl (PS) was purchased

1103 from Sigma. Pregnant Mare Serum Gonadotropin (PMSG)(110254564) and

1104 Gonadotropin and Serum chorionic Gonadotropin (SCG) (110251283) were purchased

1105 from Ningbo Second Hormone Factory.

1106 We collaborated with Epitomics to develop the rabbit monoclonal antibody against

1107 p-S164/T165-RIPK3 (Abcam, Ab255705; WB, 1:1000; IHC, 1:100). The rabbits were

1108 immunized with the peptide. Hybridoma lines were screened by western blot analysis.

1109 The final antibody was purified using protein A agarose.

1110

\section{Cell lines and cell cultures}

1112 All cells were cultured at $37^{\circ} \mathrm{C}$ with $5 \% \mathrm{CO}_{2}$. All cell lines were cultured as follows:

1113 HT29 cells were obtained from ATCC and cultured in McCoy's 5A culture

1114 medium(Invitrogen). HEK293T, HeLa and MCF7 cells were obtained from ATCC and

1115 cultured in DMEM (Hyclone). L929 $\left(\right.$ Ripk3 $\left.^{--}\right)$cells were cultured in DMEM (Hyclone)

1116 (Ying et al., 2018). Human granulosa tumor cell line (KGN) (Nishi et al., 2001), were

1117 kindly provided by Dr. Qiao Jie from Peking University Third Hospital in China and 
1118 were cultured in DMEM:F12 Medium (Hyclone). Stable KGN or MCF7 cell lines

1119 expressing the Tet repressor (KGN-Tet-On cells and MCF7-Tet-On cells) were selected

1120 with $1 \mathrm{mg} / \mathrm{ml} \mathrm{G} 418$ after being infected with virus encoding Tet repressor. KGN-Tet-On

1121 and MCF7-Tet-On cells were infected with virus encoding $3 \times$ Flag-RIPK3 or another

1122 mutant and were selected with $10 \mu \mathrm{g} / \mathrm{ml}$ puromycin to establish the

1123 KGN/TO-RIPK3/RIPK3(S164A/T165A) and

1124 MCF7/TO-RIPK3/RIPK3(D160N)/RIPK3(S164A/T165A) cell lines. All media were

1125 supplemented with 10\% FBS (Thermo Fisher) and 100 units/ml penicillin/ streptomycin

1126 (Thermo Fisher).

1127

\section{Plasmids constructs}

1129 Full-length human RIPK3, RIPK3(AAAA) (RIPK1 interaction mutant RIPK3, the 1130 residues 459-462 within RHIM region were mutated to four alanine residues) and mouse 1131 RIPK3 cDNA were kept in our lab and subcloned into the pWPI vector (GFP-tagged) to 1132 generate pWPI-HA-3×Flag-RIPK3/RIPK3(D160N)/RIPK3(AAAA) and 1133 pWPI-HA-3×Flag-mRIPK3 virus construct. Using Quickchange Site-Directed 1134 Mutagenesis Kit to generate 1135 pWPI-HA-3×Flag-RIPK3(D160N)/RIPK3(S164D/T165E)/RIPK3(S164E)/RIPK3(T165

1136 E)/RIPK3(S164A/T165A)/RIPK3(S164A)/RIPK3(T165A) and

1137 pWPI-HA-3×Flag-mRIPK3(D161N)/mRIPK3(S165D/T166E) virus construct.

1138 pLVX-Tight-Puro Vector and pLVX-Tet-On Advanced were kindly provided by Dr.

1139 Wenhui Li lab at NIBS. Full-length human RIPK3 or RIPK3 mutant were subcloned into 1140 the pLVX-Tight-Puro to gector to generate 1141 pLVX-Tight-HA-3×Flag-RIPK3/RIPK3(D160N)/RIPK3(S164A/T165A) construct. The 1142 gRNAs for targeting RIPKI(5'-ATGCTCTTACCAGGAAATGT-3'), 
1143 Caspase-8(5'-TGATCGACCCTCCGCCAGAA-3'),

$1144 F A D D(5$ '-AGTCGTCGACGCGCCGCAGC-3') and

$1145 c$ FLIP(5'-TACCAGACTGCTTGTACTTC-3') were designed and were cloned into the

1146 gRNA-Cas9 expression plasmid pX458-GFP to generate

1147 pX458-GFP-RIPK1/Caspase-8/FADD/cFLIP construct.

1148

1149 Cell survival assay

1150 Cell survival assay was performed using Cell Titer-Glo Luminescent Cell Viability Assay

1151 kit. A Cell Titer-Glo assay (Promega, G7570) was performed according to the

1152 manufacturer's instructions. Luminescence was recorded with a Tecan GENios Pro plate

1153 reader.

\section{Transfections}

1156 HeLa or HEK293T cells were transfected with plasmids using Lipofectamine 3000

1157 (ThermoFisher Scientific) following the manufacturer's instructions.

\section{Live-cell imaging}

1160 On day $1, \mathrm{KGN}$ cells were plated in a $37^{\circ} \mathrm{C}$ imaging station chamber. On day 2 , KGN cells 1161 were infected with viruses (Flag-RIPK3, GFP label) for 20 hours. Images were obtained

1162 with a Nikon Ti inverted microscope and the PerkinElmer UltraVIEW VoX system.

1163 Time-lapse images were captured at 3-min intervals using a Nikon PLAN APO 60×

1164 objective. The images were processed using Volocity software.

\section{Virus packaging}


1167 To prepare the Virus, HEK293T cells in the 10-cm dish were transfected with $15 \mu \mathrm{g}$ of

1168 pWPI $\quad$ Vector $\quad$ control viruses),

1169 pWPI-HA-3×Flag-RIPK3/RIPK3(D160N)/RIPK3(AAAA)/ RIPK3(S164D/T165E)

1170 /RIPK3(S164E)/ RIPK3(T165E) ～/RIPK3(S164A/T165A)/RIPK3(S164A)

1171 /RIPK3(T165A), pLVX-Tight-3×Flag-RIPK3/RIPK3(D160N)/RIPK3(S164A/T165A) or

1172 pLVX-Tet-On Advanced DNA together with 11.25 $\mu \mathrm{g}$ of psPAX2 and 3.75 $\mu \mathrm{g}$ of pMD2.G

1173 Eight hours after transfection, the media were changed to high-serum DMEM (20\% FBS

1174 with $25 \mathrm{mM}$ HEPES). Another 40 hours later, the media were collected and centrifuged at

11753,000 r.p.m. for $10 \mathrm{~min}$. The supernatant was filtered through a $0.22-\mu \mathrm{m}$ membrane, and

1176 aliquots of $15 \mathrm{ml}$ were stored at $-80^{\circ} \mathrm{C}$.

\section{CRISPR/Cas9 knockout cells}

$11794 \mu \mathrm{g}$ of $\mathrm{pX} 458-$ GFP-RIPK1/Caspase-8/FADD/cFLIP plasmid was transfected into $1 \times 10^{7}$

1180 MCF7/TO-RIPK3 cells using the Transfection Reagent (FuGENE \& HD, E2311) by

1181 following the manufacturer's instructions. 3 days after the transfection, GFP-positive live

1182 cells were sorted into single clones by using a BD FACSArial cell sorter. The single clones

1183 were cultured into 96-well plates for another 10-14 days or longer, depending upon the cell

1184 growth rate. The anti- RIPK1/Caspase-8/FADD/cFLIP immunoblotting was used to screen

1185 for the MCF7/TO-RIPK3 $\left(\right.$ RIPK1 $1^{-/} /$Caspase- $\left.8^{-/} / F A D D^{-/} / c F L I P^{-/}\right)$clones. Genome type

1186 of the knockout cells was determined by DNA sequencing.

1187

\section{Western blotting}

1189 Western blotting was performed as previously described. Cell pellet samples were 1190 collected and re-suspended in lysis buffer (100 mM Tris- $\mathrm{HCl}, \mathrm{pH} 7.4,100 \mathrm{mM} \mathrm{NaCl}$, 1191 10\% glycerol, 1\% Triton X-100, 2 mM EDTA, Roche complete protease inhibitor set, 
1192 and Sigma phosphatase inhibitor set), incubated on ice for $30 \mathrm{~min}$, and centrifuged at

$119320,000 \times \mathrm{g}$ for $30 \mathrm{~min}$. The supernatants were collected for western blotting. Ovary or

1194 other tissue were ground and re-suspended in lysis buffer, homogenized for 30 seconds

1195 with a Paddle Blender (Prima, PB100), incubated on ice for $30 \mathrm{~min}$, and centrifuged at

$119620,000 \times \mathrm{g}$ for $30 \mathrm{~min}$. The supernatants were collected for western blotting.

\section{Immunoprecipitation}

1199 The cells were cultured on $10-\mathrm{cm}$ dishes and grown to confluence. Cells at $70 \%$ 1200 confluence with or without Dox $(1 \mu \mathrm{g} / \mathrm{ml})$ induction for 24 hours. Then cells were 1201 washed once with PBS and harvested by scraping and centrifugation at $800 \times \mathrm{g}$ for $5 \mathrm{~min}$.

1202 The harvested cells were washed with PBS and lysed for $30 \mathrm{~min}$ on ice in the lysis buffer.

1203 Cell lysates were then spun down at $12,000 \times \mathrm{g}$ for $20 \mathrm{~min}$. The soluble fraction was 1204 collected, and the protein concentration was determined by Bradford assay. Cell extracted 1205 was mixed with anti-Flag affinity gel (Sigma-Aldrich, A2220) in a ratio of $1 \mathrm{mg}$ of 1206 extract per $30 \mu \mathrm{l}$ of agarose. After overnight rocking at $4{ }^{\circ} \mathrm{C}$, the beads were washed 3 1207 times with lysis buffer. The beads were then eluted with $0.5 \mathrm{mg} / \mathrm{mL}$ of the corresponding 1208 antigenic peptide for 6 hours or directly boiled in 1× SDS loading buffer (125 mM Tris, 1209 PH 6.8, 2\% 2-mercaptoethanol, 3\% SDS, 10\% glycerol and 0.01\% bromophenol blue).

\section{Tissue collection}

1212 Mice were sacrificed and perfused with PBS. Tissues for stain comparisons were taken at 1213 the same stage of the estrous cycle: ovarian were taken from all mice during diestrus. 1214 Major organs were removed, cut into appropriately-sized pieces, and either flash-frozen 1215 in liquid nitrogen and stored at $-80{ }^{\circ} \mathrm{C}$ or placed in $4 \%$ paraformaldehyde for 
1216 preservation. After several days of $4 \%$ paraformaldehyde fixation at room temperature,

1217 tissue fragments were transferred to $70 \%$ ethanol and stored at $4^{\circ} \mathrm{C}$.

1218

1219 Histology and immunohistochemistry

1220 Paraffin-embedded specimens were sectioned to a $5 \mu \mathrm{m}$ thickness and were then

1221 deparaffinized, rehydrated, and stained with haematoxylin and eosin (H\&E) using

1222 standard protocols. For the preparation of the immunohistochemistry samples, sections

1223 were dewaxed, incubated in boiling citrate buffer solution for $15 \mathrm{~min}$ in plastic dishes,

1224 and subsequently allowed to cool down to room temperature over 3 hours. Endogenous

1225 peroxidase activity was blocked by immersing the slides in Hydrogen peroxide buffer

1226 (10\%, Sinopharm Chemical Reagent) for $15 \mathrm{~min}$ at room temperature and were then

1227 washed with PBS. Blocking buffer (1\% bovine serum albumin in PBS) was added, and

1228 the slides were incubated for 2 hours at room temperature. Primary antibody against Flag,

1229 RIPK3, Cleaved-Caspase3, and p-S164/T165-RIPK3 was incubated overnight at $4^{\circ} \mathrm{C}$ in

1230 PBS. After 3 washes with PBS, slides were incubated with secondary antibody

1231 (polymer-horseradish-peroxidase-labeled anti-rabbit, Sigma) in PBS. After a further 3

1232 washes, slides were analyzed using a diaminobutyric acid substrate kit (Thermo Fisher).

1233 Slides were counterstained with haematoxylin and mounted in neutral balsam medium

1234 (Sinopharm Chemical).

1235 Immunohistochemistry analysis for RIPK3 or p-S164/T165-RIPK3 was performed

1236 using an antibody against RIPK3 and p-S164/T165-RIPK3. Primary antibody against

1237 Cleaved-Caspase3 or p-S164/T165-RIPK3 was incubated overnight at $4^{\circ} \mathrm{C}$ in PBS. After

12383 washes with PBS, slides were incubated with DyLight-555/488 conjugated donkey

1239 anti-rabbit/mouse secondary antibodies (Thermo Fisher) in PBS for $8 \mathrm{~h}$ at $4^{\circ} \mathrm{C}$. After a

1240 further 3 washes, slides were incubated with RIPK3 or p-S164/T165-RIPK3 antibody 
1241 overnight at $4^{\circ} \mathrm{C}$ in PBS. After a further 3 washes, slides were incubated with

1242 DyLight-488/555 conjugated donkey anti-mouse/rabbit secondary antibodies (Thermo

1243 Fisher) for 2 hours at room temperature in PBS. After a further 3 washes in PBS, the cell

1244 nuclei were then counterstained with DAPI (Thermo Fisher) in PBS. Fluorescence

1245 microscopy was performed using a Nikon A1-R confocal microscope.

1247 Isolation of mice granulosal lutein cells from ovaries (Newton et al., 1999; Tian et al., 1248 2015)

1249 Ovaries from 3-month old wild-type mice were collected and placed in Enriched 1250 DMEM:F12 (Hyclone) media and placed on ice. Ovaries were ground on the strainer (40 $1251 \mu \mathrm{m})$ with forceps. Centrifuge the cell suspension at $900 \times \mathrm{g}$ for $5 \mathrm{~min}$ at $4^{\circ} \mathrm{C}$, wash 3

1252 times with PBS. The mix cells pellet were incubated with trypsin for $15-20$ min at $37^{\circ} \mathrm{C}$ 1253 in a shaking water bath at 80 oscillations (osc)/min and were then layered over $40 \mathrm{~mL} \mathrm{5 \%}$ 1254 Percoll/95\% 1 $1 \times$ Hank's balanced salt solution in a $50 \mathrm{~mL}$ conical tube and allowed to 1255 settle for $20 \mathrm{~min}$. After incubation, $3 \mathrm{~mL}$ charcoal-stripped FBS was immediately added 1256 to halt the digestion. All fractions were mixed and immediately centrifuged at $900 \times \mathrm{g}$ for $125710 \mathrm{~min}$ at $4^{\circ} \mathrm{C}$. Pellets were re-suspended in PBS and washed 3 times, then cultured in 1258 DMEM:F12 (10\%FBS) medium at $37^{\circ} \mathrm{C}$ with $5 \% \mathrm{CO}_{2}$. After $24 \mathrm{~h}$, the suspended 1259 granulosal lutein cells were collected and cultured in a new cell dish, and the cells were 1260 treated with the indicated stimuli. The adherent follicular granulosa cells were collected 1261 and were treated with the indicated stimuli. Cell lysates were analyzed by western 1262 blotting.

1263

1264 In vivo studies of luteal regression (Carambula et al., 2002; Carambula et al., 2003) 
1265 Wild-type, Ripk3 $^{-/-}$, Fadd $^{-/}$Mlkl $^{-/}$, Ripk3 $3^{\text {S165A-T166A/S165A-T166A } \text { and Ptgfr- }}{ }^{-/}$female mice (each

1266 group, $n=16$ ) at day 25-26 postpartum were intraperitoneally injected with 7.5 IU (100

$1267 \mu \mathrm{l} /$ mouse) pregnant mare serum gonadotropin (PMSG) followed by intraperitoneal

1268 injection with $7.5 \mathrm{IU}(100 \mu \mathrm{l} /$ mouse) serum gonadotropin and chorionic gonadotropin

1269 (SCG) $46 \mathrm{~h}$ later to induce superovulation. Those mice were injected with Dinoprost

1270 Tromethamine (DT) (10 micrograms, i.p.) or saline at $24 \mathrm{~h}$ after post-ovulation. Ovaries

1271 were then collected at 12 or $24 \mathrm{~h}$ post-injection. In some experiments, ovaries were

1272 ground and re-suspended in lysis buffer, homogenized for 30 seconds with a Paddle

1273 Blender (Prima, PB100), incubated on ice for $30 \mathrm{~min}$, and centrifuged at 20,000 $\times \mathrm{g}$ for

$127430 \mathrm{~min}$. The supernatants were analyzed by western blotting. In other experiments,

1275 ovaries were fixed with $4 \%$ paraformaldehyde, paraffin-embedded, serially sectioned (5

$1276 \mu \mathrm{m}$ ), and mounted in order on glass microscope slides. Ovarian mid-sagittal sections

1277 were used for immunohistochemical analysis with RIPK3 or cleaved-caspase3 antibody.

\section{Mass spectrometry and data analysis}

$1280 \mathrm{HeLa} / \mathrm{TO}-\mathrm{RIPK} 3$ and MCF7/TO-RIPK3 cells were treated with Dox plus z-VAD for 24

1281 hours. Then the cell extracts were prepared and used for immunoprecipitation with an

1282 anti-Flag antibody. The immunoprecipitates were washed three times with lysis buffer.

1283 The beads were then eluted with $0.5 \mathrm{mg} / \mathrm{mL}$ of the corresponding antigenic peptide for 6

1284 hours or directly boiled in 1× SDS loading buffer and subjected to SDS-PAGE. RIPK3

1285 bands were excised from SDS-PAGE gel and then dissolved in $2 \mathrm{M}$ urea, $50 \mathrm{mM}$

1286 ammonium bicarbonate, $\mathrm{pH} 8.0$, and reduced in $2 \mathrm{mM}$ DTT at $56{ }^{\circ} \mathrm{C}$ for $30 \mathrm{~min}$

1287 followed by alkylation in $10 \mathrm{mM}$ iodoacetamide at dark for $1 \mathrm{hr}$. Then the protein was

1288 digested with sequencing grade modified trypsin (Promega) (1: 40 enzyme to total

1289 protein) at $37{ }^{\circ} \mathrm{C}$ overnight. The tryptic peptides were separated by an analytical 
1290 capillary column $(50 \mu \mathrm{m} \times 15 \mathrm{~cm})$ packed with $5 \mu \mathrm{m}$ spherical $\mathrm{C} 18$ reversed phase

1291 material (YMC, Kyoyo, Japan). A Waters nanoAcquity UPLC system (Waters, Milford,

1292 USA) was used to generate the following HPLC gradient: 0-30\% B in 40 min, 30-70\% B

1293 in $15 \min (\mathrm{A}=0.1 \%$ formic acid in water, $\mathrm{B}=0.1 \%$ formic acid in acetonitrile $)$. The

1294 eluted peptides were sprayed into a LTQ Orbitrap Velos mass spectrometer

1295 (ThermoFisher Scientific, San Jose, CA, USA) equipped with a nano-ESI ion source. The

1296 mass spectrometer was operated in data-dependent mode with one MS scan followed by

1297 four CID (Collision Induced Dissociation) and four HCD (High-energy Collisional

1298 Dissociation) MS/MS scans for each cycle. Database searches were performed on an

1299 in-house Mascot server (Matrix Science Ltd, London, UK) against Human RIPK3 protein

1300 sequence. The search parameters are: $7 \mathrm{ppm}$ mass tolerance for precursor ions; $0.5 \mathrm{Da}$

1301 mass tolerance for product ions; three missed cleavage sites were allowed for trypsin

1302 digestion and the following variable modifications were included: oxidation on

1303 methionine, cysteine carbamidomethylation, and serine, threonine, and tyrosine

1304 phosphorylation.

\section{Statistical analysis}

1307 All experiments were repeated at least twice, with similar results. Data represent

1308 biological replicates. Statistical tests were used for every type of analysis. The data meet

1309 the assumptions of the statistical tests described for each figure. Results are expressed as

1310 the mean \pm s.e.m or S.D. Differences between experimental groups were assessed for

1311 significance using a two-tailed unpaired Student's t-test using GraphPad prism5 and

1312 Excel software. The $* P<0.05$, $* * P<0.01$, and $* * * P<0.001$ levels were considered

1313 significant. NS, not significant. 


\section{Acknowledgements}

1316 We thank Dr. Alex Wang for critically reading and editing the manuscript. This work

1317 was supported by institutional grants from the Chinese Ministry of Science and

1318 Technology and Beijing Municipal Commission of Science and Technology. The funders

1319 had no role in study design, data collection and interpretation, or the decision to submit the

1320 work for publication.

1321

\section{Author contributions}

1323 D.L. and X.W. designed the research and analyzed the data. D.L. conducted majority of the

1324 experiments. J.C., and J.G. conducted cell death and IHC experiments. L.L., G.C., Y.C.

1325 carried out mass spectrometry analysis. Y.Z. and F.W. generated PTGFR knockout mice

1326 and helped with in vivo studies of luteal regression experiments. D.L. and X.W. wrote the

1327 manuscript.

1328 
bioRxiv preprint doi: https://doi.org/10.1101/2021.02.14.431152; this version posted February 15, 2021. The copyright holder for this preprint (which was not certified by peer review) is the author/funder, who has granted bioRxiv a license to display the preprint in perpetuity. It is made

\section{Figure 1}

A

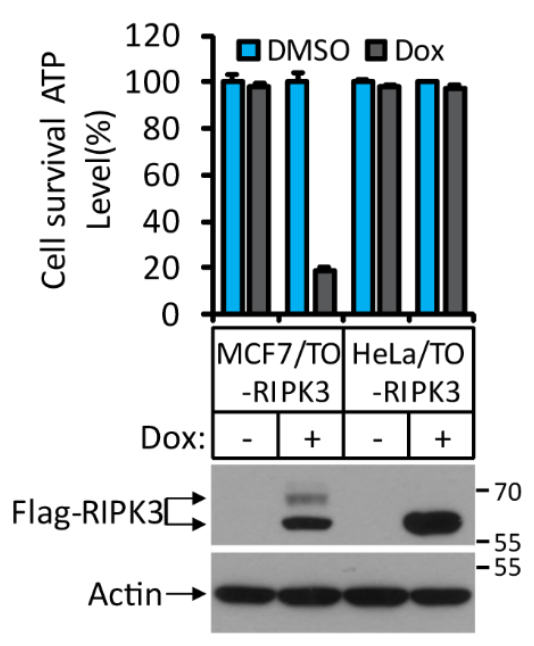

C

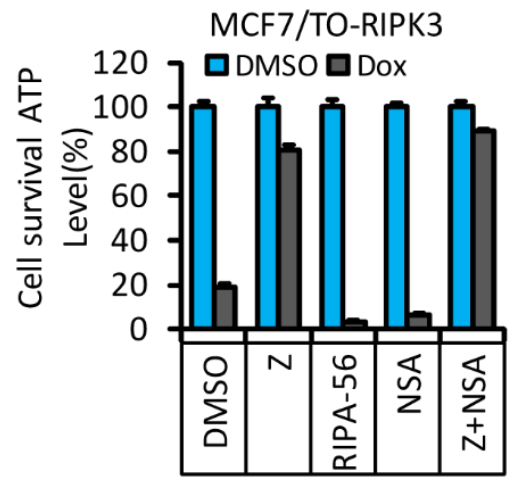

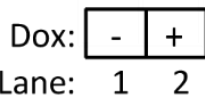

Flag-RIPK3 $\longrightarrow$

Actin $\rightarrow-55$
B

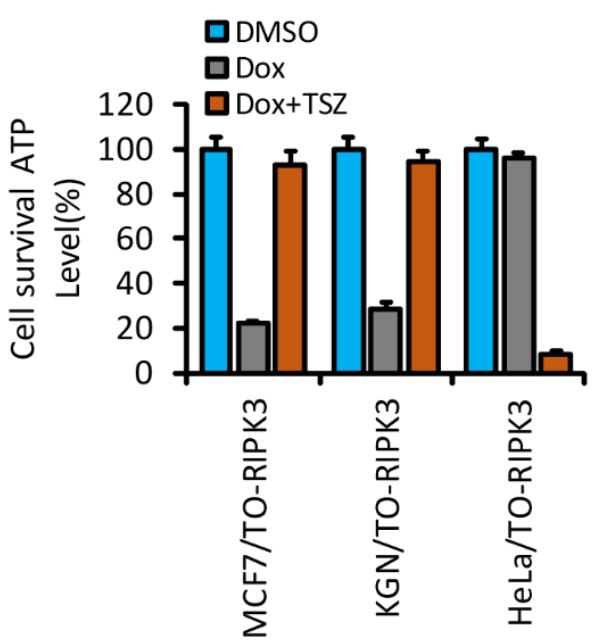

D

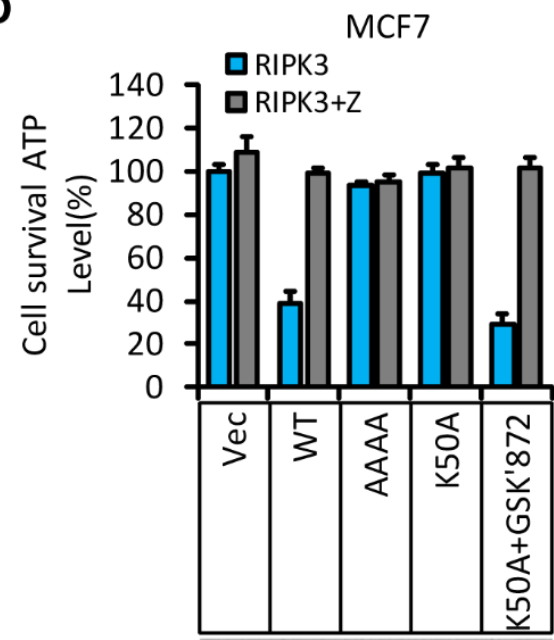

Flag-RIPK3 $\longrightarrow$ ta $\square-b_{-55}^{-70}$

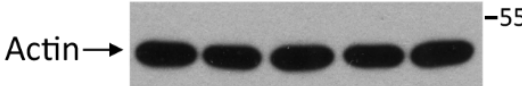


bioRxiv preprint doi: https://doi.org/10.1101/2021.02.14.431152; this version posted February 15, 2021. The copyright holder for this preprint (which was not certified by peer review) is the author/funder, who has granted bioRxiv a license to display the preprint in perpetuity. It is made available under aCC-BY 4.0 International license.

Figure 2

A

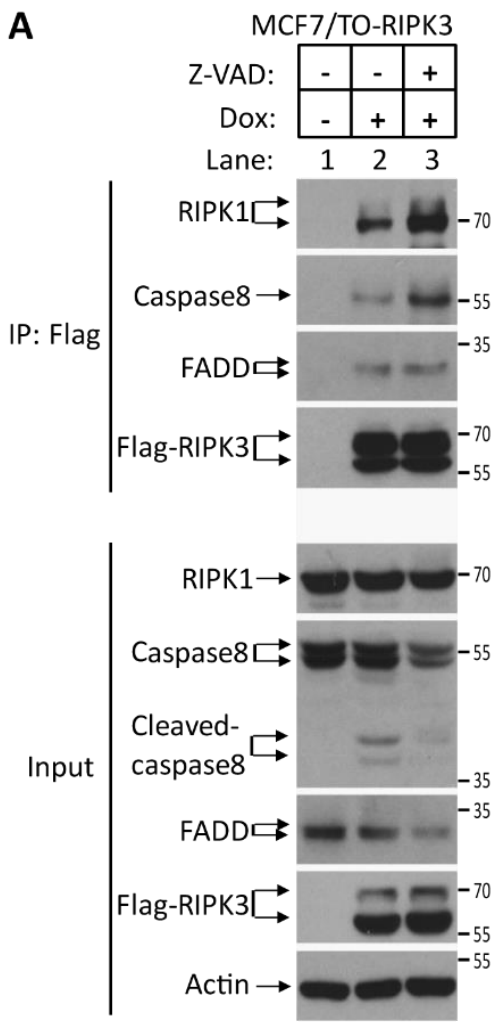

B

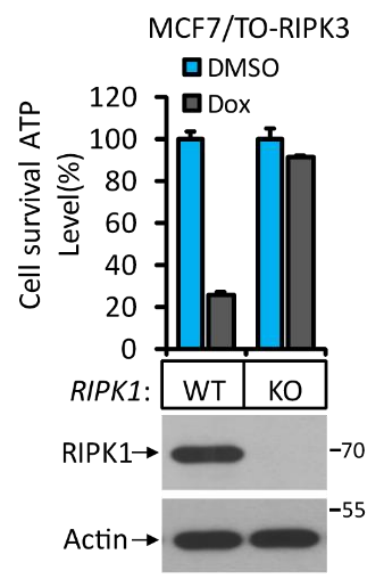

D

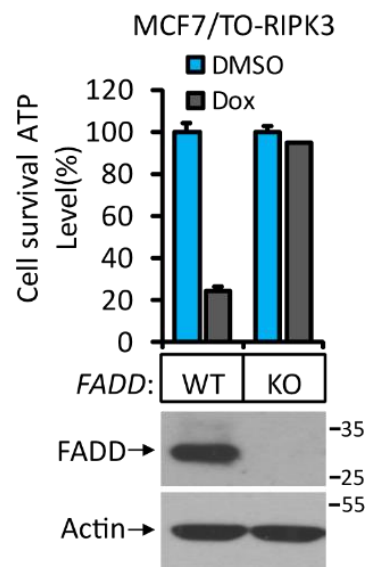

C

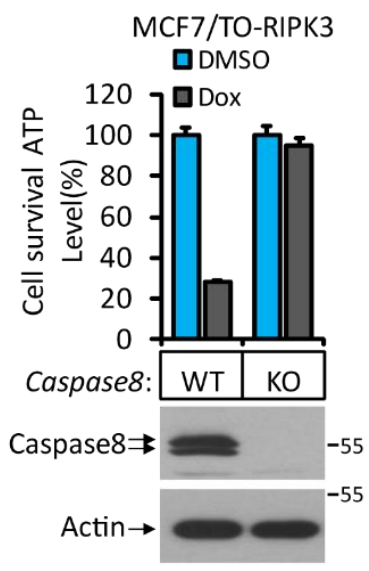

E

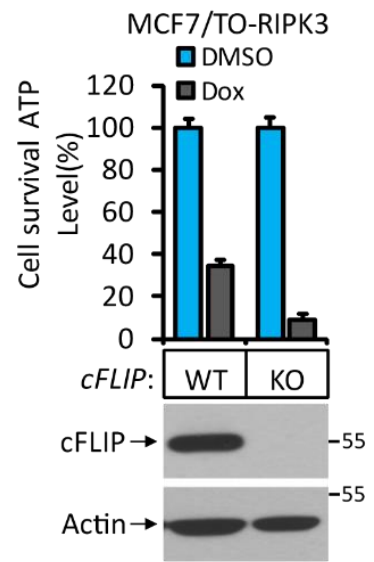


bioRxiv preprint doi: https://doi.org/10.1101/2021.02.14.431152; this version posted February 15, 2021. The copyright holder for this preprint (which was not certified by peer review) is the author/funder, who has granted bioRxiv a license to display the preprint in perpetuity. It is made Figure 3

A

RIPK3 peptide Sequences (Amino acid residues:160-176)

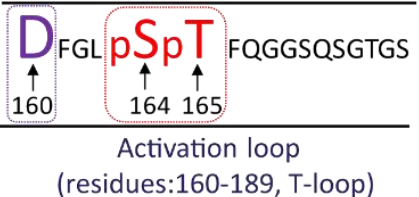

(residues:160-189, T-loop)

D
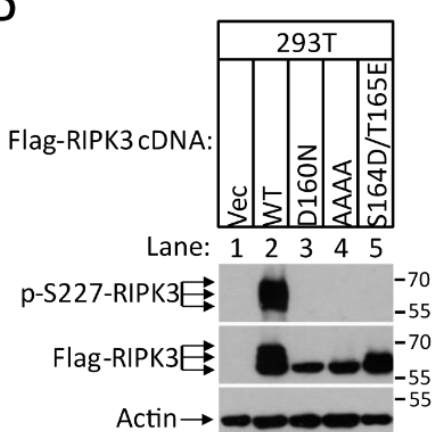

H
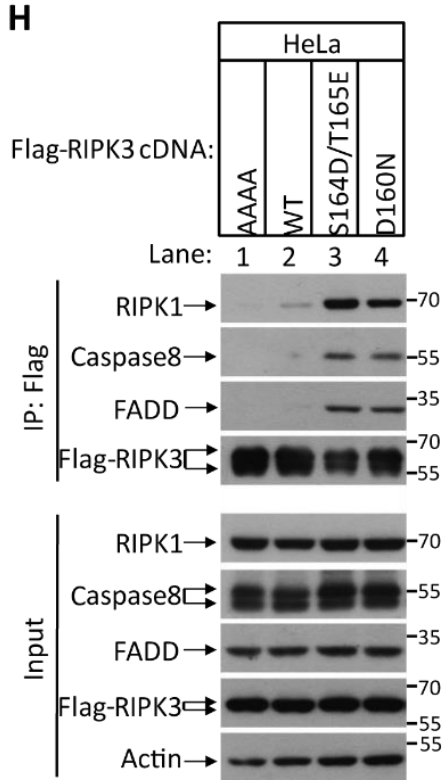

B

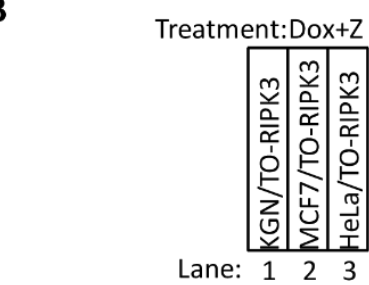

$\mathrm{p}-\mathrm{S} 164 / \mathrm{T} 165-\mathrm{RIPK} 3 \rightarrow \mathrm{e}=-70$ Flag-RIPK3E $=-7$

Actin $\rightarrow-\infty-^{-55}$

E

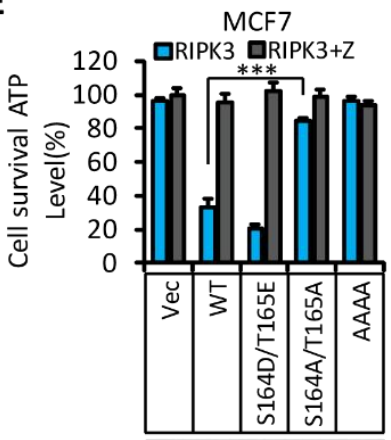

Flag-RIPK3 $\longrightarrow$

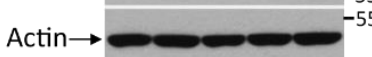

I
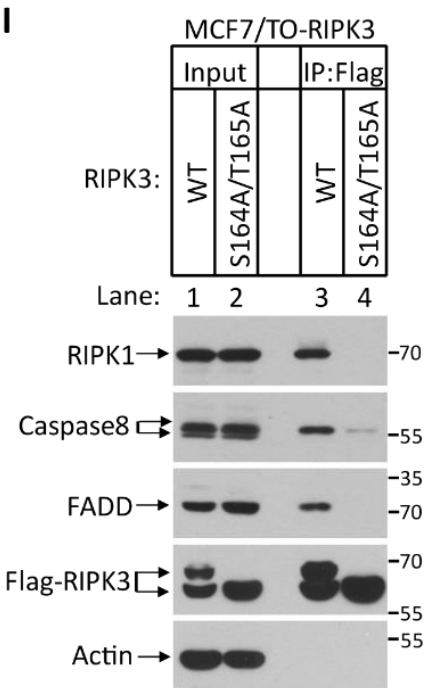

C

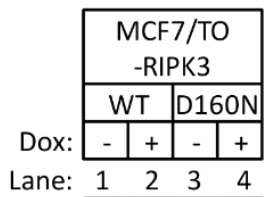

p-S164/T165-RIPK3 $\rightarrow$

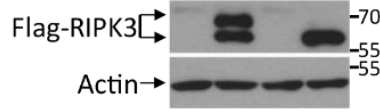

$\mathbf{F}$
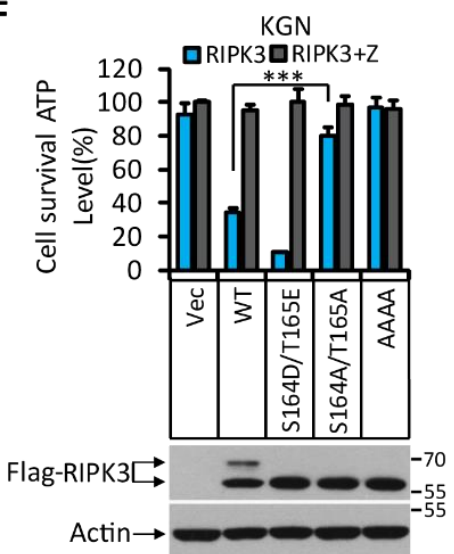

G

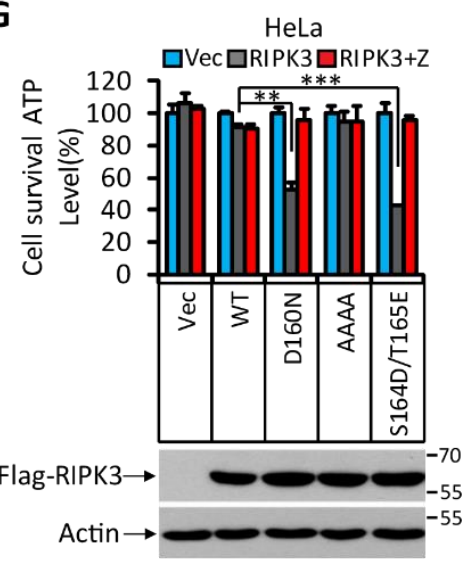


bioRxiv preprint doi: https://doi.org/10.1101/2021.02.14.431152; this version posted February 15, 2021. The copyright holder for this preprint (which was not certified by peer review) is the author/funder, who has granted bioRxiv a license to display the preprint in perpetuity. It is made Figure 4

A

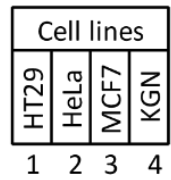

Lane: $\begin{array}{lllll}1 & 2 & 3 & 4\end{array}$

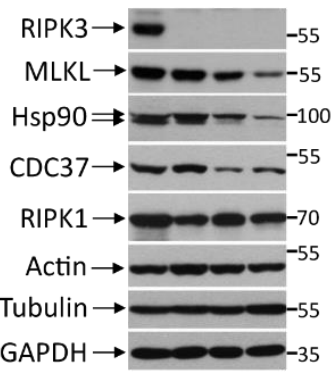

D HeLa/TO-RIPK3

口DMSO

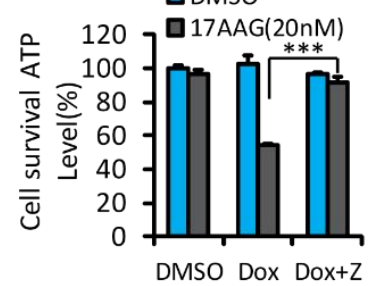

F

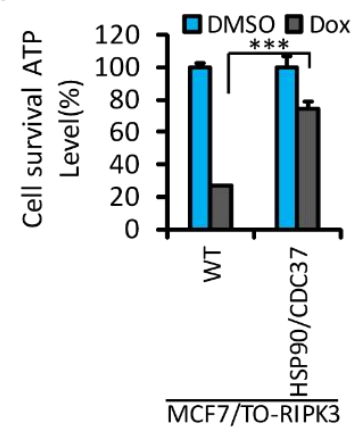

I

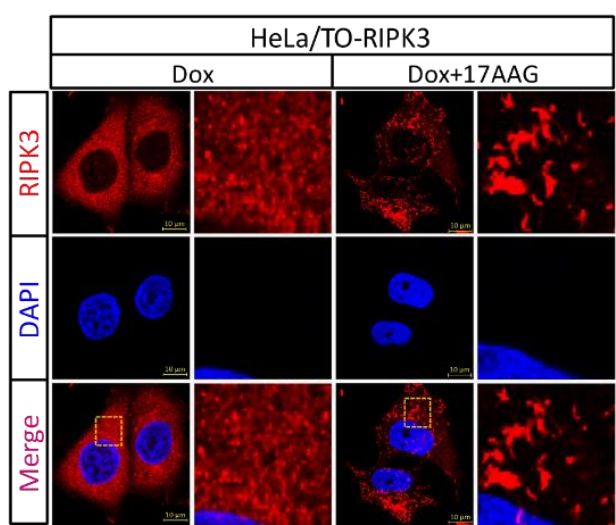

B

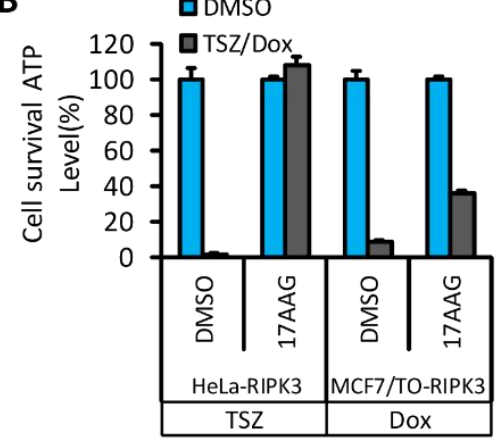

E

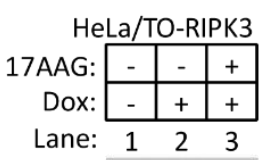

p-S164/T165-RIPK3 $\rightarrow$

Flag-RIPK3 $\vec{\longrightarrow}$

Actin $\rightarrow$

G

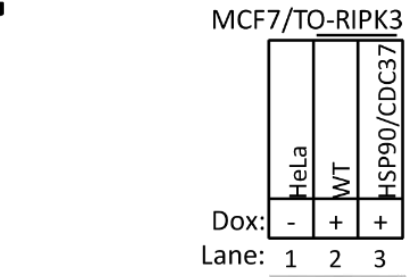

$\mathrm{p}-\mathrm{S} 164 /$ T165-RIPK3 $\rightarrow \longrightarrow-70$

Flag-RIPK3 $匚 \quad=\mathbf{b}_{-55}^{-70}$

$\mathrm{HSP} 90 \Rightarrow-0-100$

$\mathrm{CDC} 37 \rightarrow-0^{-55}$

Actin $\rightarrow=\boldsymbol{C}^{-55}$

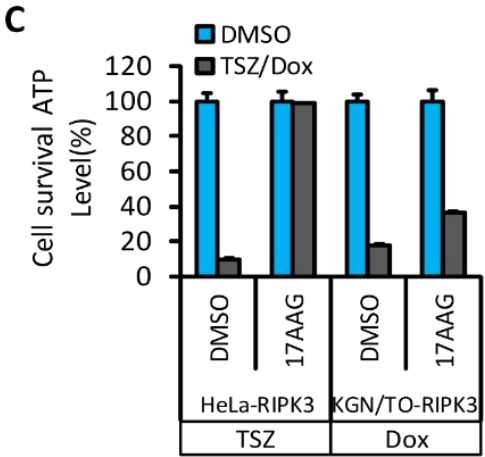

H

HeLa/TO-RIPK3

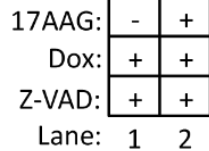

Lane: 12
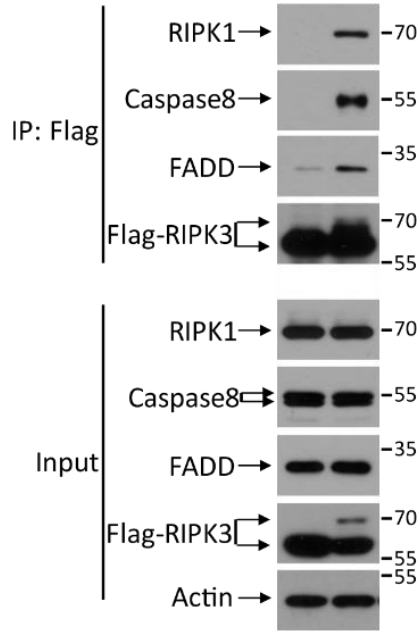

J

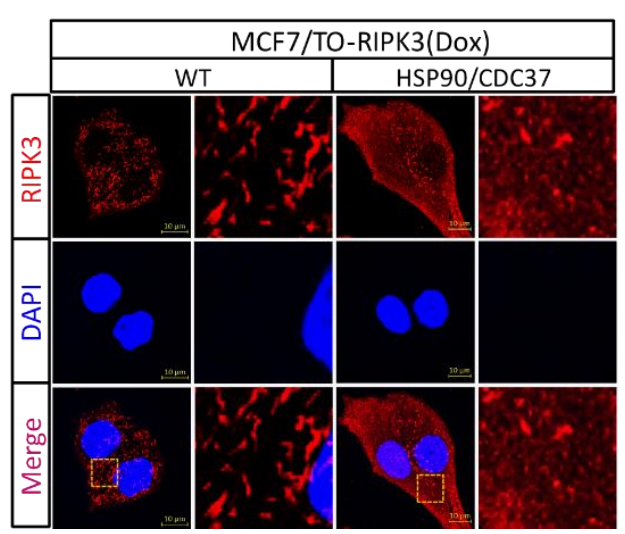


bioRxiv preprint doi: https://doi.org/10.1101/2021.02.14.431152; this version posted February 15, 2021. The copyright holder for this preprint (which was not certified by peer review) is the author/funder, who has granted bioRxiv a license to display the preprint in perpetuity. It is made

Figure 5

A

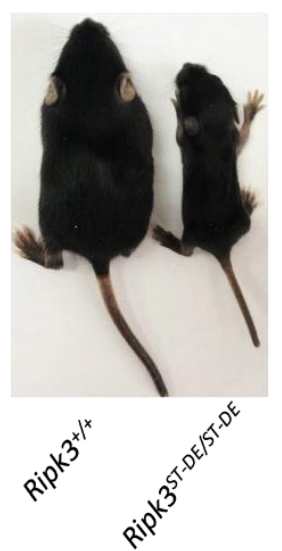

B

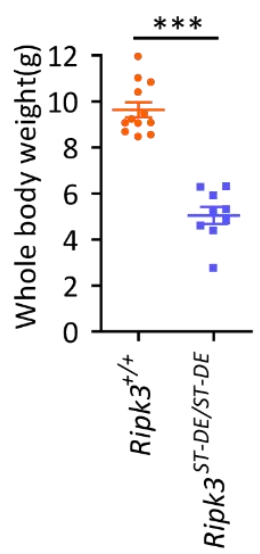

C
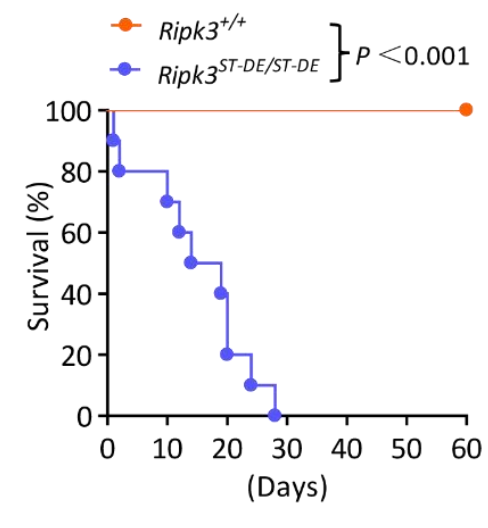

G

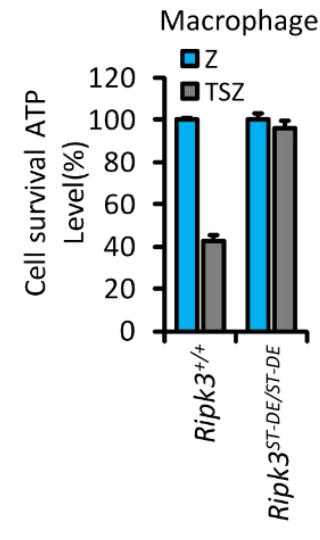

D

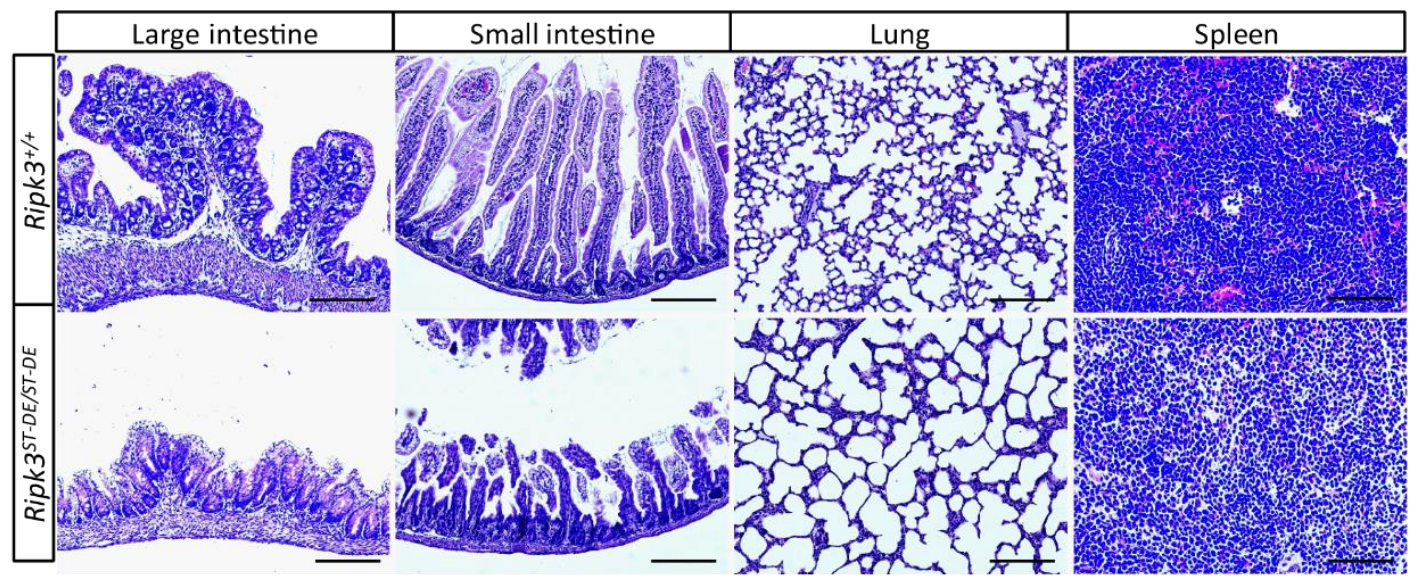

E

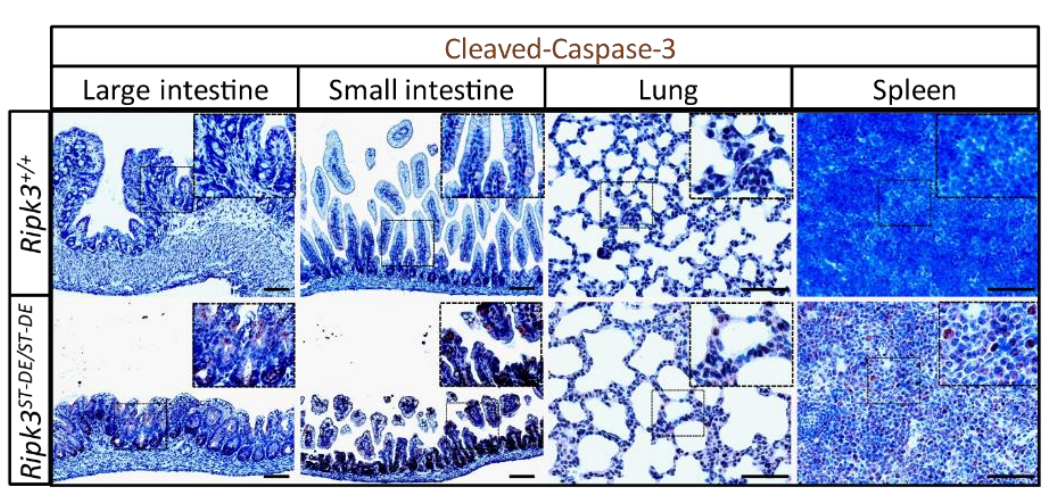

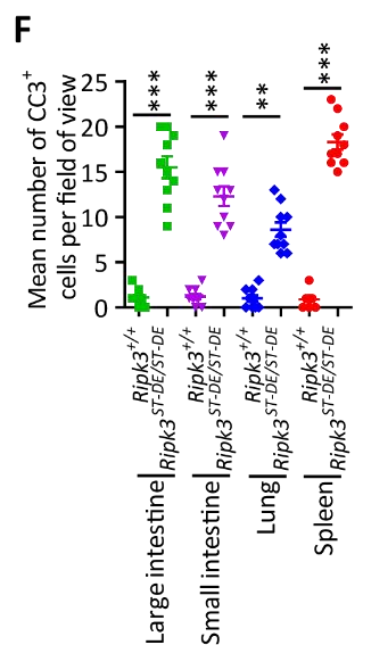


bioRxiv preprint doi: https://doi.org/10.1101/2021.02.14.431152; this version posted February 15, 2021. The copyright holder for this preprint (which was not certified by peer review) is the author/funder, who has granted bioRxiv a license to display the preprint in perpetuity. It is made

\section{Figure 6}

A

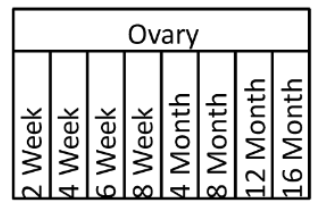

Lane: $\begin{array}{llllllll}1 & 2 & 3 & 4 & 5 & 6 & 7 & 8\end{array}$

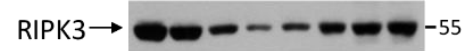

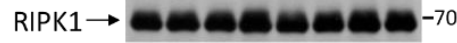

$\mathrm{MLKL} \rightarrow-\mathrm{m}-\mathrm{m}-\mathrm{-}-\mathrm{-5}$

Tubulin $\rightarrow$

$\mathrm{GAPDH} \rightarrow-000-35$
B

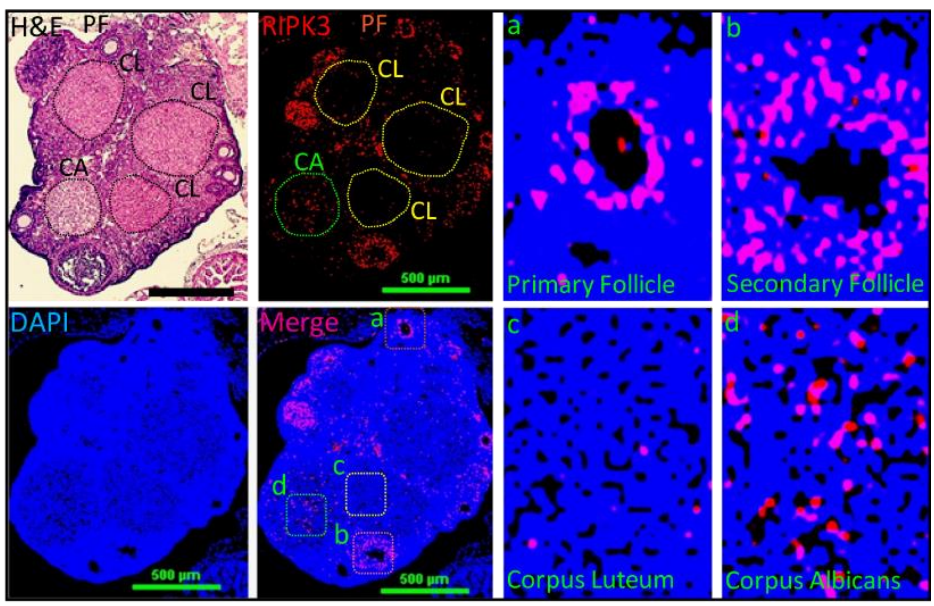

D
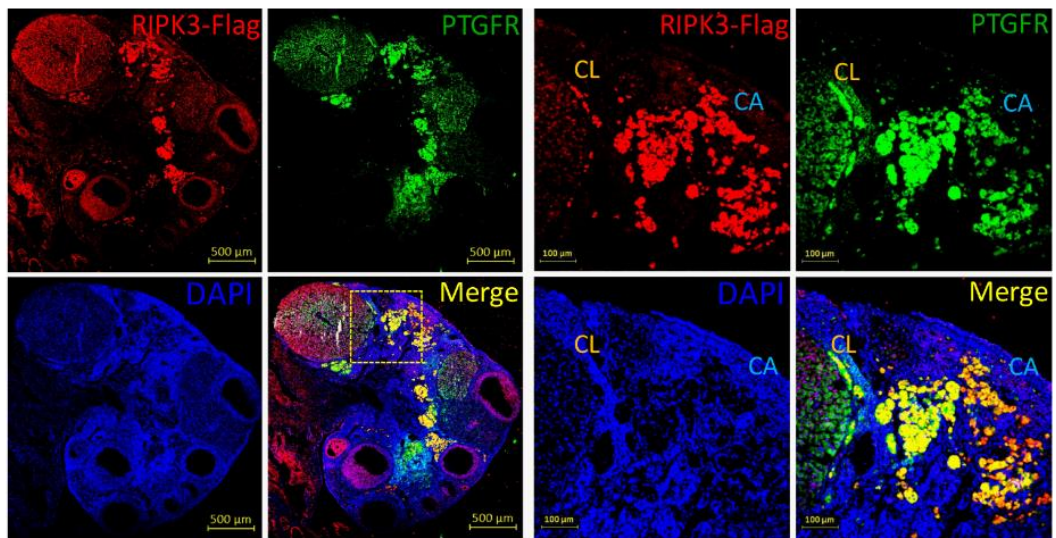
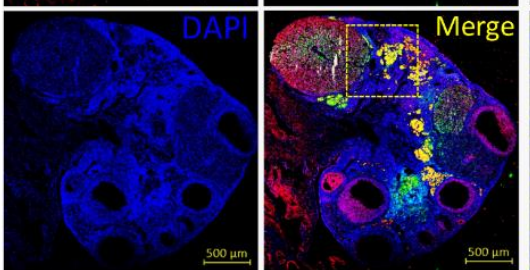

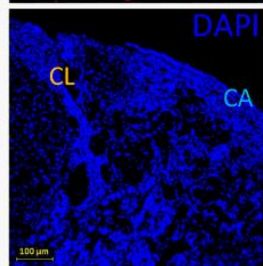

E

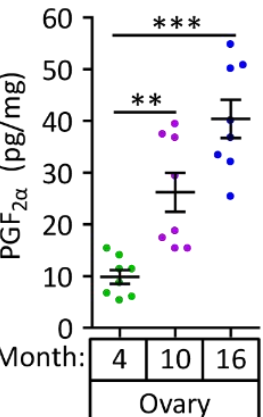

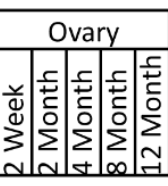

p-S164/T165-RIPK3 $\rightarrow$

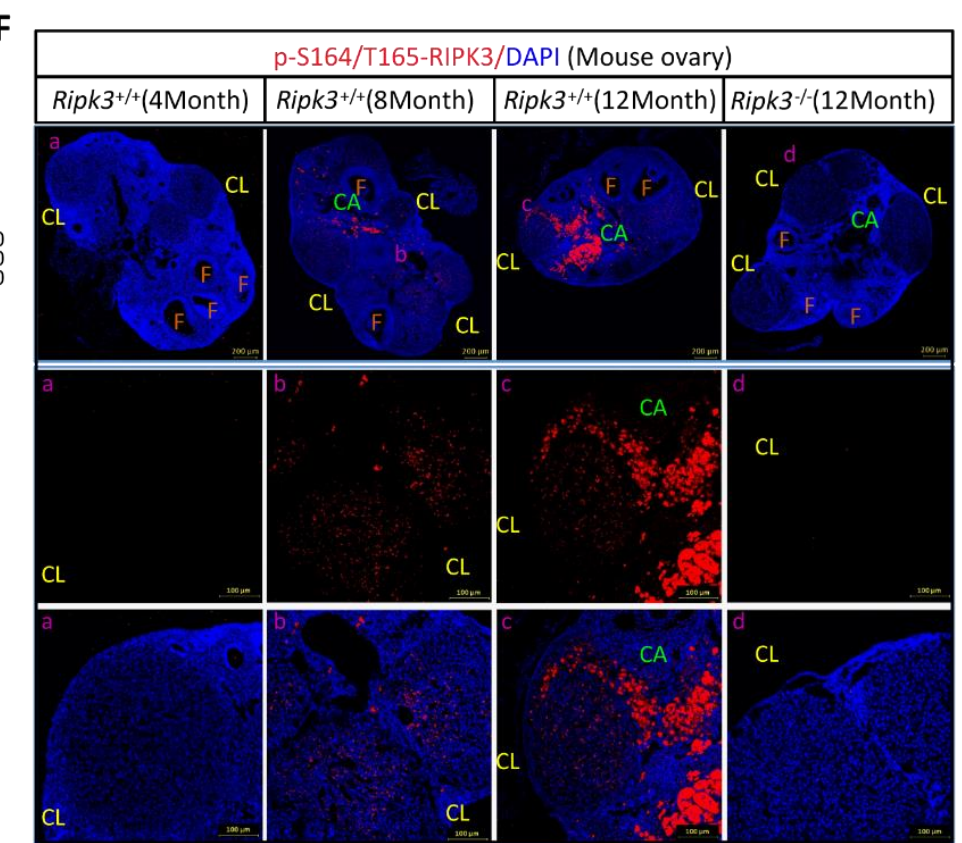


bioRxiv preprint doi: https://doi.org/10.1101/2021.02.14.431152; this version posted February 15, 2021. The copyright holder for this preprint (which was not certified by peer review) is the author/funder, who has granted bioRxiv a license to display the preprint in perpetuity. It is made Figure 7

A

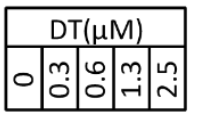

Lane: $1 \begin{array}{lllll}1 & 2 & 3 & 4 & 5\end{array}$

$\mathrm{RIPK3} \rightarrow-55$

$\mathrm{pp}_{\mathrm{pp} 42-\mathrm{ERK}} \rightarrow \quad====^{-55}$

$\begin{gathered}\mathrm{pp} 42-\mathrm{ERK} \\ \mathrm{p} 44-\mathrm{ERK} \\ \mathrm{p} 42-\mathrm{ERK}\end{gathered} \rightarrow===$

$\mathrm{p}-\mathrm{MEK} \rightarrow \ldots-\ldots-{ }^{-55}$

$\mathrm{MEK} \rightarrow$

$\mathrm{GAPDH} \rightarrow$

D

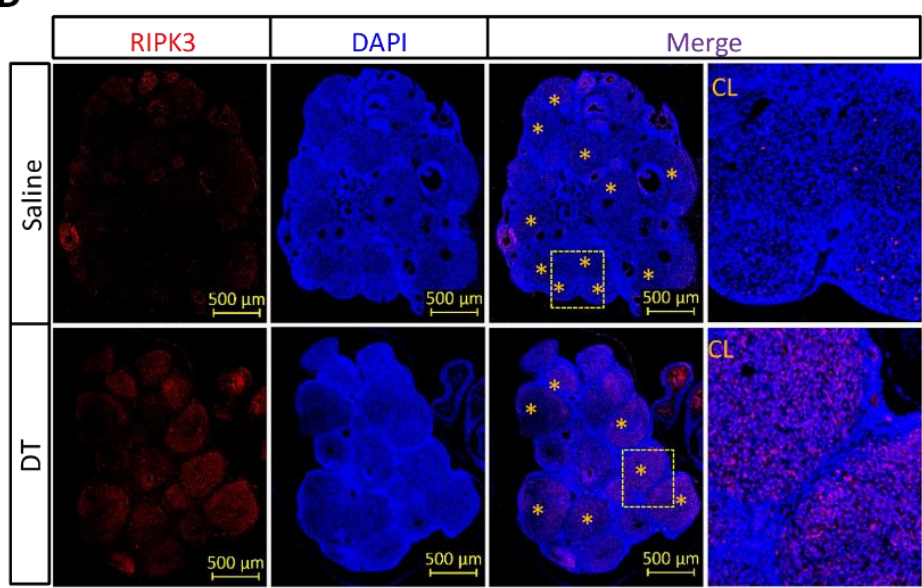

F

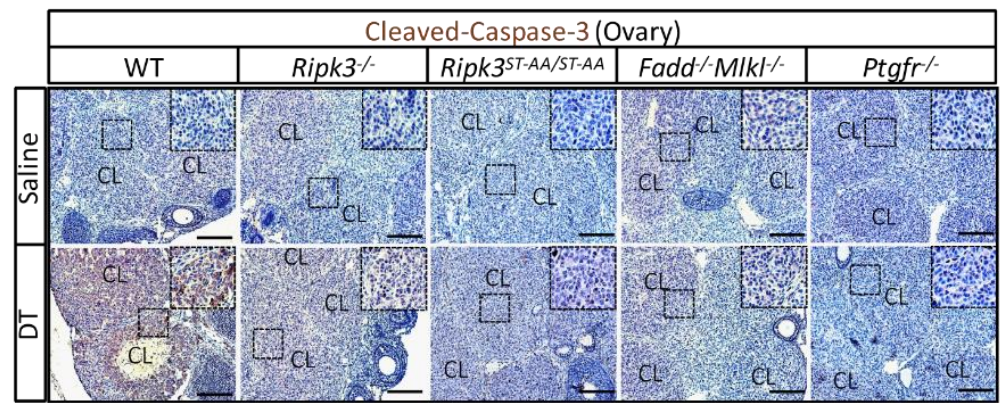

H

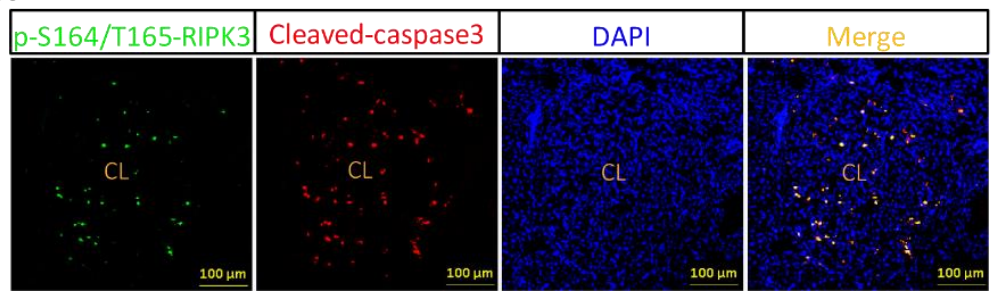

C

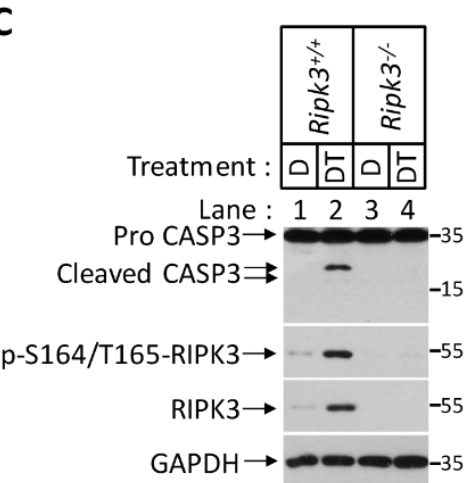

E

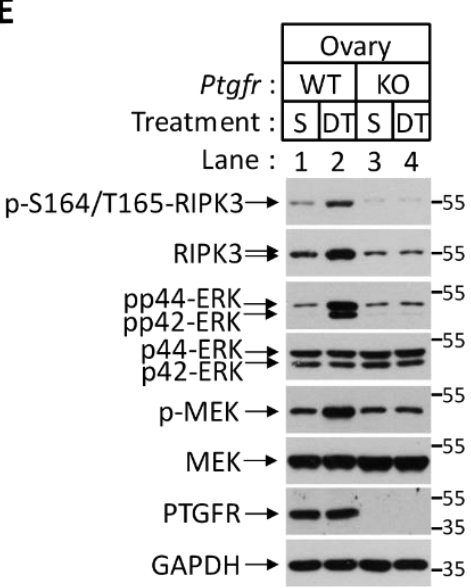

G

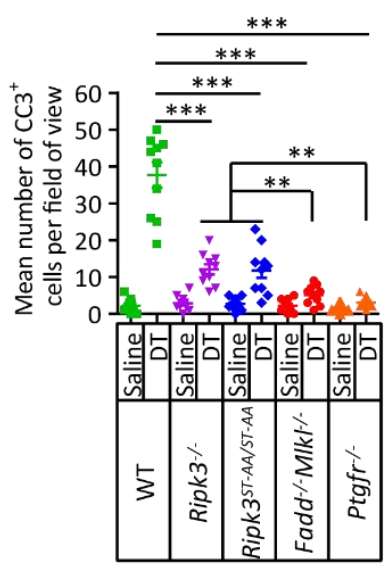


bioRxiv preprint doi: https://doi.org/10.1101/2021.02.14.431152; this version posted February 15, 2021. The copyright holder for this preprint (which was not certified by peer review) is the author/funder, who has granted bioRxiv a license to display the preprint in perpetuity. It is made

\section{Figure 1-figure supplement 1}
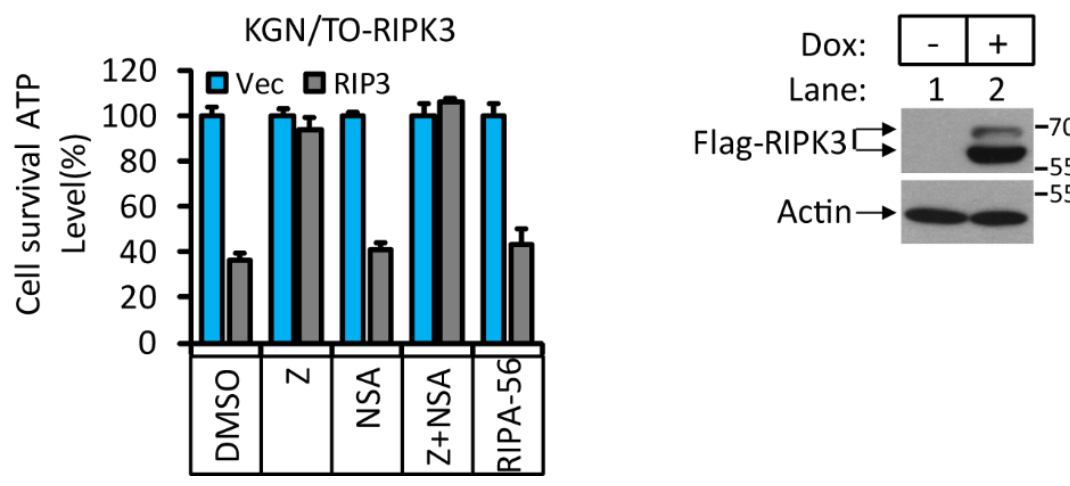
bioRxiv preprint doi: https://doi.org/10.1101/2021.02.14.431152; this version posted February 15, 2021. The copyright holder for this preprint (which was not certified by peer review) is the author/funder, who has granted bioRxiv a license to display the preprint in perpetuity. It is made Figure 3-figure supplement 1

A

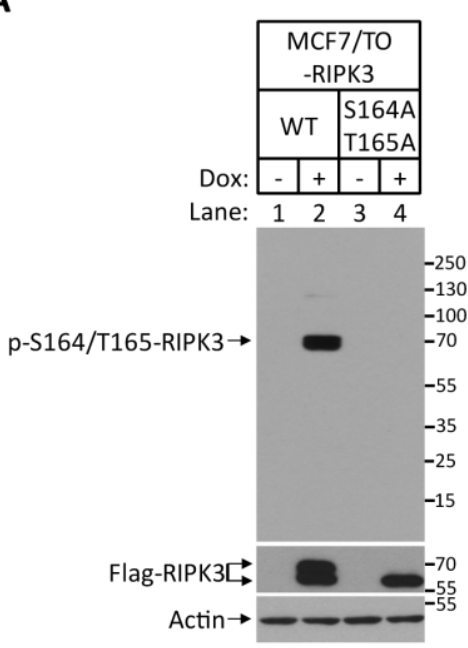

B

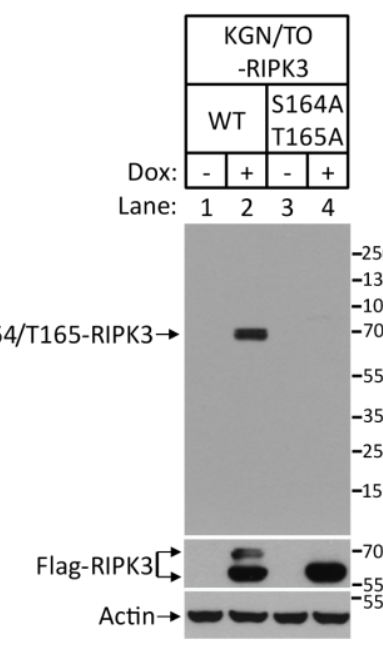

C

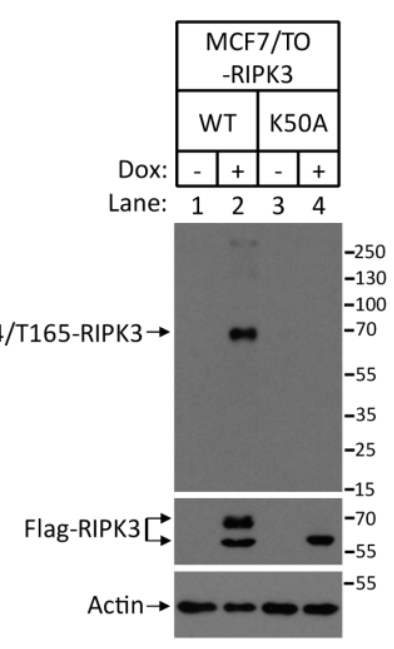

D

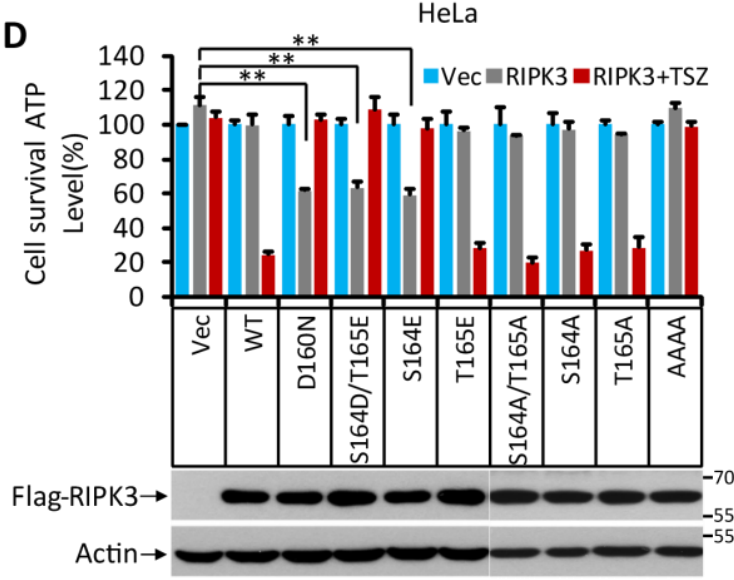

E

Flag-RIPK3 CDNA

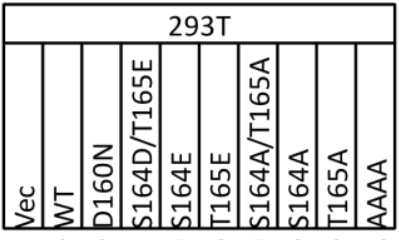

Lane: $\begin{array}{llllllllll}1 & 2 & 3 & 4 & 5 & 6 & 7 & 8 & 9 & 10\end{array}$ p-S227-RIPK3E

Flag-RIPK3E

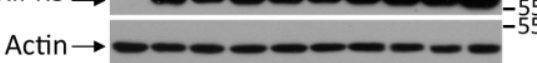

H

$\mathbf{F}$

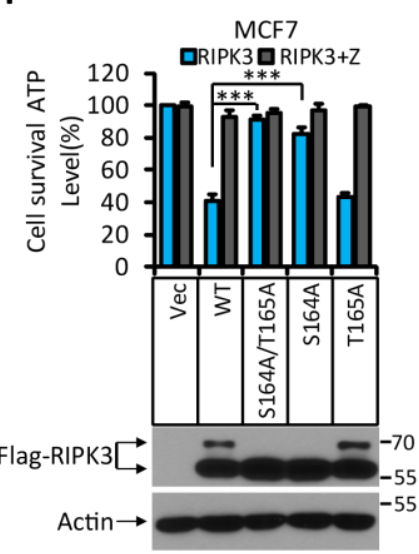

G

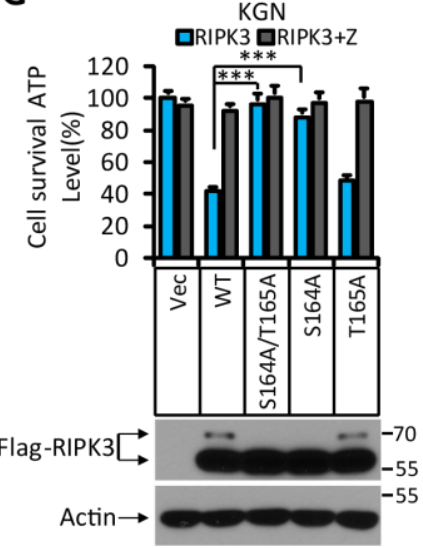

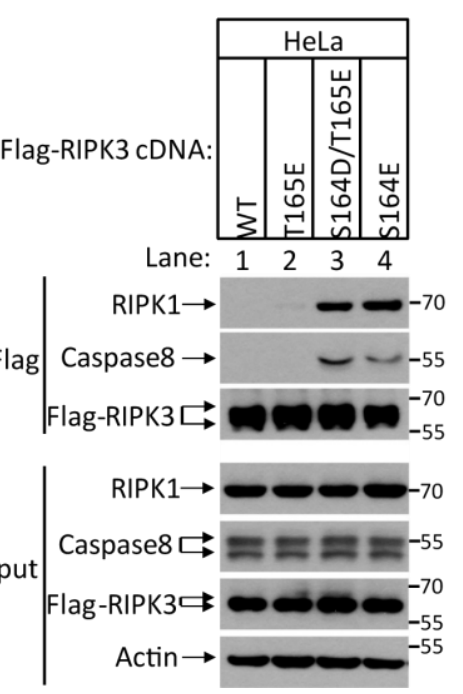


bioRxiv preprint doi: https://doi.org/10.1101/2021.02.14.431152; this version posted February 15, 2021. The copyright holder for this preprint (which was not certified by peer review) is the author/funder, who has granted bioRxiv a license to display the preprint in perpetuity. It is made Figure 3-figure suppialementent $2^{\mathrm{CC}}$

A

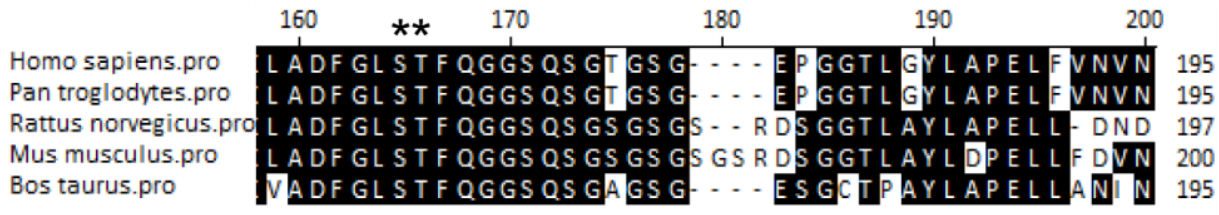

B

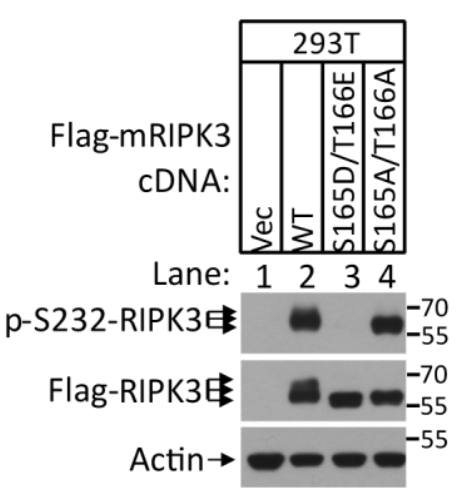

C

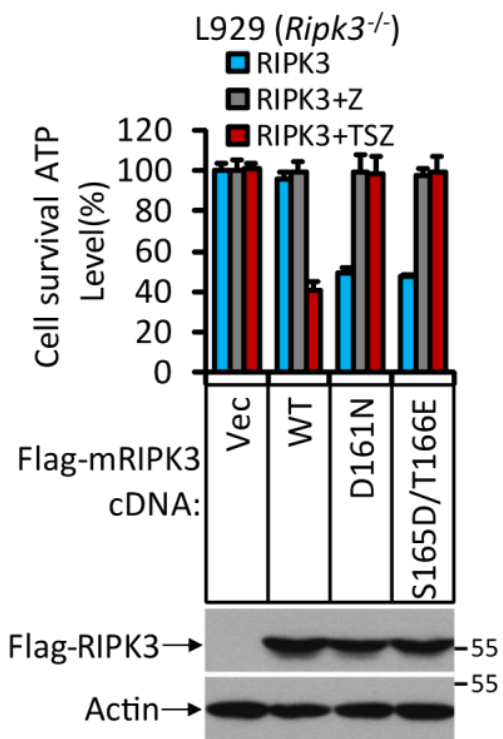


bioRxiv preprint doi: https://doi.org/10.1101/2021.02.14.431152; this version posted February 15, 2021. The copyright holder for this preprint (which was not certified by peer review) is the author/funder, who has granted bioRxiv a license to display the preprint in perpetuity. It is made Figure 4-figure supplement 1

A

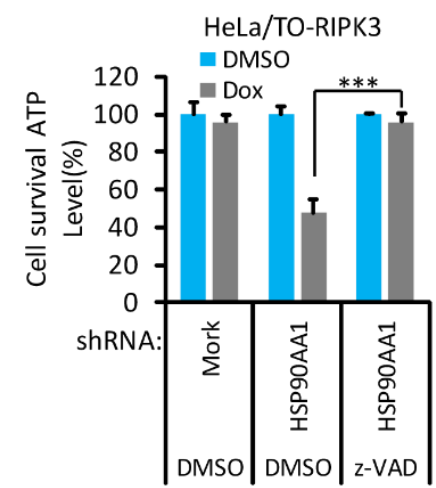

C

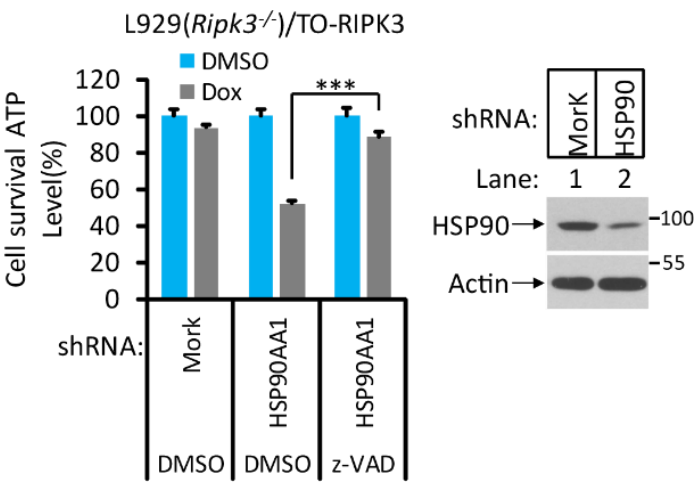

B

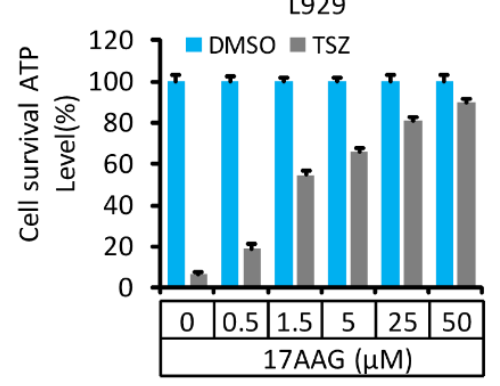

D

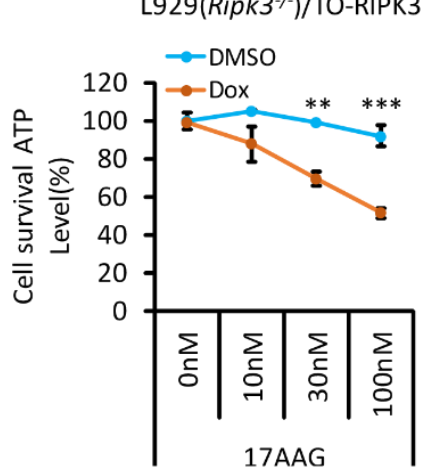

E

L929(Ripk3\%)/TO-RIPK3 \begin{tabular}{rl|l|l|l|} 
17AAG (100 nM): & - & - & + \\
\hline Dox: & - & + & + \\
\hline Lane: & 1 & 2 & 3
\end{tabular} p-S164/T165-RIPK3 $\rightarrow$ Flag-RIPK3 $\longrightarrow$ Actin $\rightarrow$ 
bioRxiv preprint doi: https://doi.org/10.1101/2021.02.14.431152; this version posted February 15, 2021. The copyright holder for this preprint (which was not certified by peer review) is the author/funder, who has granted bioRxiv a license to display the preprint in perpetuity. It is made

\section{Figure 4-figure supplemeñz 2}

A

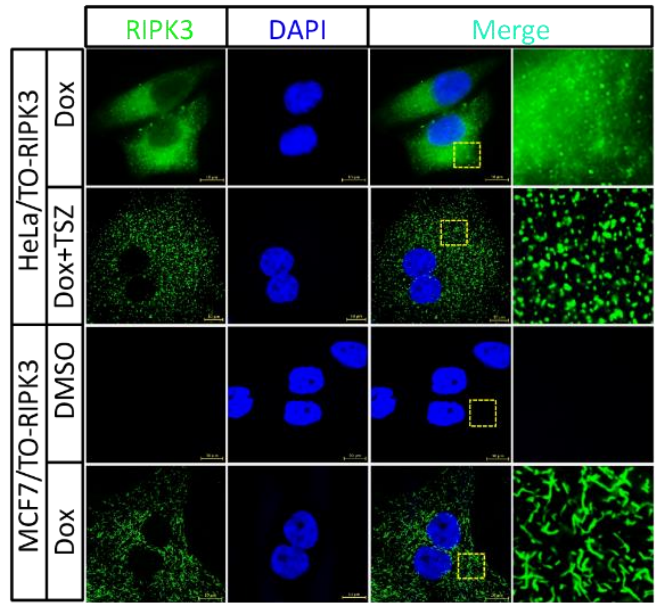

C
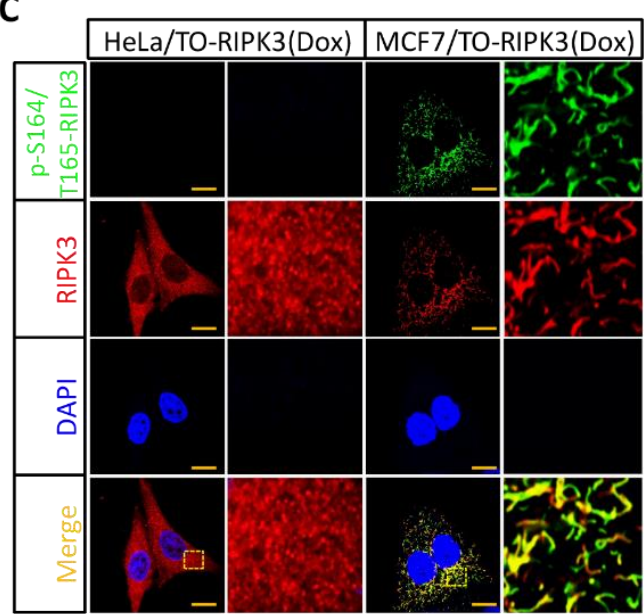

E

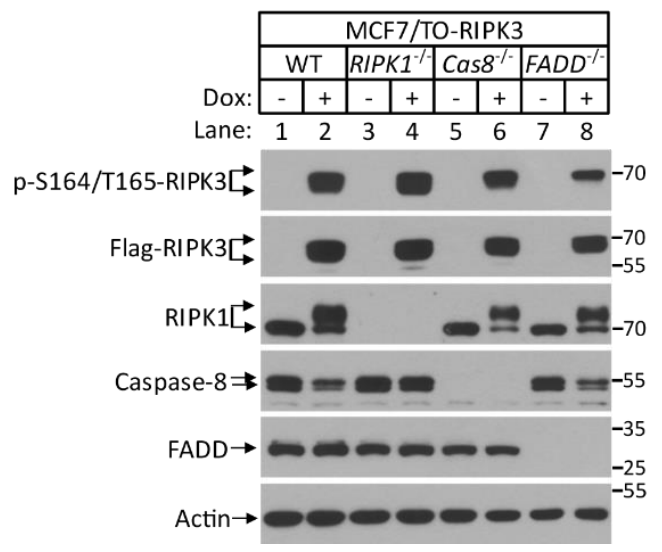

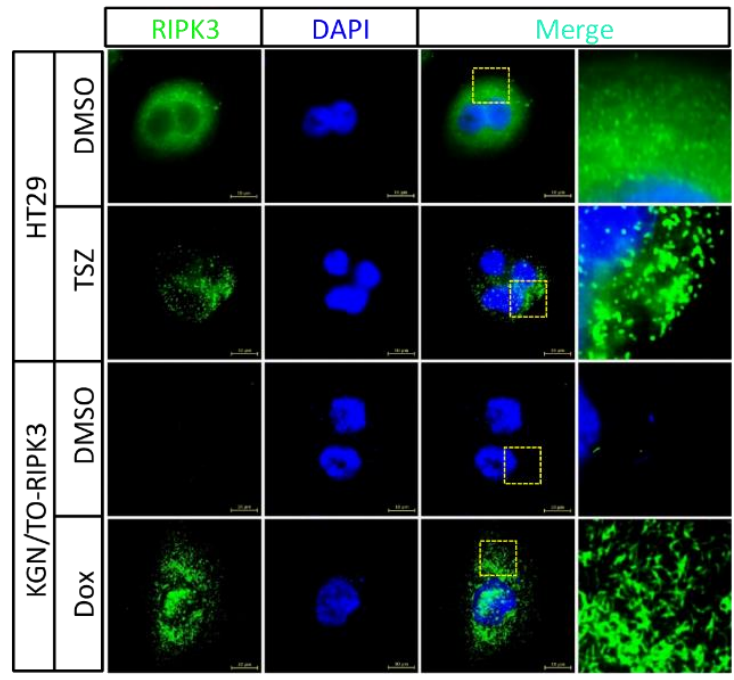

D

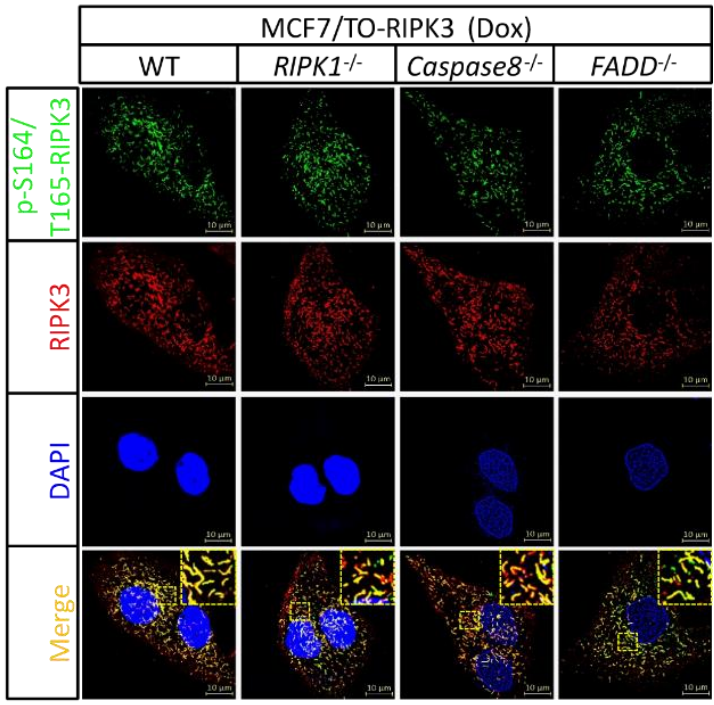


bioRxiv preprint doi: https://doi.org/10.1101/2021.02.14.431152; this version posted February 15, 2021. The copyright holder for this preprint (which was not certified by peer review) is the author/funder, who has granted bioRxiv a license to display the preprint in perpetuity. It is made Figure 4-figure supplement 3

A
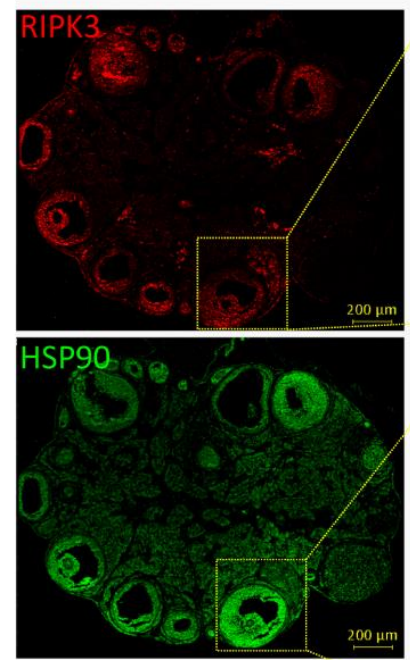

C

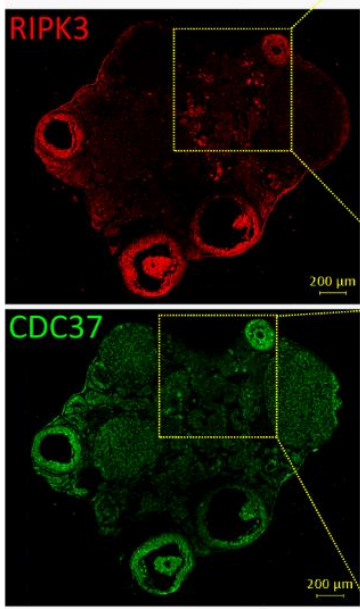

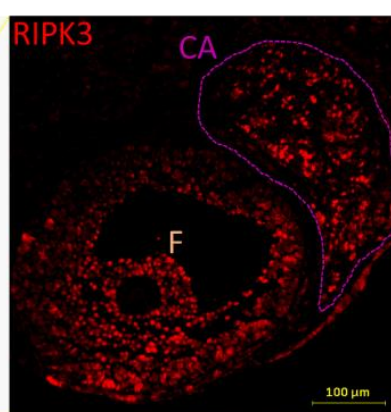
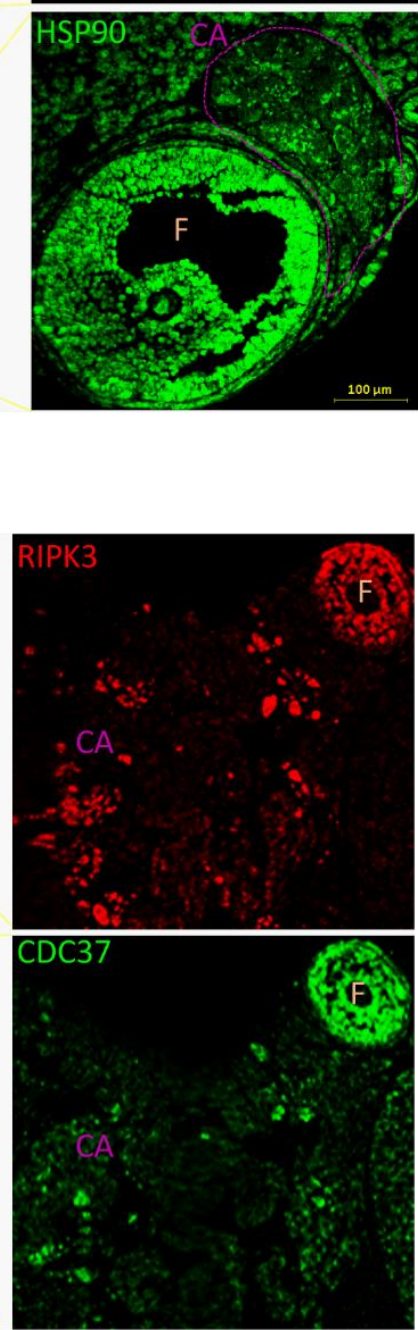

D

B
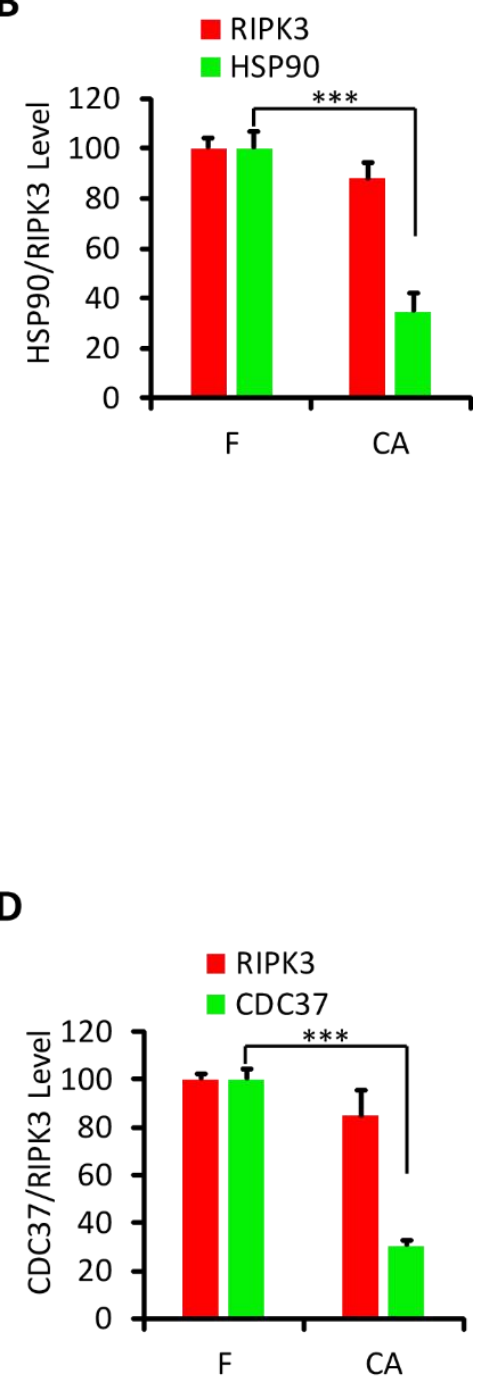
bioRxiv preprint doi: https://doi.org/10.1101/2021.02.14.431152; this version posted February 15, 2021. The copyright holder for this preprint (which was not certified by peer review) is the author/funder, who has granted bioRxiv a license to display the preprint in perpetuity. It is made Figure 5-figure supplement 1 able under aCC-BY 4.0 International license.

A

\begin{tabular}{ll}
\hline Ripk3 gRNA1: & TAATACGACTCACTATAGGGaccctccctgaaacgtggacGTTTTAGAGCTAGAAATAG \\
Ripk3 gRNA2: & TAATACGACTCACTATAGGGctgggaccctcctgaaacgGTTTAGAGCTAGAAATAG \\
\hline oligo S165A/T166A A & $\begin{array}{l}\text { ctcctcatctaataccttcctttcctttcctttacagctagcagattttggctg GCAGCAtttcagggagg } \\
\text { ccttcatctaataccttcctttcctttcctttacagctagcagattttggcctg GACGAAtttcagggag }\end{array}$ \\
oligo S165D/T166E & ggtcccagtcagggtcaggatcaggatcaggatccagggactctgggggcaccctagcgt \\
\hline
\end{tabular}

B
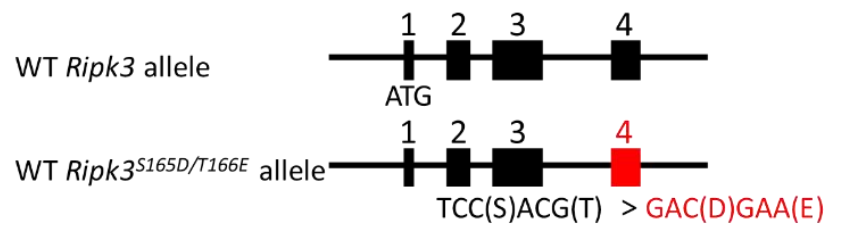

WT Ripk3 $3^{\text {S165A/T166A }}$ allele- 1

$\operatorname{TCC}(\mathrm{S}) \mathrm{ACG}(\mathrm{T})>\mathrm{GCA}(\mathrm{A}) \mathrm{GCA}(\mathrm{A})$

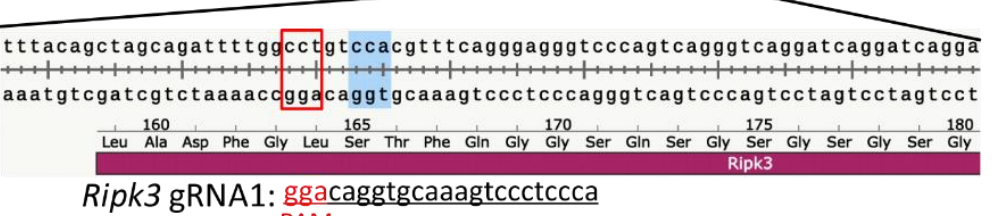

Ripk3 gRNA1: ggacaggtgcaaagtccctccca

Ripk3 gRNA2: $\quad$ ggtgcaaagtccctcccagggtc

E

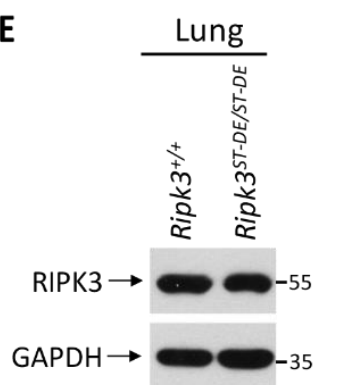

F
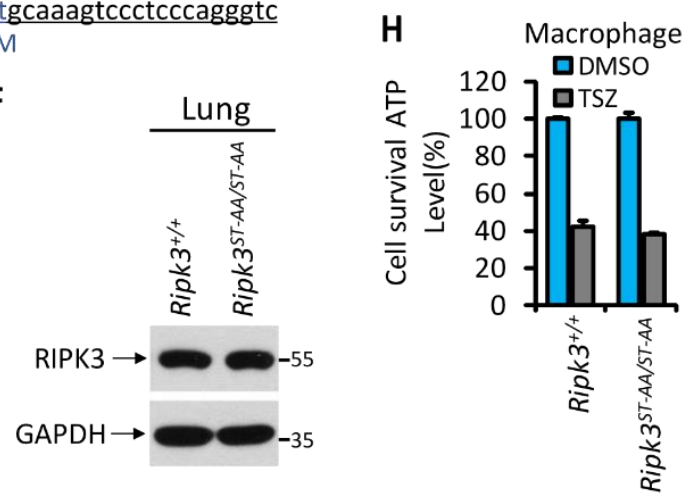

C

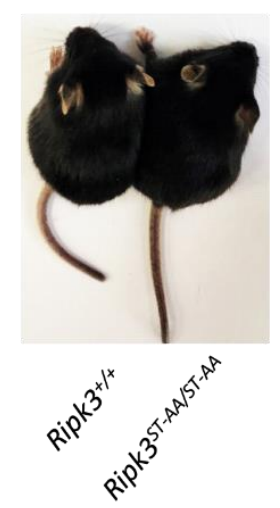

G

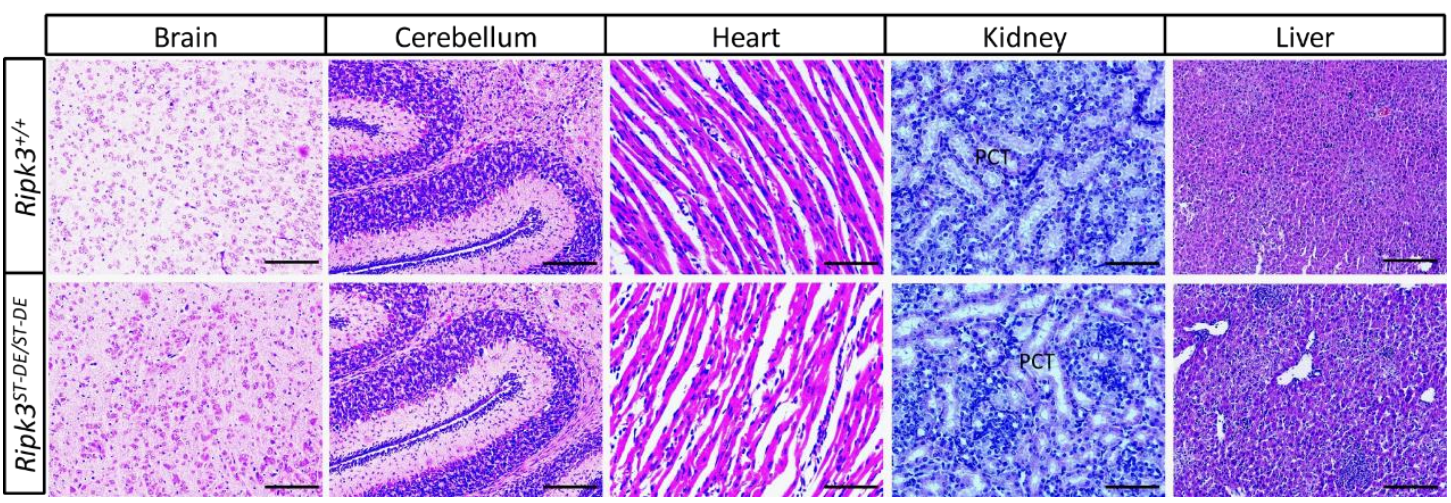


bioRxiv preprint doi: https://doi.org/10.1101/2021.02.14.431152; this version posted February 15, 2021. The copyright holder for this preprint (which was not certified by peer review) is the author/funder, who has granted bioRxiv a license to display the preprint in perpetuity. It is made Figure 6-figure suppleakmilablentunder aCC-BY 4.0 International license.

A

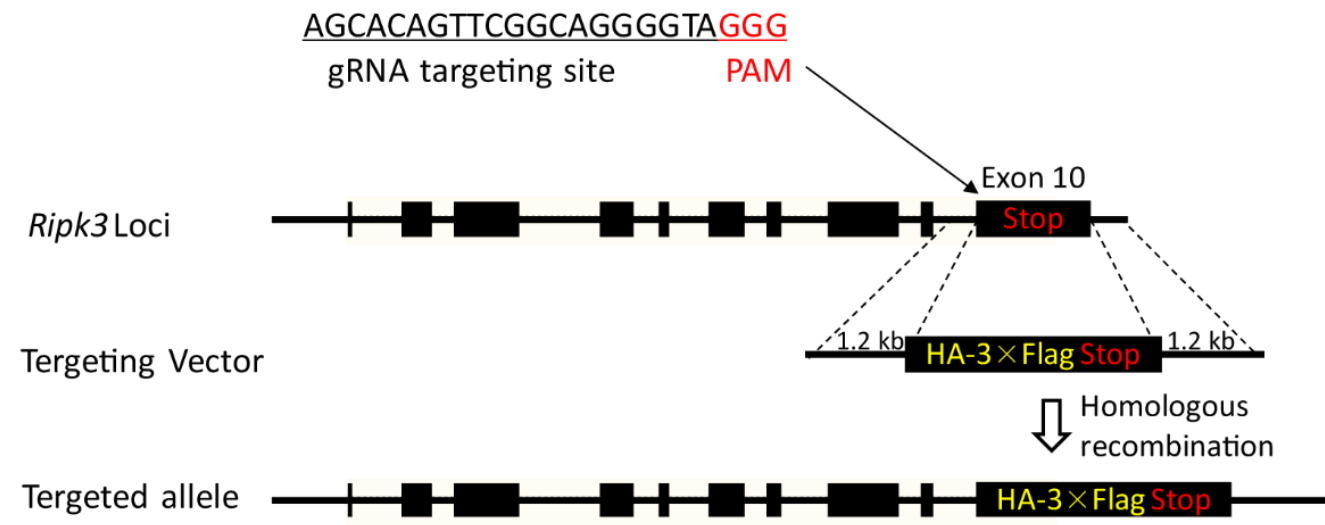

B

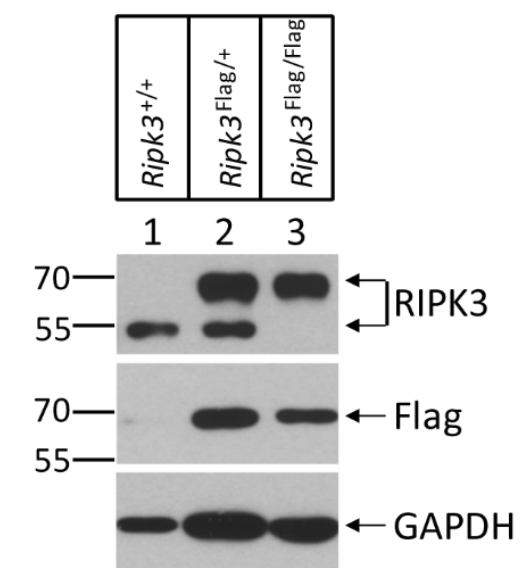

D

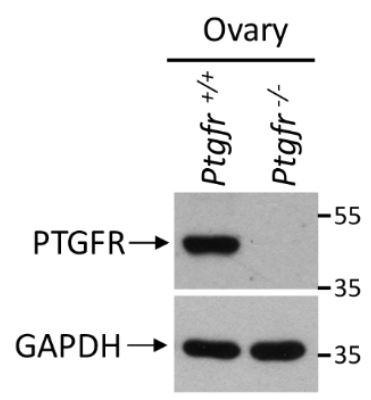

C

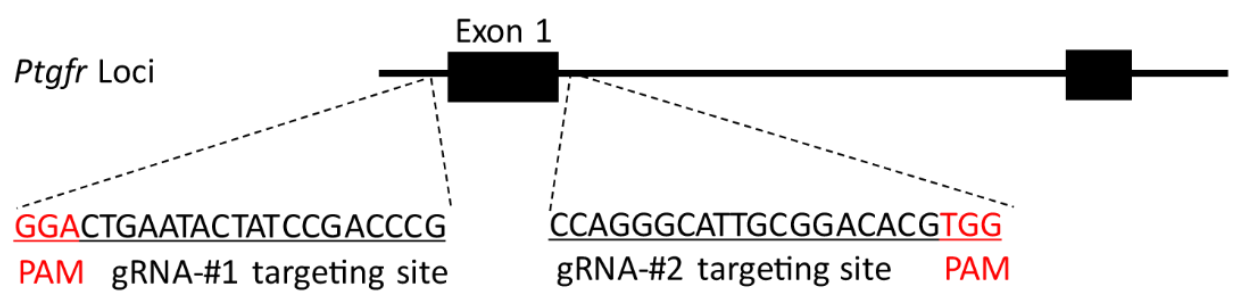


bioRxiv preprint doi: https://doi.org/10.1101/2021.02.14.431152; this version posted February 15, 2021. The copyright holder for this preprint (which was not certified by peer review) is the author/funder, who has granted bioRxiv a license to display the preprint in perpetuity. It is made

\section{Figure 7-figure supplement 1}

A

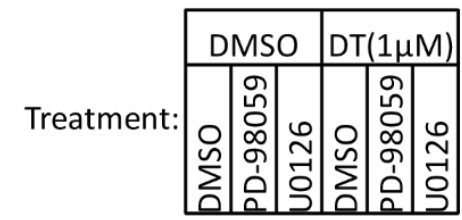

Lane : $\begin{array}{llllll}1 & 2 & 3 & 4 & 5 & 6\end{array}$

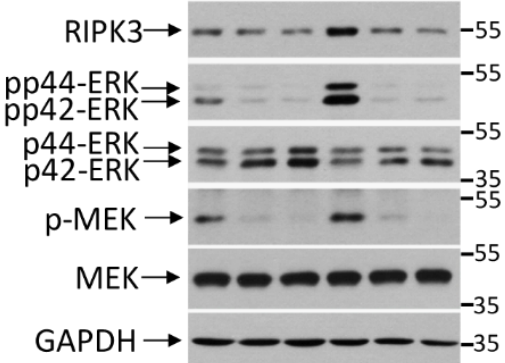

C

4 Week Female Mice

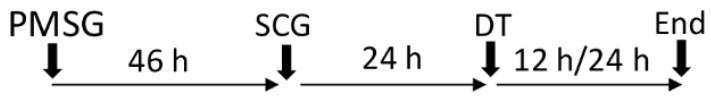

Pregnant Mare Serum Gonadotropin (PMSG)

Serum gonadotropin and Chorionic Gonadotropin (SCG)

Dinoprost Tromethamine(DT) is an analogue of $\mathrm{PGF}_{2 a}$
B

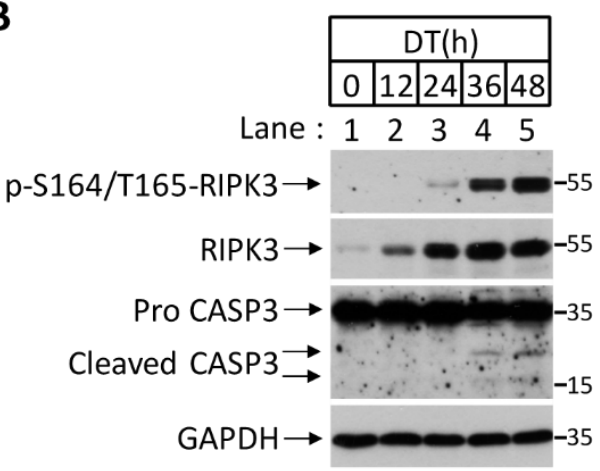

D

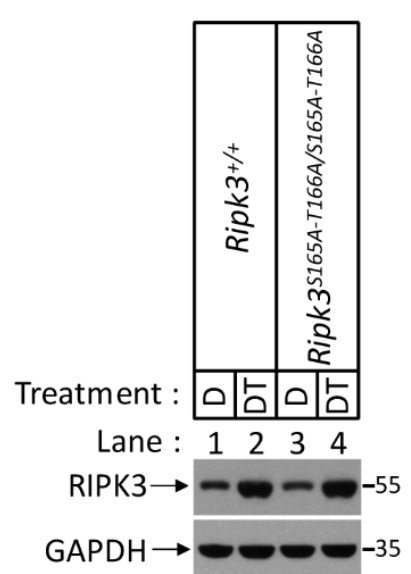

